\title{
SURFACE MODIFICATION TO ALLEVIATE PVDF MEMBRANE FOULING DURING MILK PROTEIN MICROFILTRATION
}

\author{
By \\ Diba Mirriahi \\ Bachelor of Science, Sharif University of Technology, Iran, 2015
}

\author{
A thesis \\ presented to Ryerson University \\ in partial fulfillment of the \\ requirements for the degree of \\ Master of Applied Science \\ in the Program of \\ Chemical Engineering
}

Toronto, Ontario, Canada, 2017

CDiba Mirriahi 2017 


\section{Author's Declaration}

I hereby declare that I am the sole author of this thesis. This is a true copy of the thesis, including any required final revisions, as accepted by my examiners.

I authorize Ryerson University to lend this thesis to other institutions or individuals for the purpose of scholarly research.

I further authorize Ryerson University to reproduce this thesis by photocopying or by other means, in total or in part, at the request of other institutions or individuals for the purpose of scholarly research.

I understand that my thesis may be made electronically available to the public. 


\title{
Abstract
}

\section{Surface Modification to Alleviate PVDF Membrane Fouling}

\section{during Milk Protein Microfiltration}

\author{
Diba Mirriahi \\ Master of Applied Science \\ Department of Chemical Engineering \\ Ryerson University, Canada, 2017
}

The interest in using polyvinylidene fluoride (PVDF) membrane in order to separate casein and serum proteins has been raised due to its significant stability. However, the high hydrophobicity of PVDF membrane causes severe fouling during filtration processes. Ozonation, a surface modification process in which polar groups would be formed on the membrane surface, is widely known for its high efficiency.

In the present study, the main objective was to optimize the ozonation parameters to reach the minimum fouling while the maximum mechanical strength could be retained. The contact angle of a water droplet on the membrane surface decreased from $73.5^{\circ}$ to $50.4^{\circ}$ after the treatment of the membrane at the optimal gaseous phase ozonation. This indicates an increase in the hydrophilicity of the treated membrane. Also, filtration performance demonstrated a lower fouling occurrence on the treated membrane as compared to the untreated one. Although gaseous ozonation yielded a slightly better performance in comparison to the aqueous treatment, the membrane treated with aqueous phase ozonation was benefited from conserving its mechanical strength. Activated carbon helped decreasing the contact angle and fouling as compared to the non-catalytic aqueous treatment while the tensile strength was not affected. 


\section{Acknowledgements}

I would like to express my sincere appreciation to my supervisor, Dr. Huu Doan, for his priceless supervision and guidance during my studies. Studying and working in his research group provided me with the opportunity to learn from his experience and knowledge which was a great educational milestone in my life.

I would like to thank Mr. Ali Hemmati, Mr. Tondar Tajrobehkar and Mr. Daniel Boothe for their valuable technical assistance as well as all the faculty members and staff in the Chemical Engineering Department, Ryerson University.

Also, I would like to thank Dr. Amira Abdelrasoul for her valuable insights throughout the experimental part of this research.

Furthermore, I would like to acknowledge the National Science and Engineering Council (NSERC) of Canada and Department of Chemical Engineering, Ryerson University for their financial support during this work.

Finally, I must express my profound gratitude toward my family members for their continuous support and encouragement within the last two years. 


\section{List of Contents}

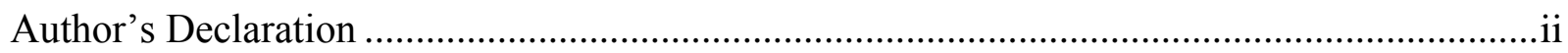

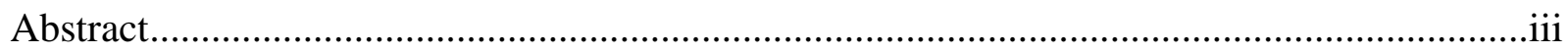

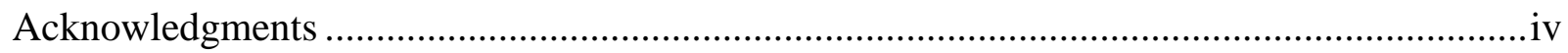

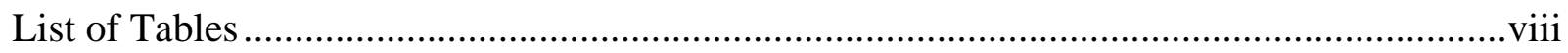

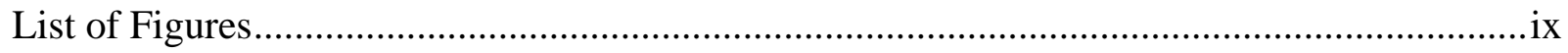

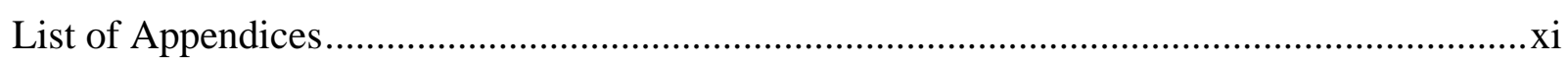

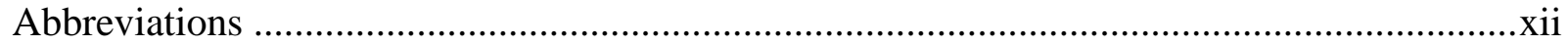

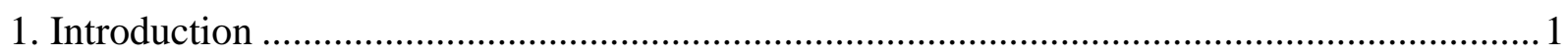

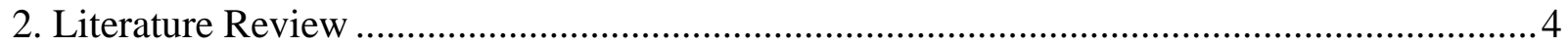

2.1. Fouling during Filtration Processes........................................................................ 4

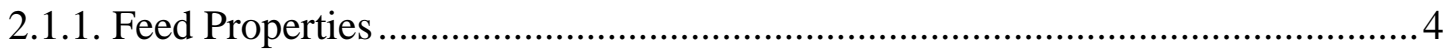

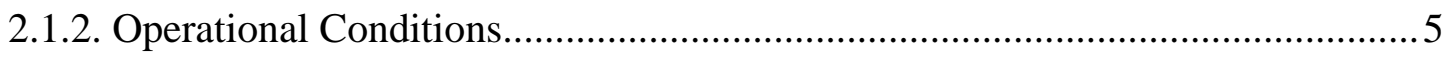

2.1.3. Membrane Properties ..................................................................................

2.2. Membrane Modification .....................................................................................

2.2.1. Effect of Ozonation on Contact Angle …………….......................................

2.2.2. Effect of Ozonation on Fouling ........................................................................11

2.2.3. Effect of Ozonation Parameters ………………………................................. 14

2.2.4. Ozonation with Catalyst .................................................................................. 19

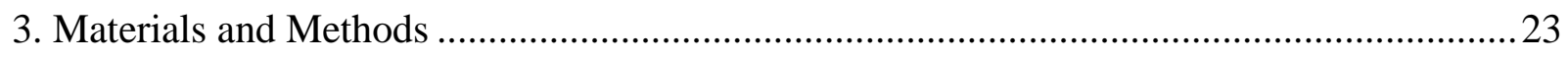

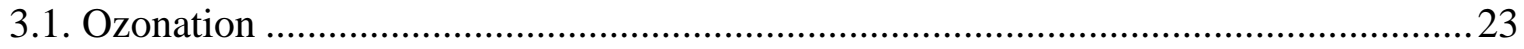

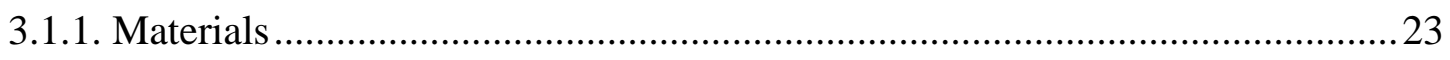

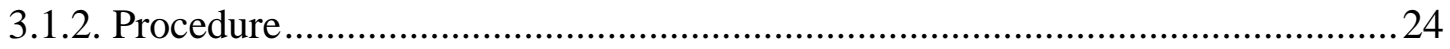




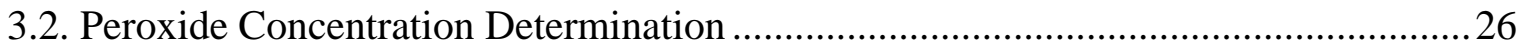

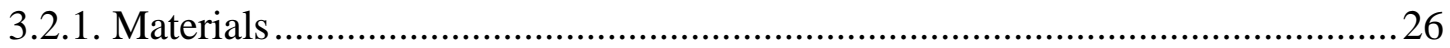

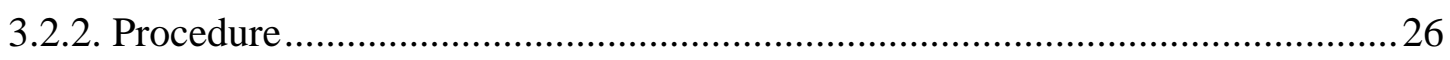

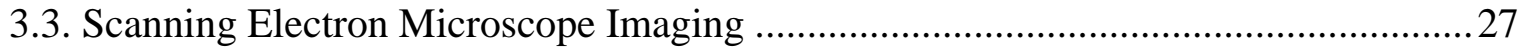

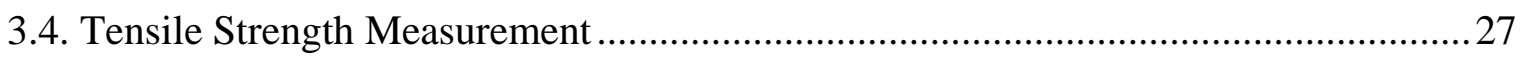

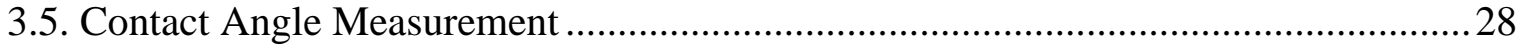

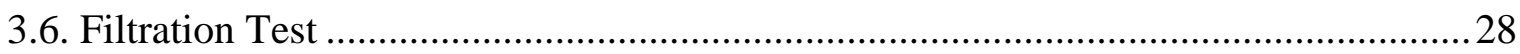

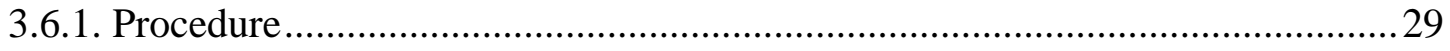

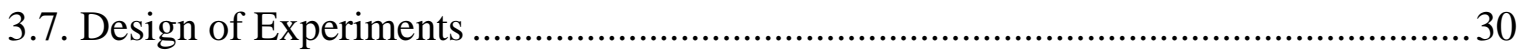

3.7.1. Full Factorial Design ....................................................................................

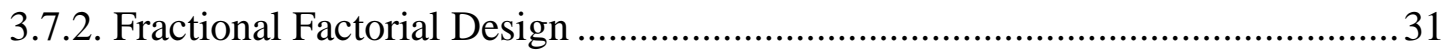

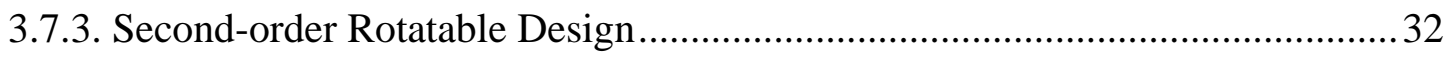

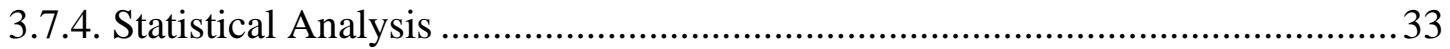

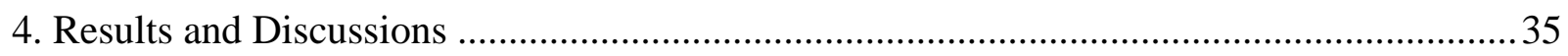

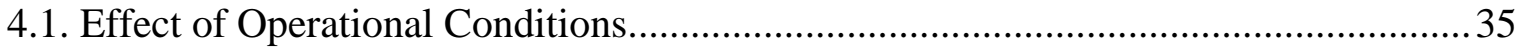

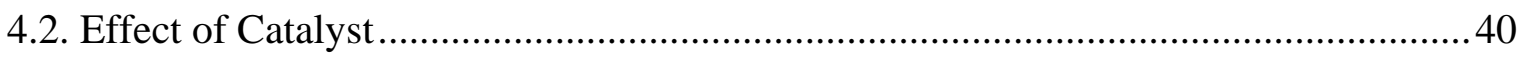

4.3. Effect of Ozone Concentration ............................................................................

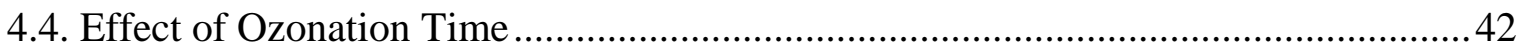

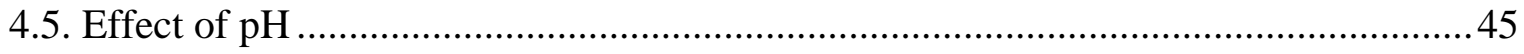

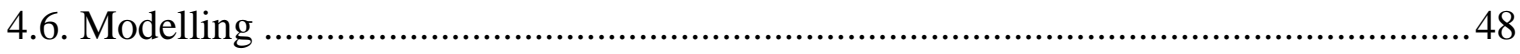

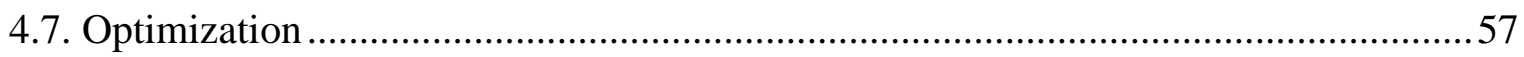

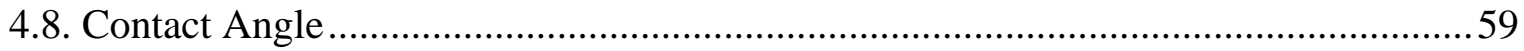

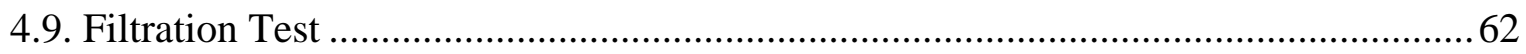




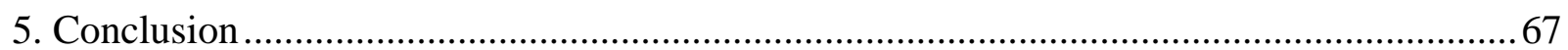

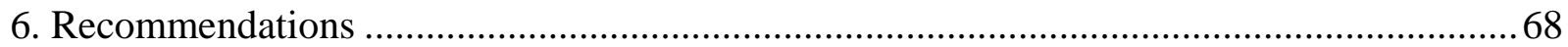

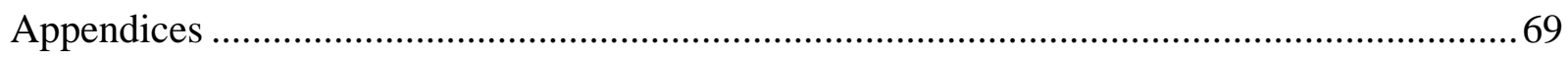

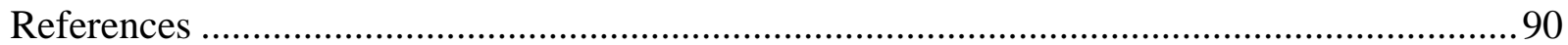




\section{List of Tables}

Table 2.1: Effect of ozonation on advancing contact angle ........................................... 10

Table 2.2: Effect of ozonation on water flux ................................................................. 14

Table 3.1: Ozonation setup equipment list ............................................................ 24

Table 3.2: The used chemicals for peroxide determination...............................................26

Table 3.3: Filtration setup equipment list .................................................................29

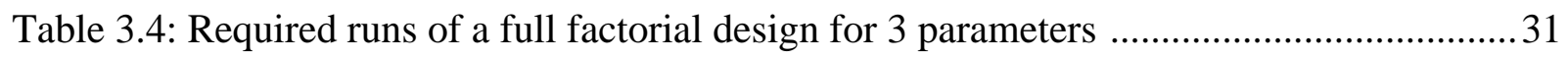

Table 3.5: Second order rotatable design parameters ....................................................... 32

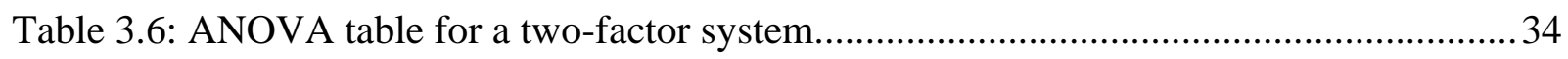

Table 4.1: Actual and coded parameters of gaseous ozonation .............................................48

Table 4.2: Required runs of gaseous treatment ......................................................... 49

Table 4.3: Actual and coded parameters of aqueous ozonation .......................................49

Table 4.4: Required runs of non-catalytic aqueous treatment ........................................50

Table 4.5: Required runs of catalytic aqueous treatment ..........................................51

Table 4.6: ANOVA table for gaseous ozonation......................................................53

Table 4.7: ANOVA table for non-catalytic aqueous ozonation ......................................53

Table 4.8: ANOVA table for catalytic aqueous ozonation .............................................53

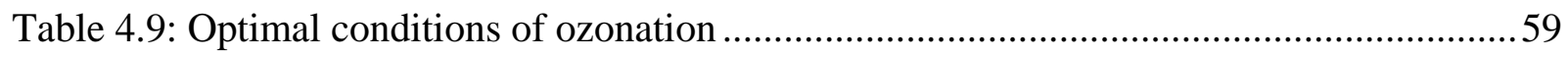

Table 4.10: Effect of ozonation on membrane and fouling resistances...............................63 


\section{List of Figures}

Figure 1.1: Schematic illustration of ozonation and graft polymerization ............................. 3

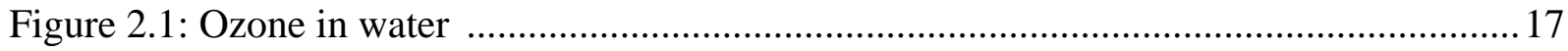

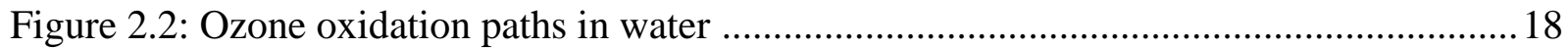

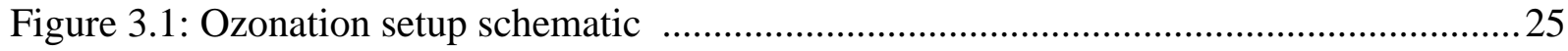

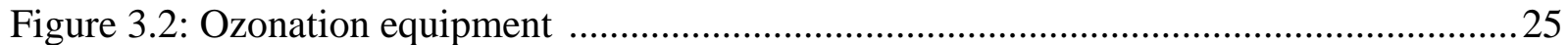

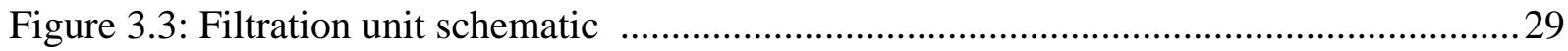

Figure 4.1: Effect of different methods on residual ozone removal .....................................35

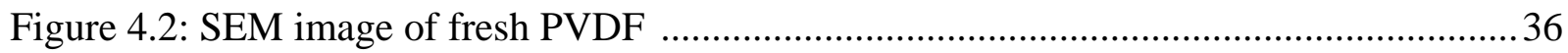

Figure 4.3: SEM image of gaseous treated PVDF, ozone at 2.5\%wt., 30min …....................37

Figure 4.4: SEM image of gaseous treated PVDF, ozone at 2.5\%wt., 1 hour ........................ 37

Figure 4.5: SEM image of gaseous treated PVDF, ozone at 4.5\%wt., 30min ........................38

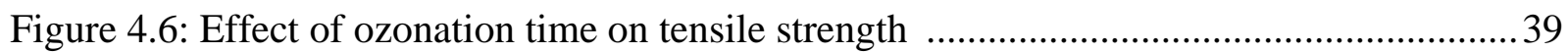

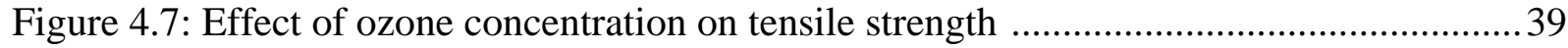

Figure 4.8: Effect of different catalysts on the concentration of peroxide formed on the membrane surface $(\mathrm{pH}=7,2 \%$ wt. ozone, 10min) ........................................................... 40

Figure 4.9: Effect of activated carbon concentration ( $\mathrm{pH}=7,2 \% \mathrm{wt}$. ozone, 10min)...............41

Figure 4.10: Effect of ozone concentration on peroxide formation after 20 minutes of gaseous ozonation, non-catalytic aqueous ozonation and catalytic aqueous ozonation at $\mathrm{pH}=7$

Figure 4.11: Effect of ozonation time on peroxide formation at $2 \%$ wt. in gaseous ozonation, non-catalytic and catalytic aqueous ozonation at $\mathrm{pH}=7$

Figure 4.12: Effect of ozonation time at different ozone concentrations in gaseous treatment 44

Figure 4.13: Effect of ozonation time at different ozone concentrations in non-catalytic aqueous treatment $(\mathrm{pH}=7)$ 
Figure 4.14: Effect of ozonation time at different ozone concentrations in catalytic aqueous treatment $(\mathrm{pH}=7)$

Figure 4.15: Effect of $\mathrm{pH}$ on peroxide concentration during non-catalytic aqueous ozonation at $2 \%$ wt. and $20 \mathrm{~min}$

Figure 4.16: Effect of $\mathrm{pH}$ on aqueous phase ozonation at $2 \% \mathrm{wt}$. and $20 \mathrm{~min}$ 47

Figure 4.17: Normal plot of residuals, gaseous ozonation

Figure 4.18: Predicted and actual peroxide concentrations, gaseous phase 55

Figure 4.19: Normal plot of resuals, non-catalytic aqueous ozonation 55

Figure 4.20: Predicted and actual peroxide concentrations, non-catalytic aqueous phase........56

Figure 4.21: Normal plot of resuals, catalytic aqueous ozonation 56

Figure 4.22: Predicted and actual peroxide concentrations, catalytic aqueous phase 57

Figure 4.23: Peroxide concentration profile, gaseous ozonation. 58

Figure 4.24: Peroxide concentration profile, non-catalytic aqueous ozonation 58

Figure 4.25: Peroxide concentration profile, catalytic aqueous ozonation 58

Figure 4.26: Contact angle image, untreated PVDF .60

Figure 4.27: Contact angle image, optimal gaseous treated PVDF .60

Figure 4.28: Contact angle image, optimal non-catalytic aqueous treated PVDF 61

Figure 4.29: Contact angle image, optimal catalytic aqueous treated PVDF 61

Figure 4.30: Effect of ozonation on flux reduction 62

Figure 4.31: Effect of backwash on milk permeate flux using untreated PVDF 64

Figure 4.32: Effect of backwash on milk permeate flux using optimal gaseous treated PVDF65 


\section{List of Appendices}

Appendix I: Peroxide determination method........................................................... 70

Appendix II: Sample calculation of peroxide determination .......................................... 72

Appendix III: Required time of boiling for peroxide determination .................................73

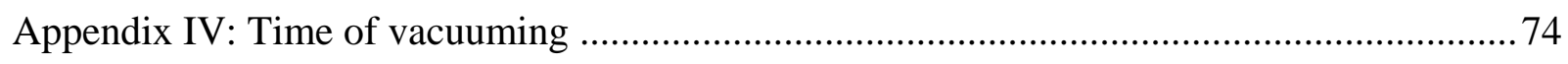

Appendix V: Details of runs, mechanical strength ...................................................... 75

Appendix VI: Details of runs, peroxide concentration ................................................... 77

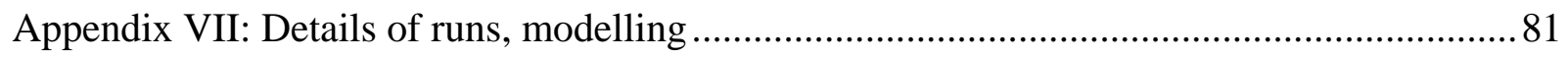

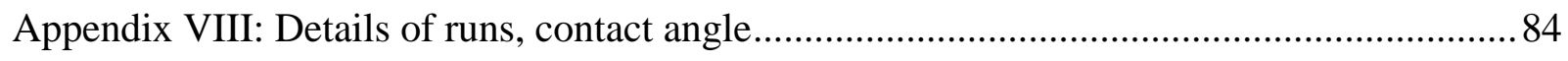

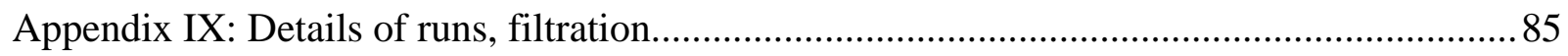

Appendix X: Sample calculation of membrane resistances ............................................8 87

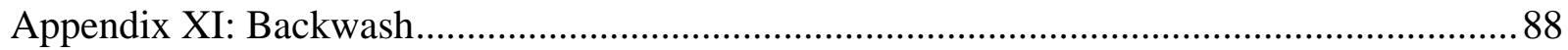




\section{Abbreviations}

\begin{tabular}{lc}
\hline 2-(2-bromoisobutyryloxy)ethyl acrylate & BIEA \\
\hline Acrylamide & AAM \\
\hline Activated carbon & AC \\
\hline Analysis of variance & ANOVA \\
\hline Bovin serum albumin & BSA \\
\hline Central composite rotatable design & DF \\
\hline Degree of freedom & DOE \\
\hline Design of experiments & DSC \\
\hline Differential scanning calorimetry & GPC \\
\hline Gel penetration chromatography & HDPE \\
\hline High density polyethylene & HEMA \\
\hline Hydroxyethyl methacrylate & IPA \\
\hline Isopropanol alcohol & LLDPE \\
\hline Linear low density polyethylene & LDPE \\
\hline Low density polyethylene & MS \\
\hline Mean square & PMMA \\
\hline Poly(methyl methacrylate) & PE \\
\hline Polyethylene & PEG \\
\hline Polyethylene glycol & PEGMA \\
\hline Polyethylene glycol methacrylate & PP \\
\hline Polypropylene & PS \\
\hline Polystyrene & PU \\
\hline Polyurethane & PVA \\
\hline Polyvinyl alcohol & PVP \\
\hline Polyvinyl pyrrolidone & PVDF \\
\hline Polyvinylidene fluoride & RSM \\
\hline Response surface methodology & SEM \\
\hline Scanning electron microscope & SPEU \\
\hline Segmented poly(ether urethane) & SBMA \\
\hline Sulfobetain methacrylate & SS \\
\hline Sum of square & THMWPE \\
\hline Transmembrane pressure & \\
\hline Ultrahigh molecular weight polyethylene & \\
\hline & \\
\hline
\end{tabular}




\section{Chapter One - Introduction}

Water, lipids, sugars and proteins are the main ingredients of milk (Singh et al., 2014). Proteins, which affect the milk properties more than other constituents, make up 1-20\% wt. of milk. (Singh et al., 2014). Proteins are large chains made of amino acids. 22 different types of amino acids are able to form chains in thousand various ways. Proteins of milk could be categorized into "casein" and "serum" types (McSweeney and Fox, 2013).

Casein proteins, which are the main part of milk proteins, form micelles with the help of calcium phosphate. Thus, their relatively larger size is in the range of 0.02 to $0.4 \mu \mathrm{m}$ (Adams, 2012; Singh et al., 2014). $\alpha \mathrm{s} 1-, \alpha \mathrm{s} 2-, \beta$ - and к- casein are the four types of casein proteins. Although there are different models which represent the formation of casein micelles, they are all common in indicating that $\kappa$ - casein, the outermost layer, covers each micelle (McSweeney and Fox, 2013). Also, it has been reported that the zeta potential of such micelles with the coverage of $к$ - casein would be $-20 \mathrm{mV}$ while the average mass of them has been reported to be around $10^{8} \mathrm{Da}$ (McSweeney and Fox, 2013; Singh et al., 2014).

Serum proteins, the other major milk proteins, are also known as whey proteins since they are concentrated from whey. They could be fractionized into soluble (albumin) and non-soluble (globulin) parts (Singh et al., 2014). Whey proteins are mainly consist of $\beta$-lactoglobulin, $\alpha$ lactalbulin, bovine serum albumin (BSA) and immunoglobulin. These kinds of proteins cannot form micelles, though. As a result, they are relatively smaller in comparison to casein proteins. The size of serum proteins is about 0.003 to $0.01 \mu \mathrm{m}$ (Adams, 2012). The molecular mass of $\beta$ lactoglobulin, $\alpha$-lactalbulin and BSA have been reported 18.36, 14.17 and 66.40 kDa, respectively (Singh et al., 2014).

The major usage (about 40\%) of membranes is in the production of dairy products, from which 1 out of 10 is used to adjust the protein percentage in either concentration or dilution processes (Saxena et al., 2009; Tamime, 2012). According to the proteins' size, using $0.1 \mu \mathrm{m}$ membrane results in the enrichment of permeate with serum proteins and blockage of casein proteins at the feed side of the membrane (Adams, 2012; Le Berre and Daufin, 1996). The retentate stream could be used in cheese manufacturing or in production of dried casein while 
whey protein in the permeate would be useful in other industries; for instance, $\alpha$-lactalbumin is used in pharmaceutical industries while $\beta$-lactoglobulin is used in emulsification, foaming and gelling (Espina et al., 2008).

Due to the membrane cost, the interest in using polymeric membranes, instead of expensive ceramic ones, has been growing recently. Polyvinylidene fluoride, PVDF, with the repeating unit of $\mathrm{C}_{2} \mathrm{H}_{2} \mathrm{~F}_{2}$ among all of polymeric membranes is widely used. PVDF's thermal, chemical and mechanical stability makes it suitable for high pressure and temperature applications (Kang and Cao, 2014). However, fouling is one the most considerable hindering issues in the mentioned processes since PVDF membranes are relatively hydrophobic. Rahimpour et al. (2009), reported that the permeate flux of pure water through fouled PVDF membrane after 30 minutes of milk ultrafiltration, decreased $78 \%$ as compared with the water flux of a fresh membrane before filtration with milk. In the same process, the total fouling resistance was $20.5 \times 10^{11} \mathrm{~m}^{-1}$. Such a large fouling resistance could cause high operational and cleaning costs.

Fouling is classified as reversible and irreversible phenomenon (Abdelrasoul et al., 2013). Irreversible foulants are not removed by washing since they have been adsorbed firmly or penetrated into the pores and lodged internally. As a filtration process continues, the foulants reduce the membrane efficiency to the point that membrane has to be replaced. On the other hand, reversible fouling could be remediated by several methods. In a very early stage of fouling, foulants could be washed off from the membrane surface by simply reversing the permeate flow direction. Some kind of fouling, though, is caused by stronger attraction forces such as hydrophilic interactions, hydrogen bonding, van der Waals attractions and electrostatic interactions between the membrane surface and the foulants (Hilal et al., 2012). In this case, chemical cleaning is necessary to restore membrane's initial functionality. The major drawback of chemical cleaning method is the chemical sensitivity of membranes. Some chemicals might shorten the effective lifetime of membranes (Puspitasari et al., 2010).

In order to reduce fouling during a filtration process, various surface treatments have been studied. Coating the membrane with another hydrophilic layer is commercially common. Although physical coating is simple to apply, detaching of the added layer from the membrane 
over time renders the modification ineffective (Hilal et al., 2012). Graft polymerization, on the other hand, uses the same concept of coating applied with a different procedure. Graft polymerization is the process in which the main membrane would be chemically grafted to another thin layer of hydrophilic polymer. Thus, the modified membrane is simultaneously benefited from the stability of the main polymer and the hydrophilicity of the applied layer. Graft polymerization could be initiated through different methods. Among them, ozonation is known as the low cost, easy-to-apply, one stage process in which peroxides would be formed on the surface uniformly. The formed peroxides would be decomposed later to initiate graft polymerization.

Chang and his co-workers in 2009 suggested a mechanism for ozonation and graft polymerization. The schematic of that is illustrated in the figure below.
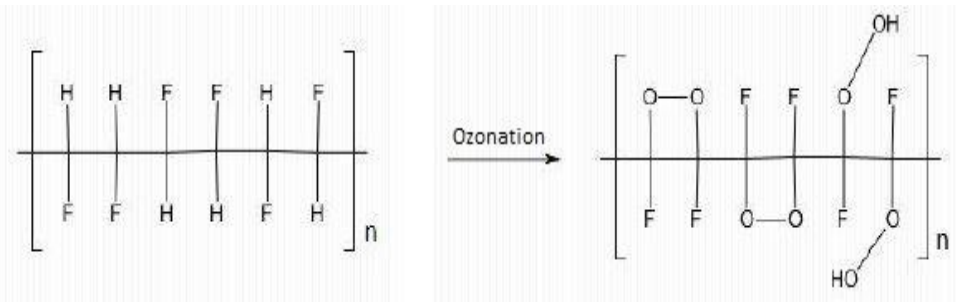

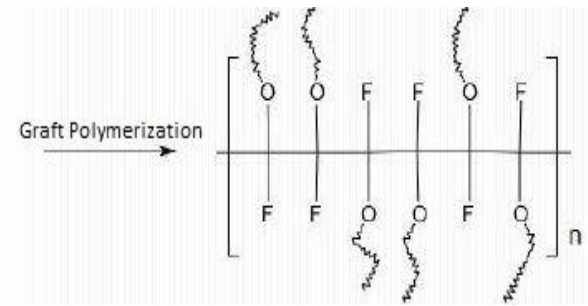

Figure 1.1 - Schematic illustration of ozonation and graft polymerization (Chang et al., 2009)

However, the effect of different parameters and various catalysts are still unknown. In the present study, the influence of ozonation media, exposure time, ozone concentration and $\mathrm{pH}$ in gaseous, catalytic and non-catalytic ozonation have been investigated in order to find the optimum conditions in terms of the highest amount of peroxide formed and the lowest contact angle which represents the lowest hydrophobicity. 


\section{Chapter Two - Literature Review}

In this chapter, general background information on ozonation of membranes is presented. In addition, more details on the parameters of ozonation, which affect the increase in hydrophilicity of PVDF membranes, are provided.

\subsection{Fouling during Filtration Processes}

Fouling could be defined as the accumulation of solids either on the top or in the pores of the membrane. As a result of fouling, which is inevitable according to the inherent concept of filtration, the passage of the feed through the membrane becomes harder due to the narrower available channels and the thicker porous media. Fouling also causes concentration polarization which would promote back diffusion of foulants from the membrane surface to the bulk feed. Thus, the permeate flow would decrease. Fouling causes increasing the required energy and cost, decreasing the membrane lifetime and more frequent membrane cleaning in filtration processes. Feed properties, filtration system and operational conditions in addition to the membrane itself are the parameters affecting the fouling degree. Studying these parameters helps controlling the fouling phenomenon so to achieve more effective filtration.

\subsubsection{Feed Properties}

Milk contains different solid particles such as proteins, minerals, carbohydrates and fats. Although carbohydrates do not cause fouling during micro and ultrafiltration due to their large pore size, proteins and minerals would be the major reason of fouling (Rice et al., 2009). The negatively charged proteins existing in milk would cause electrostatic attraction to the positively charged membranes. Trapping the proteins in the pores of the membrane might be expected in microfiltration while this would not likely to happen for ultra and nanofiltration systems. Although various minerals exist in milk, calcium phosphate has been observed as the main mineral causing fouling since its positive charge boosts protein-protein and protein-membrane attractions (Cheryan, 1998; Rice et al., 2009). During skim milk filtration where casein proteins exist, mineral fouling is negligible since casein micelles are able to stabilize calcium ions and reduce the number of free calcium ions (Cheryan, 1998). 
Among different feed properties, $\mathrm{pH}$ is the most important one. The effect of $\mathrm{pH}$ could be studied from two different views. Firstly, altering the $\mathrm{pH}$ would change the electrostatic charge of proteins. Thus, more or less attraction forces to the membrane surface might happen. Secondly, the proteins and minerals solubility depends on the $\mathrm{pH}$ of the solution. Proteins have lower solubility and higher deposition tendency at $\mathrm{pH}$ around their isoelectric points (Cheryan, 1998). In addition, salts especially calcium phosphate, show lower solubility at higher $\mathrm{pH}$, which causes severe mineral deposition on the membrane surface(Cheryan, 1998; Rice et al., 2009). Lowering the $\mathrm{pH}$, on the other hand, causes casein proteins coagulation and gel formation leading to higher degree of fouling (McSweeney and Fox, 2013). In conclusion, adjusting pH during milk protein filtration should be considered and optimized to minimum the fouling potential.

The feed temperature might also influence the permeate flux and fouling during milk protein filtration processes. Although decreasing the temperature leads to more soluble $\mathrm{Ca}^{2+}$, which hinders mineral precipitation and prevents micelle gel layer formation at low $\mathrm{pH}$, it makes the feed more viscous which would decline the permeate flux (McSweeney and Fox, 2013; Rice et al., 2009). Thus, optimizing the temperature becomes crucial.

\subsubsection{Operational Conditions}

Cross-flow velocity, operating pressure difference and temperatures are the main operational conditions affecting the permeate flux and membrane fouling.

Increasing the cross-flow velocity would increase the rate of convective flow, which leads to larger amount of solids accumulated on the membrane surface. In addition, larger cross-flow velocities increase the shear stress at the membrane walls resulting in wasting the feed energy to pass through the membrane (Le Berre and Daufin, 1996). Le Berre and Daufin (1996) introduced the ratio of cross flow velocity to the shear stress in microfiltration of skim milk using ceramic membranes. They reported that although below the critical ratio, no significant fouling happened, above that severe flux reduction was observed. On the other hand, increasing the cross-flow velocity would make turbulence in the feed compartment, helping to stir the solid particles and decrease the deposition on the membrane surface by the back diffusion mechanism (Zhao et al., 2000). 
According to Darcy's law which is provided in Equation 2.1, permeate flux (J) is proportional to transmembrane pressure (TMP) defined as the average pressure on the feed side minus the pressure on the permeate side.

$$
J=\frac{k}{\mu} \frac{d P}{d z}
$$

where $\mathrm{k}$ is the permeability of the feed through the porous layer, $\mu$ is the feed viscosity, $\mathrm{P}$ is the pressure and $\mathrm{z}$ is the thickness of the porous layer. The relation between the permeate flux and the pressure difference remains the same even after the formation of the cake layer; since the cake layer could be considered as another porous media parallel to the membrane itself which has its own thickness and permeability. In this case, although the pressure difference remains the same, increasing the porous thickness leads to lower permeate flux, J.

However, excessive pressure during filtration process might push solid particles inside the membrane's pores causing irreversible fouling which is also named as depth fouling.

The temperature of the feed affects fouling by affecting the viscosity of the feed and diffusivity coefficient of the foulant particles (Zhao et al., 2000). From this point of view, increasing the temperature decreases the feed viscosity and increases the diffusivity, resulting in larger permeate flux and less fouling due to higher rate of foulant's back diffusion from the membrane surface to the bulk feed. However, in milk filtration, the denaturation of the milk proteins and the probable chemical changes in their structures at extreme temperatures should be considered. In addition, as it was discussed earlier the solubility of $\mathrm{Ca}^{2+}$ would decrease with increasing the temperature, which leads to mineral precipitation on the membrane surface.

\subsubsection{Membrane Properties}

The chemical and the physical properties of the membrane used as the filtration media, directly affect the permeate flux and fouling. Pore size, pore structure, surface roughness, membrane charge and hydrophilicity are the most important characteristics of a membrane (Cheryan, 1998; Ho and Zydney, 1999). 
Although the membrane pore size should fall between the sizes of serum and casein proteins in order to separate those from one another, extremely small pores as well as pores with almost the same size of large casein micelles would promote fouling by narrowing the available channels and pore blockage, respectively (Zhao et al., 2000). Pore structure is also an important factor affecting fouling. Membrane porous structure with more interconnection of the internal channels would decrease fouling by increasing the available paths for the feed to go through (Ho and Zydney, 1999). Smoother membrane surface helps hinder fouling by decreasing the number of existing attachment points. While membrane charge affects the electrostatic forces between the solid particles and the membrane surface, having higher hydrophilicity facilitates the coverage of membrane with a water layer which reduces fouling by not letting foulants reach to the membrane surface.

\subsection{Membrane Modification}

Hydrophilic membranes are defined by the existence of active groups in their structures which are able of making bonds with water molecules. Consequently, hydrophilic membranes would get coated with a layer of water in the feed side during filtration processes. The water layer helps hinder fouling and pore blockage (Abdelrasoul, 2015; Baker, 2004). Thus, increasing the hydrophilicity of membranes is the aim of membrane modification methods which attempt to reduce hydrophobic foulant attachments.

Hydrophilic modification could be carried out before or after membrane formation using polymeric or inorganic modifiers. Polyvinyl alcohol (PVA), polyvinyl pyrrolidone (PVP), polyethylene glycol (PEG) and polyethylene glycol methacrylate (PEGMA) are the most common polymeric modifiers which would be blended with PVDF solution before casting (Kang and Cao, 2014). Although hydrophilicity increased using the mentioned modifiers, the weak compatibility of hydrophilic modifiers with the hydrophobic PVDF caused the stability reduction (Kang and $\mathrm{Cao}, 2014$ ). $\mathrm{TiO}_{2}, \mathrm{SiO}_{2}, \mathrm{Al}_{2} \mathrm{O}_{3}, \mathrm{ZrO}_{2}$ and $\mathrm{ZnO}$, on the other hand, are the most used inorganic modifiers (Bae and Tak, 2005; Damodar et al., 2009; Genne et al., 1996; Liang et al., 2012; Yan et al., 2006; Zuo et al., 2009). This technique is easy to apply and does not require extreme operating conditions (Damodar et al., 2009). However, the modifiers could not distribute uniformly on the surface due to the instability of the casting solution (Kang and 
Cao, 2014). Physical surface coating is an alternative, easy-to-apply method which is not considered as an industrial modification since the weak physical bonds of the added layer could not tolerate harsh operating conditions. (Hilal et al., 2012). Also, it was observed that the physical coating was considerably affected by sodium hypochlorite $(\mathrm{NaOCl})$, the widely used chemical cleaning agent (Puspitasari et al., 2010). Therefore, stability and effectiveness of chemical grafting has been focused recently. In this modification method, the bonds of the polymers would be affected using ozonation, electron beam radiation, UV radiation, X-ray radiation and plasma treatment or their combination in order to introduce functional groups on the surface of the membranes. Later, decomposition of the formed active groups could initiate graft polymerization of hydrophilic polymers onto the main membrane.

Ozonation, a single step, stable, inexpensive uniform treatment has been widely used solely or as a preparation step of graft polymerization in order to increase hydrophilicity of polymeric membranes (Fujimoto et al., 1993; Mahfoudh et al., 2010; Pan et al., 2012; Wang et al., 2000; Yang and Lin, 2002). Also, ozonation is considered as an environmental friendly method since the excess ozone could be converted into oxygen readily (Rashid et al., 2015). Ozone, an inorganic compound, is a very reactive oxidant. It would attack the carbon-hydrogen bonds of polymers. The reaction would cause the detachment of hydrogen from the polymer and the formation of functional groups, such as: ketones, aldehydes, acids, esters, hydroxyl groups, peroxides and hydroperoxides on the membrane (Robin, 2004). Among them, peroxides are more desirable not only because of their inherent hydrophilicity, but also because of their importance to start radical polymerization during grafting. Radical polymerization is one of the most common reactions in which the existence of radicals becomes essential for the initiation step. Thermal decomposition of peroxides is one of the methods to turn them into initiator radicals. This method is used to start grafting of various monomers onto the membrane surface (Chen et al., 1998; Tu et al., 2005; Wang et al., 2000). There are lots of monomers that have been used to increase wettability of membranes, such as: PEGMA (Chang et al., 2009; Liu et al, 2001), hydroxyethyl methacrylate (HEMA) (Wang et al., 2000), 2-(2bromoisobutyryloxy)ethyl acrylate (BIEA) and acrylamide (AAM) (Fujimoto et al., 1993; Gu, 2014; Gu et al., 2009; Zhai et al., 2004). However, seeking for mechanical and chemical stability led to the use of zwitterionic monomers (Chiang et al., 2009). Zwitterions are neutral molecules which have both positive and negative sites. The balanced charge of zwitterionic molecules 
enables the formation of hydrogen bonds with water which make the membrane highly antiprotein absorbent. The positive and the negative charges might be distributed either on the same molecule (polybetains) or on two separate molecules (polyampholytes) (Shen et al., 2015). Tang et al. (2017) succeed to increase permeate flux recovery ratio from $47 \%$ to $85 \%$ after BSA ultrafiltration using sulfobetaine methacrylate (SBMA), one of the most common polybetains, grafting on the ozonated PVDF membranes. However, the desire to find stable and easy-tomanufacture monomers led researchers to use polyampholytes instead of polybetains in order to increase anti-fouling properties (Shen et al., 2015; Zhao et al., 2011).

Although formation of peroxides on the polymeric ozonated samples has been reported by several researchers, hydrophilicity enhancement and fouling reduction could be actually tested with contact angle measurements and filtration performance, respectively, to demonstrate the effectiveness of ozonation.

\subsubsection{Effect of Ozonation on Contact Angle}

Where a fluid and a solid surface become in contact with each other, while they are exposed to air, three forces namely as liquid-gas, liquid-solid and gas-solid surface tensions, develop a mechanical equilibrium. Thus, contact angle forms (Young, 1805). In such a system, contact angle is defined as the angle between the tangent plane to the surface of the liquid and the tangent plane to the surface of the solid at a point along the contact line between the solid and the liquid. Contact angle measurement is a method to determine whether a treatment is useful to enhance hydrophilicity. Contact angle decline represents an easier spreading of liquids on solid surfaces which conventionally known as wettability. Contact angle of smooth surfaces could be mathematically expressed as in the Young's equation below.

$$
\gamma l v \cos (\theta)=\gamma s v-\gamma s l
$$

where $\theta$ is the contact angle; and $\mathrm{\gamma} 1 \mathrm{v}, \mathrm{\gamma}$ sv and $\mathrm{\gamma}$ sl represent liquid-vapor, solid-vapor and solid-liquid interfacial tensions, respectively. Using the Young's equation, one unique contact angle could be found, however, in the real systems, where several non-idealities exist, a range of contact angle might be measured experimentally since the contact line is not in a static equilibrium and the drop might either expand or contract. This phenomenon is called contact 
angle hysteresis. The hysteresis is the difference of the maximum formed contact angle (advancing) and the minimum one (receding).

However, surfaces are not always completely smooth. In this case, roughness of the surface should be considered in order to find the contact angle. Roughness ratio (r) is defined as the ratio of actual surface to the geometric surface (Wenzel, 1949). The hysteresis becomes larger as heterogeneity and roughness of the solid increase. The modified equation which is known as the Wenzel equation could be found as below.

$$
\gamma l v \cos (\theta)=(\gamma s v-\gamma s l) \times r
$$

The lower the contact angle is, the higher wettability would be acquired. Contact angle would vary due to either the roughness or chemical changes of the sample surface. Murakami et al. (2003) reported that although ozonation resulted in the roughness of the polystyrene (PS) and poly(methyl methacrylate) (PMMA) films, no OH bonds formation was observed in PMMA ozonated samples in contrast to PS ones. Thus, contact angle of PS decreased drastically while contact angle of PMMA slightly increased. Table 2.1 summarizes the results which indicate that ozonation could be able to reduce contact angle.

Table 2.1 - Effect of ozonation on advancing contact angle

\begin{tabular}{cccccc}
\hline Author & Material & Ozone & Ozonation & \multicolumn{2}{c}{ Contact Angle $\left(^{\circ}\right.$ ) } \\
& & Dosage & Time (min) & Fresh & Ozonated \\
\hline Mahfoudh et al. (2010) & Polystyrene & $4000 \mathrm{ppm}$ & 60 & 88 & 56 \\
Mahfoudh et al. (2010) & Polyurethane & $4000 \mathrm{ppm}$ & 60 & 103 & 90 \\
& High density & $4000 \mathrm{ppm}$ & 60 & 98 & 76 \\
Mahfoudh et al. (2010) & polyethylene & & & & \\
& Polypropylene & $3 \% \mathrm{wt}$. & 20 & 126.1 & 120.5 \\
Gu et al. (2012) & Polypropylene & $3 \% \mathrm{wt}$. & 20 & 126.1 & 113.3 \\
Gu et al. (2012)* & Polystyrene & $4000 \mathrm{ppm}$ & 360 & 82 & 49 \\
Al Abdulal et al. (2015) & polyethylene & $5.6 \mathrm{ppm}$ & 360 & 80 & 40 \\
Rashid et al. (2015)* & terephthalate & & & & \\
\hline
\end{tabular}

*- Aqueous Phase 


\subsubsection{Effect of Ozonation on Fouling}

The other method to illustrate the result of ozonation is to evaluate fouling reduction in filtration processes. Blockage of membrane pores by material adsorption and deposition on the membrane surface is known as membrane fouling. Fouling decreases the permeate flux proportional to the percentage of the closed pores (Abdelrasoul et al., 2013). Membrane fouling takes place by diverse mechanisms which are briefly explained below (Adams, 2012; Shi et al., 2014).

A. when rejected materials adhere to the surface of a membrane, adsorption is the reason of the fouling. Van der Waals forces, electrostatic attractions and chemical bonding are the main forces that conjunct particles to the membrane surface.

B. if adsorption continues, cake formation begins layer by layer. The inert layers act like an extra filter parallel to the membrane and thus add an undesirable resistance to the system.

C. If a particle size be slightly larger than pores, it would get stuck at the entrance of the pores and cause pore blockage.

D. if a larger particle or colloid gets pushed into the pores by an external force, depth fouling takes place.

The primary cause of fouling is the adherence of rejected materials to membrane surface. Electrostatic forces between membrane and feed solution lead to either attraction or repulsion. Colloids are generally tightened to the membrane surface with electrostatic attraction. Therefore, if they are oppositely charged, the strength of attraction makes solute adsorption more intense (Hilal et al., 2012).

Several models for fouling have been proposed and reported in literature, namely gel polarization model, osmotic pressure model, adsorption model, resistance model as well as different empirical models are some of the most used ones (Baker, 2004; Beicha and Zaamouche, 2012; Chang et al., 2002; Hermia, 1982; Merten, 1963).

During a constant pressure filtration process, Darcy's law (Equation 2.1), which is also known as the resistance-in-series model, could mathematically describe the fouling 
phenomenon (Kim and DiGiano, 2009). Resistance model considers the membrane, the cake layer and the adsorbed foulants as three resistances in series which the permeate goes through (Chang et al., 2002; Field et al., 1995). This could be presented as the model below. It would be worth mentioning that during microfiltration, osmotic pressure, the minimum applied pressure required in order to prevent osmosis, is negligible due to large size of cake particles.

$$
J=\frac{T M P}{\mu .\left(R_{M}+R_{C}+R_{F}\right)}
$$

where $\mathrm{J}$ is the permeate flux, TMP is the applied transmembrane pressure, $\mu$ is the dynamic viscosity of permeate, $R_{\mathrm{M}}$ is intrinsic membrane resistance, $R_{\mathrm{C}}$ is surface cake resistance caused by the cake layer deposited over the membrane surface and $R_{\mathrm{F}}$ is pore fouling resistance.

To find the different resistances, filtration runs with distilled water and the feed could be useful. Using permeate flux of distilled water while the membrane is still fresh and clean ( $\left.\mathrm{J}_{\text {initial }}\right)$, the instinct membrane resistance $\left(\mathrm{R}_{\mathrm{M}}\right)$ could be calculated.

$$
R_{M}=\frac{T M P}{\mu_{\text {distilled water }} J_{\text {initial }}}
$$

Also, permeate flux of distilled water through a fouled membrane when the cake layer has been rinsed $\left(\mathrm{J}_{\text {final }}\right)$, would be used in the equation to find $\mathrm{R}_{\mathrm{F}}$.

$$
R_{F}=\frac{T M P}{\mu_{\text {distilled water }} J_{\text {final }}}-R_{M}
$$

During low-pressure filtration processes, cake layer resistance becomes more significant in comparison to the clean or the fouled membrane resistance (Kim and DiGiano, 2009). Finding the cake layer resistance, however, requires additional information about the particles trapped at the back of the filter. Using Carmen-Kozeny equation, $\mathrm{R}_{\mathrm{c}}$ could be found (Chang et al., 1999; Kim and DiGiano, 2009).

$$
R_{C}=\frac{L \cdot K \cdot S^{2}(1-\varepsilon)^{2}}{\varepsilon^{3}}
$$




$$
S=\frac{6}{\varphi \cdot d}
$$

$\mathrm{L}$ is the cake layer thickness, $\mathrm{S}$ is the specific surface area of the cake media, $\mathrm{K}$ is the Kozeny constant, $\varepsilon$ is the porosity of the cake layer, $\varphi$ is sphericity and $\mathrm{d}$ is the diameter of the particles in the cake layer.

Resistance-in-series model, however, could not accurately describe a cross-flow filtration unit since it does not consider concentration polarization and pore blockage, two important mechanisms of the permeate flux reduction (Abdelrasoul, 2015; Lee and Clark, 1998). Concentration polarization occurs due to concentration gradient between the bulk feed and the membrane surface (Lee and Clark, 1998). As a result of concentration polarization, diffusion of solutes from the membrane surface back to the bulk solution takes place since the concentration of solute on the membrane surface is higher than its concentration in the bulk feed.

Percentage fouling resistances could also be used to evaluate fouling phenomenon in a filtration process (Tang et al., 2017). In this case, the total resistance is the sum of the reversible and irreversible resistances. In a similar fashion as for the resistance-in-series model, three filtration runs would be required to find the resistances. $J_{\text {initial }}$ and JDWB represent the permeate fluxes of distilled water before and after fouling with the feed solution, respectively. Total, reversible and irreversible fouling resistances would be defined as below where $\mathbf{J}_{\text {solution }}$ is the permeate flux with the solution used as the feed through a membrane.

$$
\begin{array}{lll}
\text { Total Fouling Resistance }(\%) & R_{\text {total }}=\left(1-\frac{J_{\text {solution }}}{J_{\text {initial }}}\right) \times 100 & \text { Equation (2.9) } \\
\text { Irreversible Fouling Resistance }(\%) & R_{\text {irreversible }}=\left(1-\frac{J_{D W B}}{J_{\text {initial }}}\right) \times 100 & \text { Equation (2.10) } \\
\text { Reversible Fouling Resistance }(\%) & R_{\text {reversible }}=\left(\frac{J_{D W B}}{J_{\text {initial }}}-\frac{J_{\text {solution }}}{J_{\text {initial }}}\right) \times 100 & \text { Equation (2.11) }
\end{array}
$$

$\mathrm{J}_{\mathrm{DWB}}$ is the distilled water permeate flux that is determined after backwashing which removes reversible foulants. Thus, if a complete permeate flux recovery is possible $\left(\mathrm{J}_{\text {initial }}=\mathrm{J}_{\mathrm{DWB}}\right)$, there would be no irreversible fouling resistance based on the non-recoverable definition of this fouling type. On the other hand, the difference in the permeate flux of water after backwashing 
the sample $\left(\mathrm{J}_{\mathrm{DWB}}\right)$ and the permeat flux of the solution such as milk $\left(\mathrm{J}_{\text {solution }}\right)$ is attributed to the resistance caused by the cake layer containing the solution's particles, which is known as the reversible fouling resistance. The sum of these two resistances makes the total percentage fouling resistance.

Chang and his colleagues investigated the efficiency of ozonation in terms of water flux through the PVDF membrane before and after being fouled with platelets. The results illustrated that ozonation was effective in increasing the permeate flux and reducing the flux drop during a filtration process, due to the hydrophilicity enhancement by the ozone-induced modification of the membrane (Chang et al., 2008). However, the significant increase of water flux before fouling was attributed to the material deterioration during ozone exposure (Chang et al., 2008). The results are shown in Table 2.2.

Table 2.2 - Effect of ozonation on water flux (Chang et al., 2008)

\begin{tabular}{lcc} 
& Water Flux Before Fouling $\left(\mathbf{L} / \mathbf{m}^{2} \mathbf{h}\right)$ & Flux Reduction After Fouling (\%) \\
\hline Untreated PVDF & 534.5 & $62 \%$ \\
Ozonated $^{\text {a }}$ PVDF & 2354.5 & $49 \%$ \\
\hline
\end{tabular}

a) Ozonation time $=30 \mathrm{~min}$; Ozone dosage $=46 \mathrm{~g} / \mathrm{L}$

Although ozonation is generally effective to enhance surface hydrophilicity of membranes, there are parameters which require more elaborate studies.

\subsubsection{Effect of Ozonation Parameters}

a) Phase of Ozonation

While a membrane surface is exposed to ozone, various functional groups might be produced. Among all of them, peroxide and hydro-peroxides are responsible of initiating graft polymerization (Fujimoto et al., 1993). This is the reason that the amount of peroxide on the surface of membranes is the major indicator of the efficiency of the remediation process.

Polymeric membranes could be exposed to ozone in gaseous or aqueous phase. In addition to air and water, isopropanol alcohol (IPA) was reported as the medium which the polymers soaked in and ozone bubbled through (Chang et al., 2008; Tu et al., 2005). In an aqueous media, 
not only direct oxidation with the molecular ozone would occur, but also strong radicals could initiate indirect oxidation. In 2009, Gu et al. investigated whether there was any difference in the efficiency of gaseous and aqueous high density polyethylene (HDPE) ozonation. Their obtained data showed that independent of ozone dosage, aqueous ozonation was more effective in generating peroxides (Gu et al., 2009).

On the other hand, Patel and his co-workers investigated ozonation of low density polyethylene (LDPE)/ linear low density polyethylene (LLDPE) in different mediums and observed that not only there was no significant difference between gaseous and aqueous phase in terms of the generated peroxide concentration, but also gaseous phase ozonation contributed to slightly higher peroxides generation (Patel et al., 2012). Similar trend was observed with polyethylene (PE) membranes exposed to ozone (Mastan et al., 2013). The similar result was also obtained with ozonation of polypropylene (PP) microfiltration membrane (Gu et al., 2012).

In the same research, Gu and his colleagues added scavengers into aqueous phase in order to trap free radicals and investigate the effect of molecular ozone on peroxide concentration solely. It was observed that after adding scavengers, the amount of peroxide produced slightly decreased, which demonstrated that molecular ozone and free radicals might have affected the peroxide generation simultaneously in an aqueous medium. However, since the difference was not significant, molecular ozone in comparison to free radicals could be considered as the major affecting the peroxide generation (Gu et al., 2012).

Despite of the comparable results in terms of peroxide generation, aqueous ozonation with catalyst boosted the efficiency and reduced the negative side effects of the ozonation such as the decline of the mechanical strength of the treated membrane.

\section{b) Exposure Time}

Researchers have found that the amount of peroxide generated on the polymers was raised as time passed either in gaseous or aqueous media (Chen et al., 2003; Gu et al., 2009; Laitman et al., 2014; Patel et al, 2012; Wang et al., 2000). Kinetic studies of the reactions between ozone and PE, showed that although reaction time helped increasing the peroxide concentration on the PE samples, the rate of peroxide formation decreased as time passed (Kefeli et al., 1971). However, in some cases, extra ozonation time could result in a sudden drop of peroxide 
concentration (Fujimoto et al., 1993; Park et al., 2000; Yang and Lin, 2003). Chang et al. studied ozonation of PVDF membrane and found that prolonged ozonation time resulted in sample deterioration rather than increasing the peroxide concentration (Chang et al., 2008). The drop in peroxide concentration might be due to material deterioration or conversion of active peroxides into radicals and inactive species (Yang and Lin, 2003). Since peroxide formation happens due to surface reaction of ozone and the polymers, it highly depends on the material used. Ko et al. (2001) observed different trends of peroxide formation on polyurethane (PU), PE and PMMA films. Peroxide concentration did not changed significantly on PU and PE after 1 hour of ozonation, while it kept increasing on PMMA films even after 4 hours under the same operational conditions (Ko et al., 2001). Yuan et al. (2003) reported that the insignificant increase of peroxide concentration on segmented poly(ether urethane) (SPEU) film after 30 minutes of ozonation might be due to the saturation of the film as it could not be participated in the oxidation reaction anymore.

Differential scanning calorimetry (DSC) of ultrahigh molecular weight polyethylene (UHMWPE) showed that ozone would rather attack amorphous phase than crystalline arrangement. Amorphous materials, due to their less compact structures, allow ozone molecules to penetrate more readily (Cataldo et al., 2011). Ko et al., (2001) reported that PE ozonation resulted in less peroxide concentration in comparison to PU and PMMA due to its crystalline structure. Hence, the less crystallinity exists in the sample, the less ozone resistance would be observed. PVDF homopolymers are categorized as semi-crystalline structures consisting 35\% to $70 \%$ crystallinity based on the method of preparation (Cui et al., 2014).

Gatenholm and his co-workers reported that the pores of polypropylene membrane became larger and larger till deterioration occurred (Gatenholm et al., 1997). Scanning electron microscope (SEM) images of microfiber polysulfone undergone ozone treatment showed pore size changes from $1 \mu \mathrm{m}$ to $10 \mu \mathrm{m}$, which finally resulted in a complete cleavage of fibrous structure (Obvintseva et al., 2010).

Wang et al. (2014) studied the molecular weight of PVDF using gel penetration chromatography (GPC) method before and after ozonation. The results showed that ozone 
treated materials had relatively lower molecular weight due to ozone attack to the molecular chains which could cause chain unlinking after the extended exposure time (Wang et al., 2014).

Another evidence of the polymer structure disintegration was revealed by the tensile strength test, which determined mechanical properties of samples after ozonation. According to the test results, polymers gradually lost their strength during ozonation process, become more and more fragile, and finally their structure might disintegrate (Patel et al, 2012; Wang et al., 2000; Yang and Lin, 2002).

In conclusion, ozonation process would have an optimum reaction time which balances peroxide generation and mechanical strength lost. Alternatively, in order to maintain appropriate mechanical properties, catalysts could be used to achieve a higher peroxide generation in a shorter ozonation time that helps reducing the loss of tensile strength (Patel et al., 2012).

c) $\mathrm{pH}$

One of the advantages of aqueous ozonation over gaseous one is the ability of adjusting $\mathrm{pH}$ which controls peroxide formation directly. However, due to complex chain reactions of ozone in water, which is shown in Figure 2.1, the effect of $\mathrm{pH}$ is still unknown.

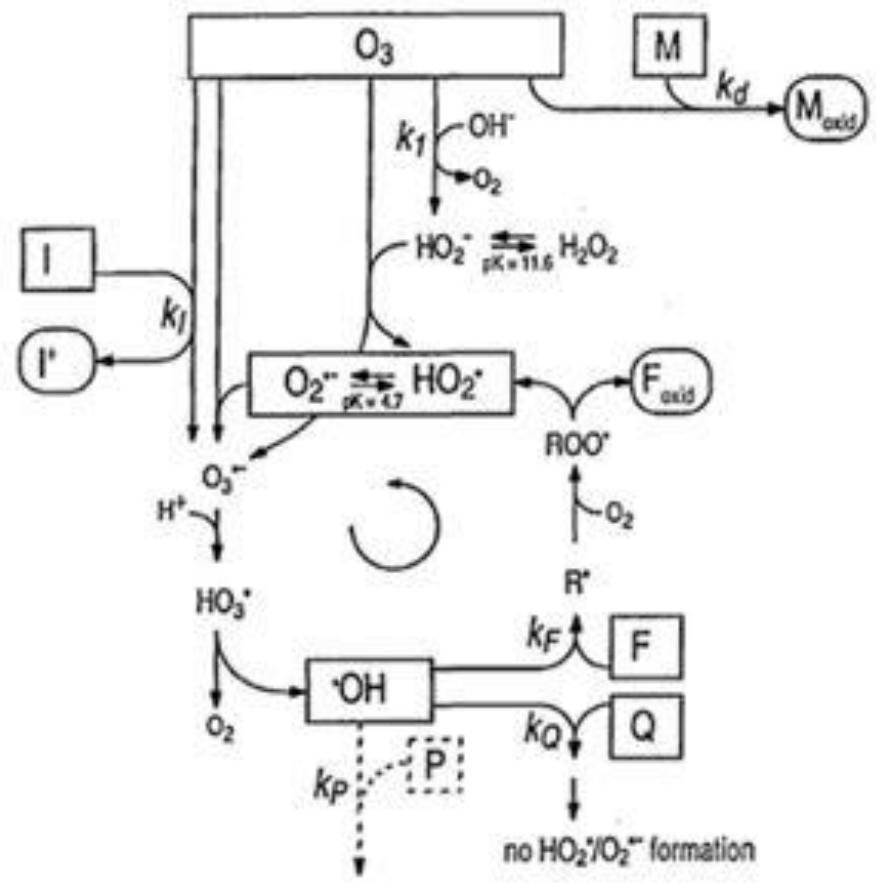

Figure 2.1 - Ozone in water (Adopted From: Jans and Hoigne, 1998) 
In the presence of water, peroxide formation could be happened through either direct or indirect oxidation. While in the former one ozone attacks the polymer directly, the latter one would occur after the transformation of ozone into hydroxyl radicals, which are relatively stronger oxidizers. The different paths of ozone oxidation reactions are illustrated in Figure 2.2. The left one is known as the direct oxidation while the other three paths lead to formation of radicals.

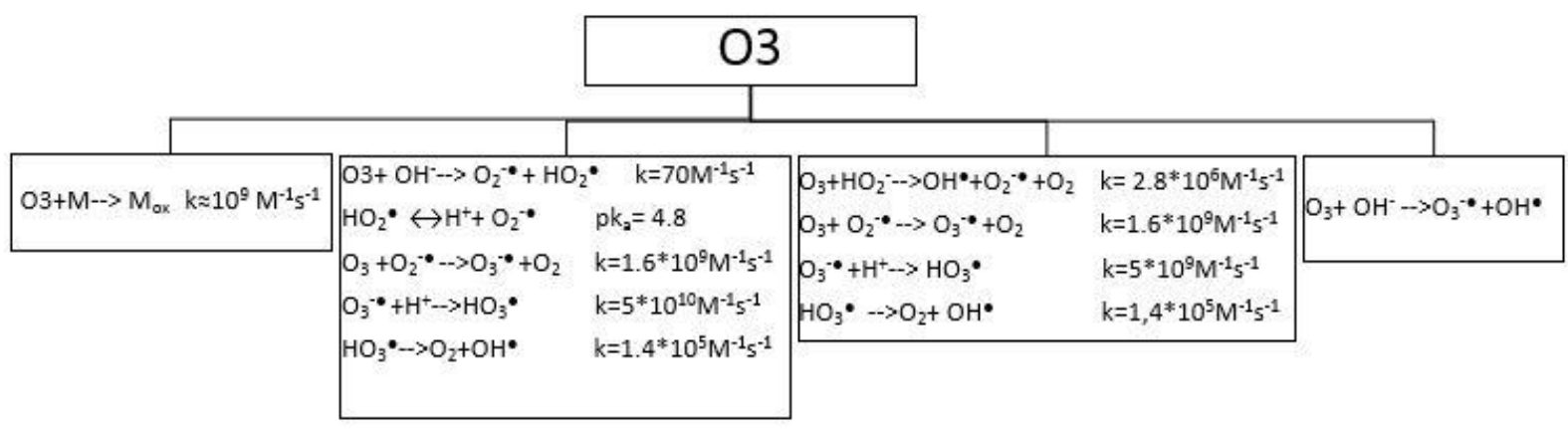

Figure 2.2 - Ozone oxidation paths in water (Elovitz and von Gunten, 1999; Staehelin and Hoigne,

Although there are disagreements over the effect of ozone on peroxide formation, different studies showed that at higher $\mathrm{pH}$, more ozone molecules would be decomposed into radicals (Sotelo et al., 1989). At low $\mathrm{pH}$, the indirect oxidation has been reported to become less significant through all the three paths. The first indirect oxidation rate would be slower at low $\mathrm{pH}$ since not enough $\mathrm{OH}^{-}$exists in the medium. The second one also would decrease since $\mathrm{HO}_{2}{ }^{-}$ mainly forms from $\mathrm{H}_{2} \mathrm{O}_{2} \leftrightarrow \mathrm{H}^{+}+\mathrm{HO}_{2}{ }^{-}$. The mentioned reaction was reported not to take place at $\mathrm{pH}$ below 5 (Staehelin and Hoigne, 1982). Also, the decomposition of ozone through the last one was observed only around high pH values (around 14) (Staehelin and Hoigne, 1982). From all above, decreasing the $\mathrm{pH}$, led to less hydroxyl radicals and thus less peroxide would be formed on the surface of the membrane through the indirect oxidation.

In addition, the lifetime of ozone molecules decreased significantly under higher $\mathrm{pH}$ conditions which led to more decomposition of ozone into radicals (Staehelin and Hoigne, 1982). Also, another evidence of the $\mathrm{pH}$ role on ozone decomposition is the Henry's law constant which was observed to be increased with increases in the $\mathrm{pH}$ of the medium (Sotelo et al., 1989). Thus, the disagreement was mainly over the importance of direct oxidation in comparison to that of indirect one. 
Patel et al. (2012) reported the importance of molecular ozone over free radicals since they observed a decreasing trend of the peroxide amount generated versus $\mathrm{pH}$. However, investigation of the influence of $\mathrm{pH}$ on peroxide generation conducted by Mastan (2010) showed a maximal peroxide amount under an acidic condition. Since only few investigations have been done on this issue, consistent trend and solid explanation of the relationship between $\mathrm{pH}$ and the amount of peroxide generated is not available yet.

\section{d) Temperature}

Temperature is an effective parameter for both gaseous and aqueous ozonation. The temperature dependence of the ozonation reaction was reported by Kefeli et al. (1971) where increasing the temperature from 30 to $70^{\circ} \mathrm{C}$ led to more peroxides formed on PE powder. Boutevin et al. (2002) observed a highly exothermic reaction between ozone and HDPE and LDPE powders. A long ozone exposure time resulted in a high reactor temperature causing polymer melting. Thus, applying a temperature regulator helped avoiding polymer degradation and investigating the effect of temperature. In the mentioned study, the positive correlation between the temperature and the rate of peroxide formation was found in the range of 25 to $45^{\circ} \mathrm{C}$.

Finding the effect of temperature on aqueous ozonation, however, requires the consideration of ozone solubility in water. Although ozonation rate and self-decomposition of ozone become faster at high temperatures in all the pH range (Sotelo et al., 1987), less ozone molecules would be available in aqueous media as water temperature increases due to the lower solubility.

On the other hand, Ozen et al. (2002) reported that an increase in the temperature caused more significant mechanical strength loss of LLDPE films because of the polymer deterioration. They attributed their result to the larger distance between polymer chains at higher temperatures so that ozone molecule permeability through the film would increase.

\subsubsection{Ozonation with Catalyst}

Since an aqueous medium allows addition of catalysts, several metal salts have been examined to find out their efficiency (Mastan et al., 2013; Patel, 2008). Homogeneous catalysts could boost surface density of peroxides on the membranes. While $\mathrm{Mg}(\mathrm{II}), \mathrm{Mn}$ (II), $\mathrm{Ni}(\mathrm{II})$, $\mathrm{Co}$ (II) and 
$\mathrm{Ag}$ (I) ions, did not affect peroxide concentration, $\mathrm{Cu}(\mathrm{II}), \mathrm{Fe}(\mathrm{III})$ and $\mathrm{Zn}(\mathrm{II})$ ions significantly accelerated peroxide generation on PE films (Mastan et al., 2013; Patel, 2008).

According to $\mathrm{Gu}$ et al. (2012), although $\mathrm{Cu}^{2+}$ led to a higher peroxide concentration on polypropylene microfiltration membranes in comparison to non-catalyst ozonation, not only the amount of peroxides did not increase continuously by adding extra salt, but also it fell after an optimum value. Also, Mastan et al. (2013), reported the optimum amount of metal salts beyond which changes in the peroxide concentration were insignificant. The observation suggested that $\mathrm{Cu}^{2+}$ catalyzed peroxide generation and decomposition simultaneously. In the mechanism proposed by Bhaduri and Mukesh (2000), metal salts react with the peroxides to form radicals which would transform into other oxygenated species. In an alkaline solution, where the indirect oxidation becomes more dominant, though, copper salt is not usable due to its low solubility.

Heterogeneous catalysts have not been investigated for the purpose of membrane modification. However, activated carbon (AC), has been widely used to accelerate the effect of ozone in wastewater treatments. The role of activated carbon is still unclear. Sanchez-Polo and his co-workers suggested that since the activity of AC decreased under an extended exposure to ozone, AC could not be considered as a catalyst, however, it is more likely to be a conventional initiator or promoter for the formation of $\mathrm{OH}$ radicals (Sanchez-Polo et al., 2005). Nonetheless, some other researchers did not report any significant change in the activity of AC after the oxidation process that supports the hypothesis of AC catalytic role (Alvarez et al., 2006). Though, in all the studies, the addition of AC led to a higher amount of hydroxyl radicals which are stronger oxidizers than ozone itself (Beltran et al., 2002; Sanchez-Polo et al., 2005).

During such a process, in addition to the surface area, pore volume, the basicity of AC and the concentration of AC also played an important role (Alvarez et al., 2006; Guiza et al., 2004). Several researchers came to a conclusion that by increasing the AC concentration, the ozone decomposition rate constant would be increased (Alvarez et al., 2006; Guzman-Perez et al., 2011; Sanchez-Polo et al., 2005). This acceleration was more significant at higher $\mathrm{pH}$, as reported by Guzman-Perez et al., 2011.

Based on the method of activated carbon preparation and the intensity of oxidation reaction, activated carbon could be categorized into the H-type and the L-type. The former one 
shows hydrophobic characteristics in the presence of water molecules while the latter one would be hydrophilic (Chiang et al., 2002). It is worth noticing that the H-type activated carbons could gradually convert into the L-type even at room temperature (Chiang et al., 2002; Corapcioglu and Huang, 1987). Corapcioglu and Huang (1987) studied various commercial activated carbons and reported different behaviors of their zeta potential versus $\mathrm{pH}$ value. In addition, different activated carbons showed different isoelectric points, the $\mathrm{pH}$ at which the zeta potential is neutral. When activated carbon was treated with $\mathrm{NaOH}$ and ozone, higher total concentration of oxygen in $\mathrm{AC}$ was observed with both treatments. Further, the zeta potential of activated carbon became more negative after the alkaline treatment and ozone exposure (Chiang et al., 2002).

Activated carbon addition to an aqueous medium of ozonation could totally change the dominant reaction, nonetheless, the effect of $\mathrm{pH}$ would be still considerable. Although different mechanisms of $\mathrm{AC}$ behavior in water in the presence of ozone have been proposed by various researchers, the catalytic effect of $\mathrm{OH}^{-}$ions on increasing the rate of ozone decomposition in the presence of $\mathrm{AC}$ is common among all of them (Faria et al., 2006).

One mechanism has been suggested by Sanchez-Polo et al. (2005) in which ozone reaction with pyrrolic groups $\left(\mathrm{C}_{4} \mathrm{H}_{4} \mathrm{NH}\right)$ of $\mathrm{AC}$ would produce radicals. The reactions are presented in Equations 2.12 to 2.15 , below.

$$
\begin{aligned}
& \mathrm{C}_{4} \mathrm{H}_{4} \mathrm{NH}+\mathrm{O}_{3} \rightarrow \mathrm{C}_{4} \mathrm{H}_{4} \mathrm{~N}^{+} \mathrm{O}^{-}+\mathrm{HO}_{2} \bullet \\
& \mathrm{HO}_{2} \bullet \leftrightarrow \mathrm{H}^{+}+\mathrm{O}_{2}^{-\bullet} \\
& \mathrm{O}_{2}^{-\bullet}+\mathrm{O}_{3} \rightarrow \mathrm{O}_{3} \bullet+\mathrm{O}_{2} \\
& \mathrm{O}_{3} \bullet+\mathrm{H}^{+} \rightarrow \mathrm{HO}^{\bullet}+\mathrm{O}_{2}
\end{aligned}
$$

On the other hand, Beltran and his co-workers (2002) proposed another mechanism. They reported that activated carbon could be helpful to accelerate radical formation only at $\mathrm{pH}>6$ while at acidic $\mathrm{pH}$ below 6 , the reaction chain did not result in any radical formation. Also according to this proposed mechanism, more radicals would be formed with increasing the $\mathrm{pH}$ (Beltran et al., 2002). According to the mentioned mechanism, the reactions of Equation 2.16 to Equation 2.22 would happen at $\mathrm{pH}>6$. 
$\mathrm{OH}^{-}+\mathrm{S} \leftrightarrow \mathrm{OH}-\mathrm{S}$

Equation (2.16)

$\mathrm{O}_{3}+\mathrm{OH}-\mathrm{S} \leftrightarrow{ }^{\bullet} \mathrm{O}_{3}-\mathrm{S}+\mathrm{HO}^{\bullet}$

Equation (2.17)

- $\mathrm{O}_{3}-\mathrm{S} \leftrightarrow{ }^{\bullet} \mathrm{O}-\mathrm{S}+\mathrm{O}_{2}$

Equation (2.18)

$\mathrm{O}_{3}+{ }^{\bullet} \mathrm{O}-\mathrm{S} \leftrightarrow{ }^{\bullet} \mathrm{O}_{2}^{-}+\mathrm{S}+\mathrm{O}_{2}$

Equation (2.19)

$\mathrm{O}_{2}^{-\bullet}+\mathrm{O}_{3} \rightarrow \mathrm{O}_{3}^{-\bullet}+\mathrm{O}_{2}$

Equation (2.20)

$\mathrm{O}_{3}^{\bullet \bullet}+\mathrm{H}^{+} \rightarrow \mathrm{HO}_{3}^{\bullet}$

Equation (2.21)

$\mathrm{HO}_{3}^{\bullet} \rightarrow \mathrm{HO}^{\bullet}+\mathrm{O}_{2}$

Equation (2.22)

The reactions below show the mechanism of the reduction of ozone to oxygen by activated carbon in water under acidic conditions $(2<\mathrm{pH}<6)$. As shown in the reactions, although activated carbon and ozone are involved in the reaction chain, this does not help producing any type of radicals (Beltran et al., 2002).

$$
\begin{aligned}
& \mathrm{O}_{3}+\mathrm{S} \leftrightarrow \mathrm{O}_{3}-\mathrm{S} \\
& \mathrm{O}_{3}-\mathrm{S} \leftrightarrow \mathrm{O}_{2}+O-S \\
& \mathrm{O}_{3}+O-S \leftrightarrow 2 \mathrm{O}_{2}+S
\end{aligned}
$$

Equation (2.24)

Equation (2.25) 


\section{Chapter Three - Materials and Methods}

In this part, materials and procedures used in the present study would be explained. This chapter has been divided into 7 sections; each represents the related materials and procedures.

\subsection{Ozonation}

Ozonation, an effective, inexpensive, one-stage procedure has been used to increase the hydrophilicity of polymeric membranes. In this part, the used chemicals, applied equipment and the process have been represented.

\subsubsection{Materials}

Ozonation has been carried out on PVDF membranes. Synder Flat Sheet Membrane was obtained from Sterlitech (Kent, WA, USA). The average pore size of the mentioned membrane was reported by the provider as $0.1 \mu \mathrm{m}$. The average thickness of the membrane was measured to be $0.2 \mathrm{~mm}$.

Sulfuric acid and sodium hydroxide were used to alter the aqueous medium's $\mathrm{pH}$ to a desired value. They were obtained from EMD Chemicals Inc. (Gibbstown, NJ, USA).

Granular AC, Darco 20-40 mesh particle size, was used as heterogeneous catalyst, provided from Sigma-Aldrich Co. (St. Louise, MO, USA). It is worth mentioning that since granular activated carbon $20-40$ mesh $(420-840 \mu \mathrm{m})$ was used, the membrane internal pore blockage with activated carbon during catalytic ozonation was not probable.

Cupric nitrate, 2.5-hydrate and ferric chloride, 6-hydrate were used as the homogenous catalysts for comparison purposes. They were provided from J.T. Baker Inc. (Phillipsburg, NJ, USA). The list of equipment used is provided in Table 3.1. 
Table 3.1 - Ozonation setup equipment list

\begin{tabular}{ll}
\hline Equipment & Manufacturer \\
Ozone Generator, S-50G & A2Z Ozone Inc. (Louisville, KY, USA) \\
Oxygen Cylinder & Linde Canada \\
Ozone Monitor, 106-H & Ozone Solutions, 2B Technologies (Boulder, CO, USA) \\
Flow Meter, 0-50 SCFH & Brooks Instruments (Hatfield, PA, USA) \\
Pressure Meter, 0-5 psi & Weiss Instruments (Holtsville, NY, USA) \\
Ozone Destructor & Ryerson University (Toronto, ON, CA) \\
pH Meter, 2100e & Mettler Toledo (Mississauga, ON, CA) \\
Reactor & Ryerson University (Toronto, ON, CA) \\
\hline
\end{tabular}

\subsubsection{Procedure}

- Membrane sheet was cut into $2 \mathrm{~cm} \times 5 \mathrm{~cm}$ strips. Thus $10 \mathrm{~cm}^{2}$ was used as the nominal surface area for calculations.

- In case of aqueous phase ozonation, the reactor was filled with distilled water. As the $\mathrm{pH}$ of the used distilled water was measured to be 6.2 , in some cases, $\mathrm{pH}$ was changed using sulfuric acid and/or sodium hydroxide solutions.

- In catalytic ozonation, $1 \mathrm{~g} / \mathrm{L}$ of activated carbon (AC) was added to the medium.

- Samples were placed into the reactor after washing with distilled water and vacuuming for 1 hour.

- While the exhauster valve (V1) and ozone monitoring valve (V2) were fully opened, the ozone concentration was adjusted to a required level.

- The valve of the reactor (V3) was then opened to let ozone into the reactor while V1 was closed. Ozonation process was started at this point.

- After a predetermined period, samples were taken out of the reactor, washed with distilled water and placed under vacuum for 1 hour in order to let the physically-adsorbed ozone molecules be desorbed from the surface of the samples.

- After being placed under vacuum, the samples were ready for the next steps.

Ozonation experiments were run at room temperature $\left(23^{\circ} \mathrm{C}\right)$. A temperature change in the reactor of less than $5^{\circ} \mathrm{C}$ and $3^{\circ} \mathrm{C}$ was observed with gaseous and aqueous phase reactions, respectively. 
The schematic illustration of ozonation setup as well as a picture of the ozonation setup are shown in Figure 3.1 and 3.2, respectively.

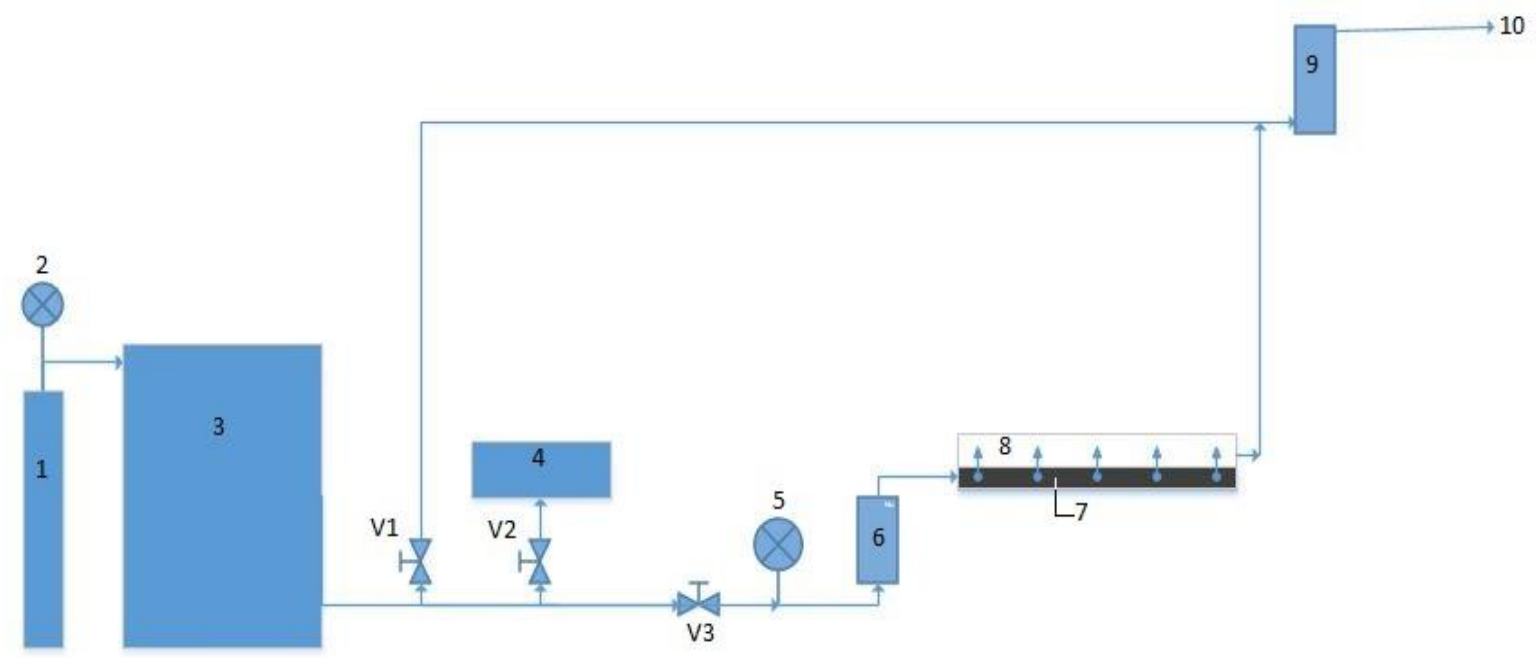

Figure 3.1 - Ozonation setup schematic (1: oxygen cylinder, 2: pressure gauge; 3: ozone generator; 4: ozone monitor; 5: pressure gauge; 6: flow meter; 7: diffuser; 8: reactor; 9: ozone destructor; 10: exhauster; V1: exhauster valve; V2: ozone monitor valve; V3: reactor valve)

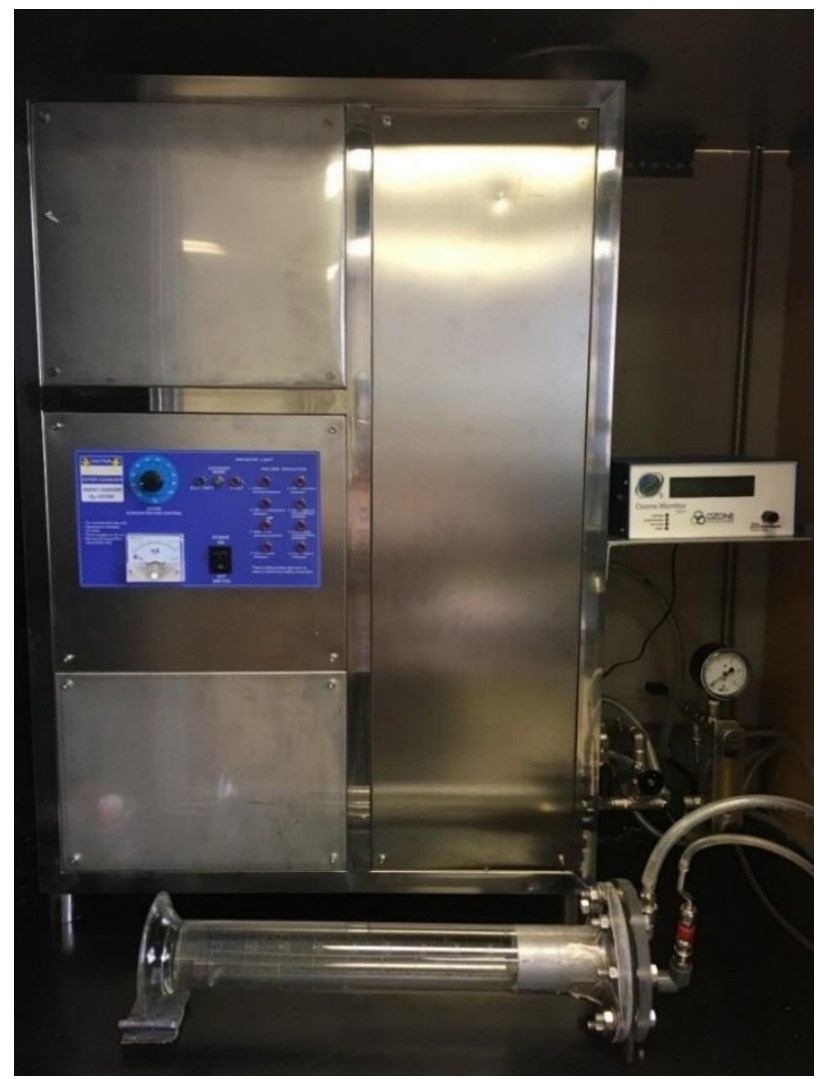

Figure 3.2 - Ozonation equipment 
The exact weight of chemicals was measured using the scale from Mettler Toledo (Mississauga, ON, CA), Model AB54-S/FACT.

\subsection{Peroxide Concentration Determination}

There are different methods of measuring the concentration of peroxides. The most common ones are DPPH, iodometry and indirect titration by thiol (Mastan, 2010). Standard iodometry was chosen for these experiments since this method works for a broad concentration range and detects the peroxide both on the surface and in the pores (Fujimoto et el., 1993). The reactions and the sample calculations could be found in Appendix I and II.

\subsubsection{Materials}

The chemicals used for the peroxide determination are listed in Table 3.2.

Table 3.2 - The used chemicals for peroxide determination

\begin{tabular}{ll}
\hline Chemicals & Provider \\
Isopropanol Alcohol (IPA) & Sigma-Aldrich Co. (St. Louise, MO, USA) \\
Granular Potassium Iodide & Sigma-Aldrich Co. (St. Louise, MO, USA) \\
Glacial Acetic Acid & EMD Chemicals Inc. (Gibbstown, NJ, USA) \\
Sodium Thiosulfate & BDH Inc. (Toronto, ON, CA) \\
Potassium Dichromate & EMD Chemicals Inc. (Gibbstown, NJ, USA) \\
Corn Starch Powder & Fisher Scientific Company (Fair Lawn, NJ, USA) \\
\hline
\end{tabular}

\subsubsection{Procedure}

Although this procedure is mainly used to determine chlorine concentration, it could also be followed to measure peroxide concentration (Kokatnur and Jelling, 1941).

- Each sample was soaked in $25 \mathrm{ml}$ of IPA as a titration medium.

- $1 \mathrm{~mL}$ of saturated potassium iodide $(\mathrm{KI})$ was added.

- $1 \mathrm{~mL}$ of glacial acetic acid was added to reduce the $\mathrm{pH}$ of the medium.

- The solution was heated up to its boiling point and kept at that temperature for 7 minutes in order to let the reaction take place completely. More details could be found in Appendix III. 
- The solution then was titrated with sodium thiosulfate $\left(\mathrm{Na}_{2} \mathrm{~S}_{2} \mathrm{O}_{3}\right)$ until the yellow color disappeared.

- The volume of consumed sodium thiosulfate was used to calculate the peroxide amount based on the equation provided in Appendix I.

\subsection{Scanning Electron Microscope Imaging}

SEM images of the membrane samples were used to observe the effect of ozonation on the texture of membranes as well as the occurrence of fouling after filtration tests. Samples were first coated with a thin layer of gold using Denton Vacuum- Desk IV (Moorestown, NJ, USA) which provided standard gold coatings of the membrane. The coated samples were later placed in a scanning electron microscope (Model JSM-6380LV from JEOL Company, Tokyo, Japan) in order to take SEM imaging.

\subsection{Tensile Strength Measurement}

Tensile strength is the maximum force on the stress-strain curve divided by the initial cross sectional area of the samples. Tensile strength at the breaking point is defined as the ratio of the load at the breaking point over the initial cross sectional area. In many cases these two concepts are the same. Mechanical strength of the membrane represents the maximum pressure that it can tolerate during a filtration process. Also, having appropriate strengths in both directions makes the cleaning process possible from both feed and filtrate side.

Since the thickness of the samples was less than $1 \mathrm{~mm}$, Standard Test Method for Tensile Properties of Thin Plastic Sheets, ASTM D-882, was followed (ASTM, 2009). In this method, a sample was placed vertically between two grips in such a way to prevent any movement of the sample. The grips then started to separate from each other at a known rate. The sample was pulled until it broke. The load at which the breakage of the samples happened is known as the ultimate load. The ratio of the ultimate load to the initial cross sectional area of the sample is defined as the tensile strength. According to ASTM D-882, for each sample, the test should be carried out 5 times. The failure should occurs in the upper two third of the samples in order to be able to consider the trial (ASTM, 2009). 
All the tensile strength test were carried out using the tensile testing machine from United Testing Systems Canada, Ltd., model STM- 50KN (Concord, Ontario, CA).

According to the preliminary tests, the isotropy was observed for the samples; there was no significant difference between horizontal and vertical orientations (Appendix V). Also, since the percent elongation at break was less than 20 percent, the initial grip separation was chosen as $125 \mathrm{~mm}$ (ASTM, 2009). The width of the samples was $20 \mathrm{~mm}$ for tensile strength tests.

\subsection{Contact Angle Measurement}

In the present study, contact angle of a water droplet with the membrane sample was optically measured using the sessile-drop method with a goniometer (Model p/n 250-F1, 400-30; RameHart Instrument Co, Netcong, NJ, USA) where a camera captured the photo of the liquid droplet on the solid surface. In order to achieve accurate contact angle measurements the following steps have been followed.

- Goniometer was turned on and the software was started on the controlling computer

- The sample was placed on the glass.

- Micro syringe was adjusted above the sample using live video window screen.

- The syringe was lowered and twisted to make a drop of 4 microliters. The drop was let in contact with the surface. The syringe was then moved up.

- A picture of the drop was taken.

- Using the software, the baseline and the vertical line of the drop were exactly determined.

- Clicking on the "measure" button to start the measurement of the contact angle at the right and left hand sides of the droplet. If the difference was less that $0.1^{\circ}$, the measurement could be taken as a successful one.

\subsection{Filtration Test}

For filtration tests, distilled water and skim milk were used under a cross-flow mode in a filtration unit. The schematic diagram of the unit is shown in Figure 3.3 and the list of equipment used is provided in Table 3.3. Beatrice skim milk was purchased and used in the experiments. 
Also, the viscosity of distilled water and the milk was measured using Spindle viscometer, LV2000, Cannon Instrument Company (State College, PA, USA).

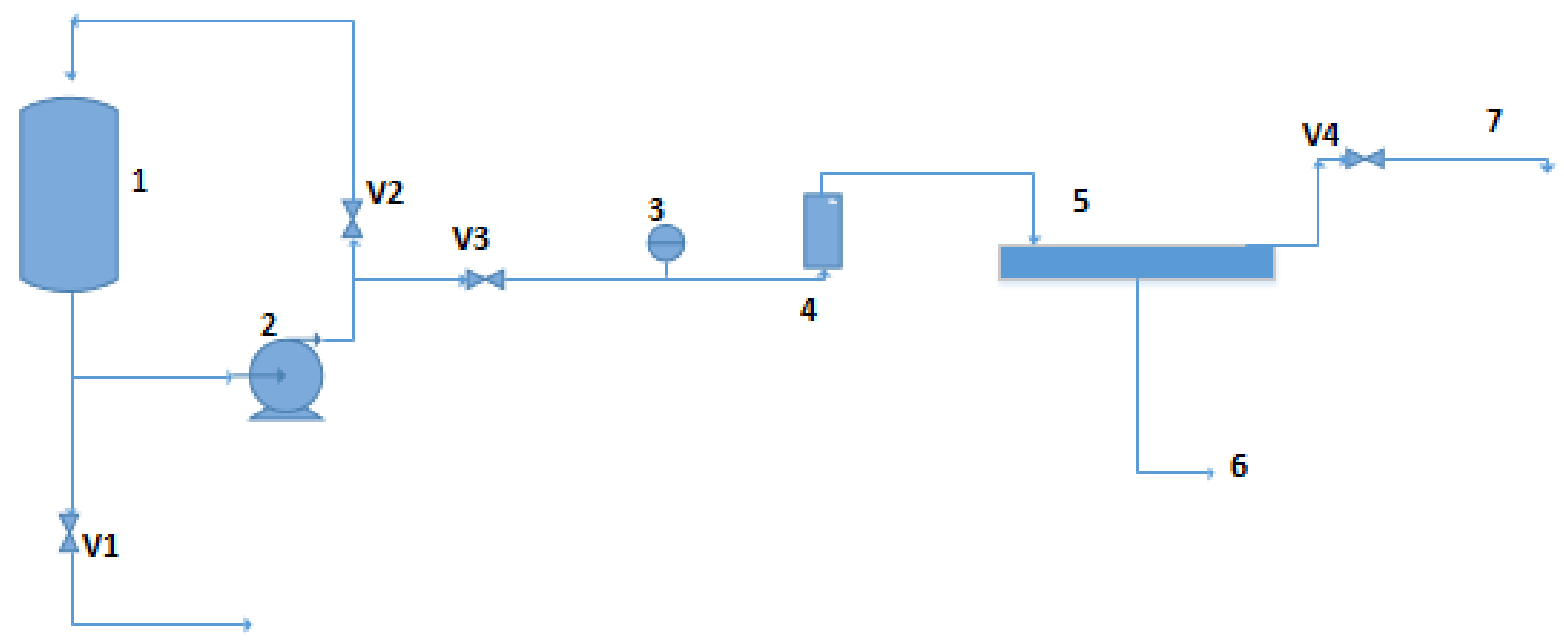

Figure 3.3 - Filtration unit schematic (1: feed tank-; 2: pump; 3: pressure meter; 4: flow meter; 5: membrane holder; 6 : permeate; 7 : retentate)

Table 3.3 - Filtration setup equipment list

\begin{tabular}{ll}
\hline Equipment & Manufacturer \\
Flow Meter, F-400N & Blue-White Industries Ltd. (Huntington Beach, CA, USA) \\
Pressure Meter, -0.6 to 2 bar & Budenburg Ltd. (Manchester, UK) \\
Pump, 1.0 hp & Oberdorfer Pumps (Syracuse, NY, USA) \\
\hline
\end{tabular}

\subsubsection{Procedure}

- The tank was filled with the feed liquid which could be either distilled water or skim milk.

- The membrane, which had been cut into a $10 \mathrm{~cm} \times 30 \mathrm{~cm}$ rectangle, was soaked in distilled water for 5 minutes. It was then placed between the holders and the two plates were sealed using nuts and bolts.

- V3 was closed initially.

- V2 was opened to recirculate the feed to the tank so that the feed was well mixed.

- V3 was then opened to let the feed entering the filtration unit.

- The pressure and the feed flow rate were adjusted using V2, V3 and V4. 
- The permeate was collected from stream 6 and its volume was measured over a certain period.

The procedure was repeated for distilled water, skim milk and distilled water to compare the flux before and after fouling with milk proteins. The filtration runs carried out under a constant pressure difference at 18psi during the experiments. Also, the filtration time was kept at 5 minutes for all the runs.

The cake layer was rinsed with distilled water after milk filtration. The rinsed membrane then used again to find distilled water flux after fouling.

In case of backwashing, distilled water entered from the permeate side which has been depicted as stream 6 on Figure 3.3 in order to remove the particles trapped in the pores of the membrane. The pressure of the entering distilled water in this case was kept constant at 8psi. Backwashing was continued for 1 minute each time.

\subsection{Design of Experiments}

Taking a cause-and-effect model into account becomes necessary when a system is being studied. The scientific method of finding a mathematical equation between parameters and the response(s) is called Design of Experiments (DOE). DOE should be accurate at least in the range of the defined parameters, randomized and reproducible. The lower required number of runs, the more practical the design would be since more time and material would be saved while less error would happen (Lazic, 2004). The selected response(s) should be quantitative, measurable and physically meaningful. Further, the selected parameters should be controllable, measurable and non-correlated linear-wise in order to investigate the effect of each, independently. The range of each parameter and the center points should be determined intently. The maximum, the null point and the minimum are assigned as $+1,0$ and -1 , respectively. DOE could be fractionized into qualitative and quantitative analyses while the former includes screening, blocking and ranking of parameters, full and fractional factorial, second order and rotatable designs are of the latter one. Since in engineering experiments, finding a general response function (response surface) such as $\mathrm{y}=\mathrm{f}\left(\mathrm{x}_{1}, \mathrm{x}_{2}, \ldots, \mathrm{x}_{\mathrm{n}}\right)+\varepsilon$ is looked for, quantitative analysis and 
finding the optimum point becomes more favorable. The most common quantitative designs used in Response Surface Methodology (RSM) are explained briefly below.

\subsubsection{Full Factorial Design}

The general governing model is approximated with a linear function which could be written as Equation 3.1 (Lazic, 2004).

$$
y=a_{0}+\sum_{i}^{k} a_{i} x_{i}+\sum_{i}^{k} \sum_{j}^{l} a_{i j} x_{i} x_{j}+\varepsilon
$$

where $\mathrm{y}$ is the response, $\mathrm{x}$ is the factor, $\varepsilon$ is the error, $\mathrm{a}_{\mathrm{i}}$ are the linear regression coefficients and $\mathrm{a}_{\mathrm{ij}}$ are regression coefficients of the interactions meaning that the behavior of one factor depends on the value of other ones.

Since in a full factorial design, all the possible arrangements of factors are considered, $2^{\mathrm{n}}$ runs would be required where $\mathrm{n}$ is the number of affecting parameters. If 3 parameters are considered, Table 3.4 shows the required experiments.

Table 3.4 - Required runs of a full factorial design for 3 parameters

\begin{tabular}{llll}
\hline$\#$ & $\mathbf{x}_{\mathbf{1}}$ & $\mathbf{x}_{\mathbf{2}}$ & $\mathbf{x}_{\mathbf{3}}$ \\
\hline 1 & +1 & +1 & +1 \\
2 & +1 & +1 & -1 \\
3 & +1 & -1 & +1 \\
4 & +1 & -1 & -1 \\
5 & -1 & +1 & +1 \\
6 & -1 & +1 & -1 \\
7 & -1 & -1 & +1 \\
8 & -1 & -1 & -1 \\
\hline
\end{tabular}

\subsubsection{Fractional Factorial Design}

Having numerous parameters requires many runs in a full factorial design. To consider reducing material expenses, time saving and involving less error, fractional factorial design could be 
substituted. In this design, high order interactions are neglected in order to conduct less experiments. If $\mathrm{p}$ is a number of linear effects which could be aliased with the main interaction effects, $2^{\text {n-p }}$ runs would be required. This method is usually used to distinguish the parameters with the highest effect from the ones which do not influence the response relatively (Montgomery, 2005).

\subsubsection{Second-order Rotatable Design}

Experimental data does not always fit in a linear model. Polynomial second-order functions are then used to predict the system. Unlike linear functions, center point data in addition to the other 2 levels (maximum and minimum) are required. Hence, the final equation would be like below (Lazic, 2004).

$$
y=a_{0}+\sum_{i}^{k} a_{i} x_{i}+\sum_{i}^{k} a_{i i} x_{i}^{2}+\sum_{i}^{k} \sum_{j}^{l} a_{i j} x_{i} x_{j}+\varepsilon
$$

Rotatability is defined as a property of a design which makes it possible to move around the center point without interfering with the prediction. Thus, getting data out of the defined range of the parameters becomes necessary. The distance of the mentioned additional levels from the center point $(\alpha)$ and the total required runs depend on the number of the considered factors. Also, considering a fractional replica of possible combinations rather than considering all of the combinations makes a difference in finding $\alpha$ (Montgomery, 2005). Table 3.5 shows the parameters of the different cases.

All combinations: $\alpha=2^{\mathrm{n} / 4}$

Fractional replica of type $2^{\mathrm{n}-\mathrm{p}}: \alpha=2^{(\mathrm{n}-\mathrm{p}) / 4}$

Table 3.5 - Second order rotatable design parameters

\begin{tabular}{cccc}
\hline $\begin{array}{c}\text { Number of } \\
\text { Factors }\end{array}$ & $\boldsymbol{\alpha}$ & $\begin{array}{c}\text { Number of Center Point } \\
\text { Replication }\end{array}$ & Number of Runs \\
\hline 2 & 1.414 & 5 & 13 \\
3 & 1.682 & 6 & 20 \\
4 & 2.000 & 7 & 21 \\
\hline
\end{tabular}


The table of required runs for a second-order rotatable design including center points, axial points of all parameters and various possible factors' arrangements, which is also called Central Composite Rotatable Design (CCRD), have been showed in the Result and Discussion part.

\subsubsection{Statistical Analysis}

Using analysis of variance (ANOVA) is a scientific exact mathematical method to evaluate the adequacy of each model according to the variance ratios. However, ANOVA is not practical unless the errors are distributed around zero homogenously. Since in experimental studies, having such an assumption is not necessary reasonable, analyzing the residuals has been introduced to validate the assumptions (Montgomery, 2005). Residuals are defined as the difference between the actual experimental data and the predicted value using the suggested model. When errors are distributed normally, a linear trend of normal probability of residuals could be obtained. Linear normal probability plot indicates that the non-normality has not occurred severely.

Regression model is commonly used to determine the fitness of the predicted model to the experimental data. Total, regression and error sum of squares $\left(\mathrm{SS}_{\mathrm{T}}, \mathrm{SS}_{\mathrm{R}}, \mathrm{SS}_{\mathrm{E}}\right)$ are the defined parameters which are used. The mathematical definitions are provided below.

$$
\begin{array}{ll}
S S_{T}=\sum_{i=1}^{n}\left(y_{i}-\bar{y}\right)^{2} & \text { Equation (3.3) } \\
S S_{R}=\sum_{i=1}^{n}\left(\widehat{y}_{l}-\bar{y}\right)^{2} & \text { Equation (3.4) } \\
S S_{E}=\sum_{i=1}^{n}\left(y_{i}-\widehat{y}_{l}\right)^{2} & \text { Equation (3.5) } \\
S S_{T}=S S_{R}+S S_{E} & \text { Equation (3.6) }
\end{array}
$$

where $\mathrm{y}$ is the experimental value of the response, $\hat{y}$ is the predicted response by the model, $\bar{y}$ is the mean value of the experimental responses and $\varepsilon$ is the error which could be obtained from the difference of actual and predicted responses.

The high R-squared which is the ratio of $\mathrm{SS}_{\mathrm{R}}$ to $\mathrm{SS}_{\mathrm{T}}$ indicates the low error from which a good fitting might be interpreted by the definition of the minimum distance between the assumed model and the data. However, adding a new parameter to the model could increase Rsquared as well (Montgomery, 2005). Thus, the adjusted R-squared (Radjusted) has been defined. 


$$
R_{\text {adjusted }}^{2}=1-\frac{\frac{S S_{E}}{n-p}}{\frac{S S_{T}}{n-1}}=1-\left(\frac{n-1}{n-p}\right)\left(1-R^{2}\right)
$$

where $\mathrm{n}$ is the number of observations or runs and $\mathrm{p}$ is the number of variables in the model. Unless the actual R-squared and the adjusted one have a significant difference, the model provides a satisfactory prediction (Montgomery, 2005).

Statistical hypotheses could be used as well to investigate the significance of each parameter in a suggested mode. While null hypothesis and alternative hypothesis are taking into account, only one could be accepted. Null hypothesis states the irrelevance of a parameter to the response which could be testified using F-test and the p-value that represents the probability of falsely rejection of the null hypothesis. In order to use F-test, ANOVA and calculations of the mean squares of parameters are necessary. Mean square (MS) is defined as a ratio of sum of squares (SS) to the related degree of freedom (DF). The next step would be finding the F-value which is defined as $\mathrm{MS}_{\mathrm{R}} / \mathrm{MS}_{\mathrm{E}}$. In order to reject null hypothesis, the founded F-value should be greater than the critical F-value which depends on the number of parameters, the total degree of freedom and the p-value.

The ANOVA table for a system with 2 parameters $\mathrm{A}$ and $\mathrm{B}$, where $\mathrm{a}$ and $\mathrm{b}$ represent the number of levels of each parameter and $\mathrm{n}$ is the total number of observations, has been illustrated in Table 3.6.

Table 3.6 - ANOVA table for a two-factor system

\begin{tabular}{ccccc}
\hline Parameter & SS & D.F. & MS & F-value \\
\hline Main Effect A & $\mathrm{SS}_{\mathrm{A}}$ & $\mathrm{DF}_{\mathrm{A}}=\mathrm{a}-1$ & $M S_{A}=\frac{S S_{A}}{D F_{A}}$ & $F=\frac{M S_{A}}{M S_{E}}$ \\
Main Effect B & $\mathrm{SS}_{\mathrm{B}}$ & $\mathrm{DF}_{\mathrm{B}}=\mathrm{b}-1$ & $M S_{B}=\frac{S S_{B}}{D F_{B}}$ & $F=\frac{M S_{B}}{M S_{E}}$ \\
Interaction AB & $\mathrm{SS}_{\mathrm{AB}}$ & $\mathrm{DF}_{\mathrm{AB}}=(\mathrm{D} \cdot \mathrm{F} \cdot \mathrm{A})(\mathrm{D} \cdot \mathrm{F} \cdot \mathrm{B})$ & $M S_{A B}=\frac{S S_{A B}}{D F_{A B}}$ & $F=\frac{M S_{A B}}{M S_{E}}$ \\
Error & $\mathrm{SS}_{\mathrm{E}}$ & $\mathrm{DF}_{\mathrm{E}}=\mathrm{n}-\mathrm{ab}$ & $M S_{E}=\frac{S S_{E}}{D F_{E}}$ & \\
Total & $\mathrm{SS}_{\mathrm{T}}=\mathrm{SS}_{\mathrm{A}}+\mathrm{SS}_{\mathrm{B}}+\mathrm{SS}_{\mathrm{AB}}+\mathrm{SS}_{\mathrm{E}}$ & $\mathrm{DF}=\mathrm{n}-1$ & & \\
\hline
\end{tabular}




\section{Chapter Four - Results and Discussions}

In this chapter, the results of the preliminary tests are provided. In addition, the effects of different treatment parameters on the modification of the properties of the membrane are discussed. Modelling and optimization of the treatment parameters were also carried out and the results are presented in this section.

\subsection{Effect of Operational Conditions}

Removing extra physically-absorbed ozone molecules from the surface of the membrane is highly important since ozone would be involved in the titration process for the determination of the amount of generated peroxide. During iodometry, peroxides react with $\mathrm{I}^{-}$ions and produce I 2 which is yellow. Afterwards, the titration would be continued until the yellow color of the solution disappears. Due to the reaction of residual ozone on the membrane surface with iodine ions, which is $\mathrm{O}_{3}+\mathrm{I}^{-} \rightarrow \mathrm{I}_{2}+\mathrm{H}_{2} \mathrm{O}+\mathrm{O}_{2}$, not only peroxides, but also ozone could contribute to the amount of $\mathrm{I}_{2}$ formed in the solution. Thus, removing ozone molecules from the surface of the membrane samples before starting the titration should be considered. Different methods of removing ozone molecules including keeping the samples in ambient air or putting them under vacuum at the pressure of 20 inch of $\mathrm{Hg}$ were tried in the present study. According to Figure 4.1 below, keeping the samples under vacuum for 1 hour is enough to eliminate extra molecular ozone attached on the sample surface.

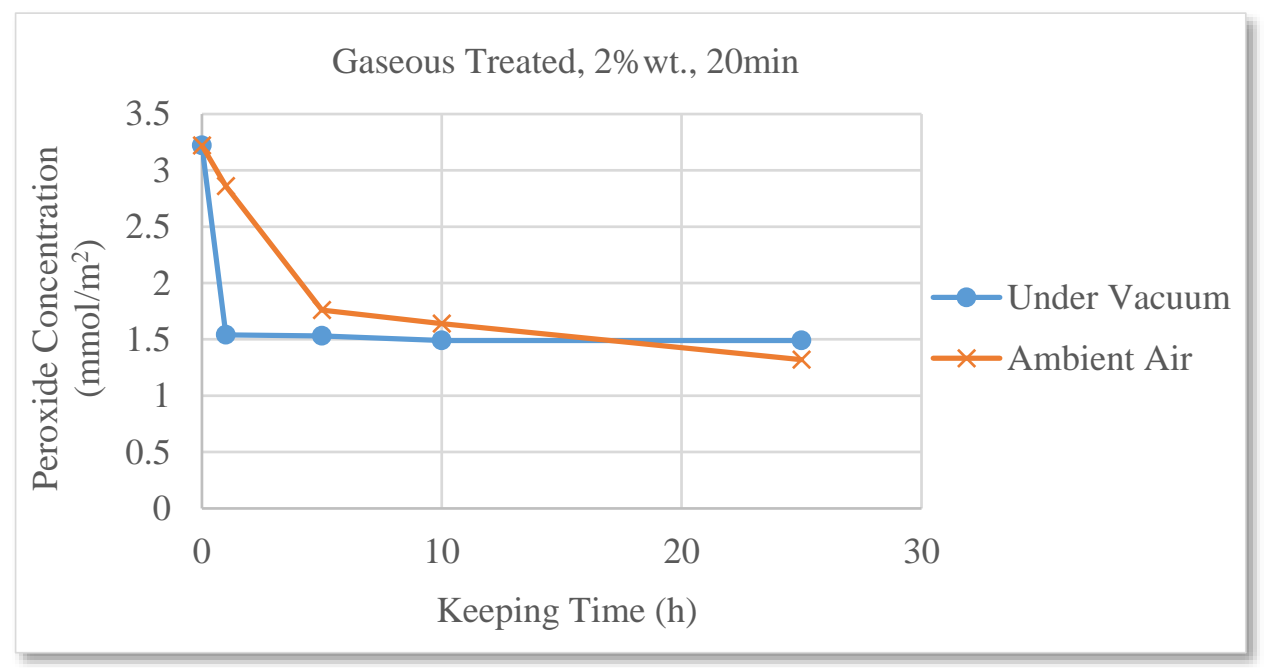

Figure 4.1 - Effect of different methods on residual ozone removal 
After one day from ozonation, water drops have been observed visually on the samples which were kept in ambient air. That might be because of the reaction between peroxides and oxygen in the air which would produce water molecules. This observation supported the result obtained in Figure 4.1 in which less peroxide was detected after 25 hours on the surface of the membrane kept in ambient air in comparison to the one which was kept under vacuum. As it could be observed in Appendix IV, after 1 hour vacuuming, the peroxide concentration did not changed significantly. Thus, this duration was used throughout the present study.

It has been reported that long and intense exposure of ozone to polymeric membranes would result in material deterioration (Ozen et al., 2002). In order to find the limit and to investigate the damage to the membrane by ozonation qualitatively, SEM was used to obtain SEM images. Figures 4.2 to 4.5 show the SEM images of untreated PVDF membrane and those of treated ones at different conditions with 100 times magnification.

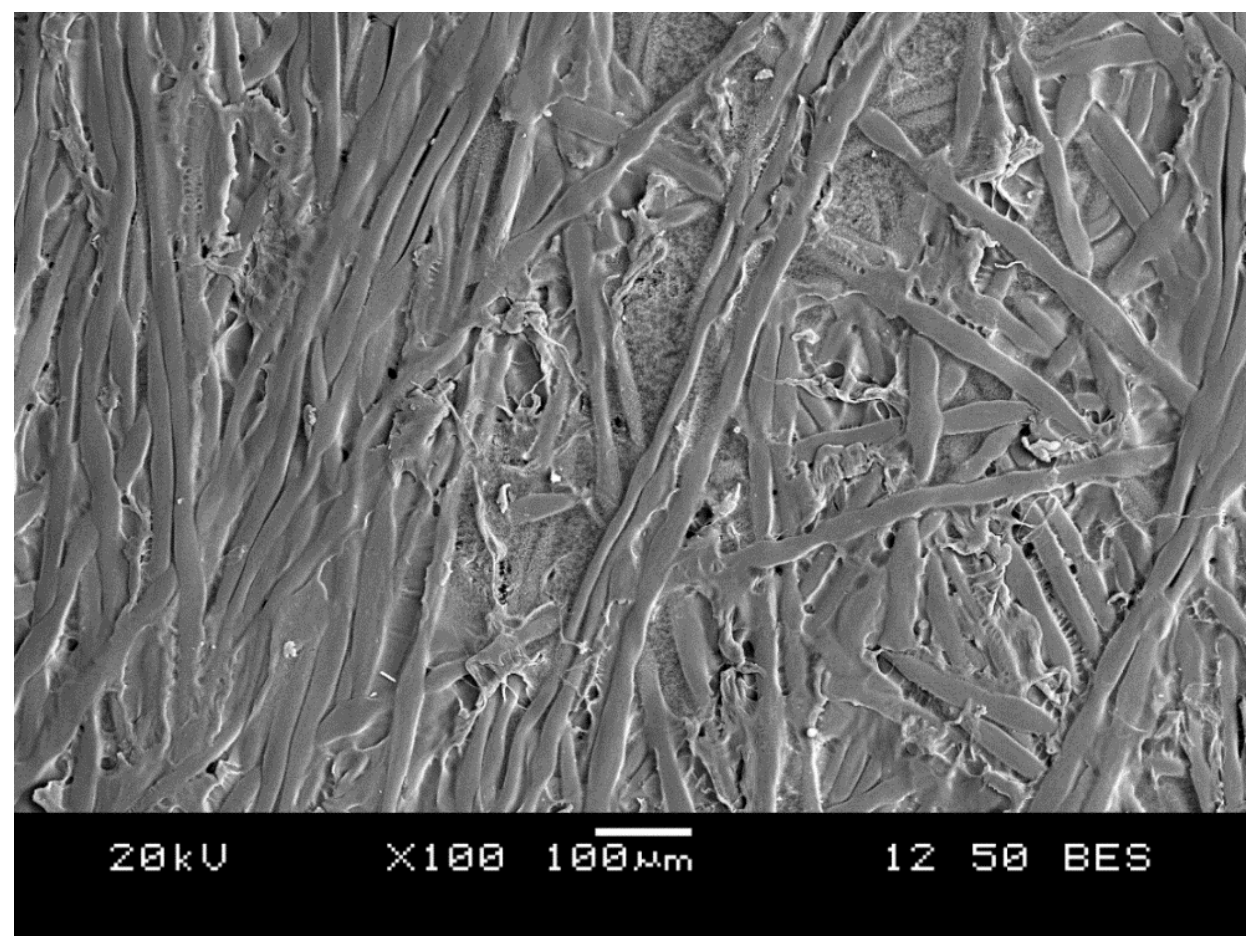

Figure 4.2 - SEM image of fresh PVDF 


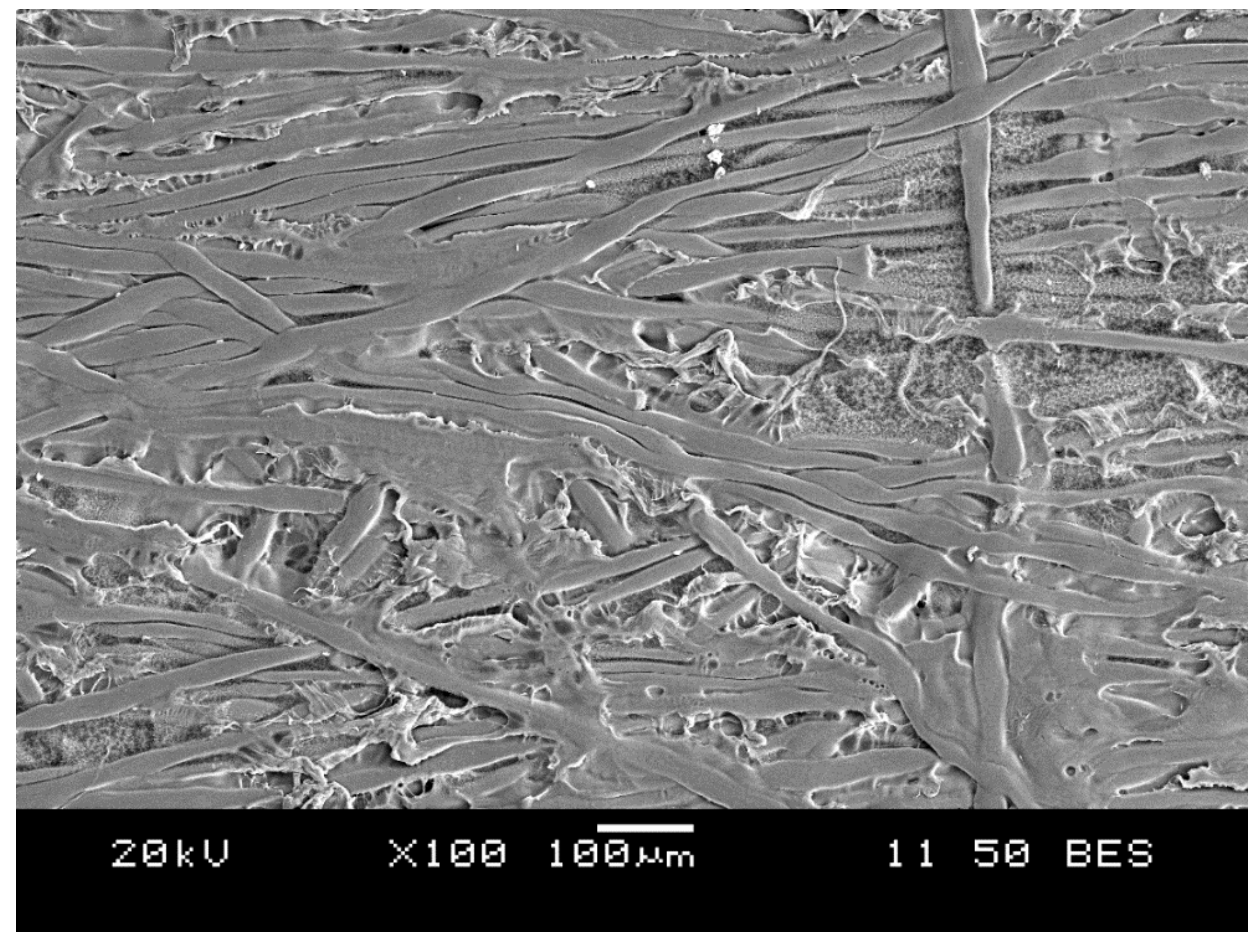

Figure 4.3- SEM image of gaseous treated PVDF, ozone at 2.5\%wt., 30min

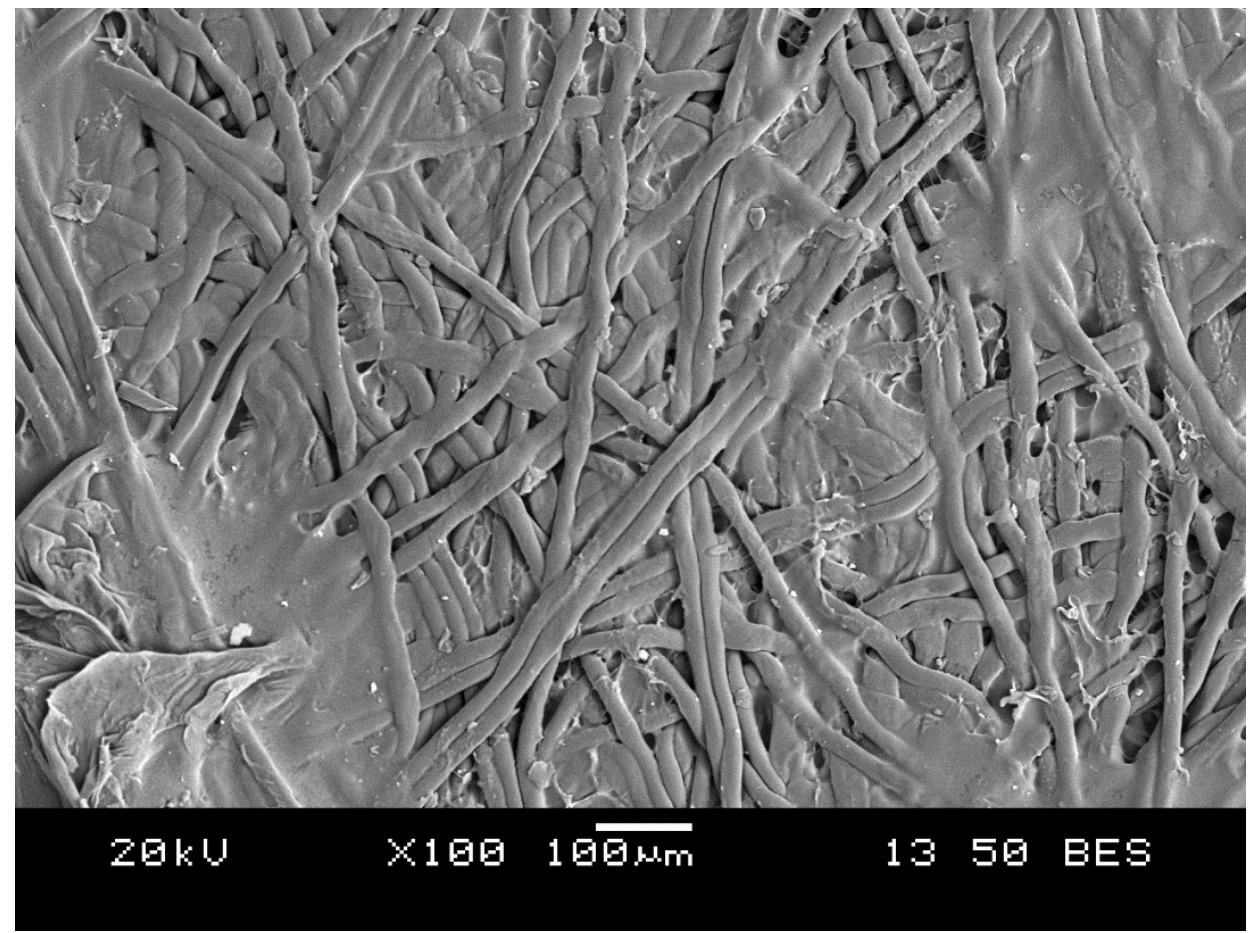

Figure 4.4 - SEM image of gaseous treated PVDF, ozone at 2.5\%wt., 1 hour 


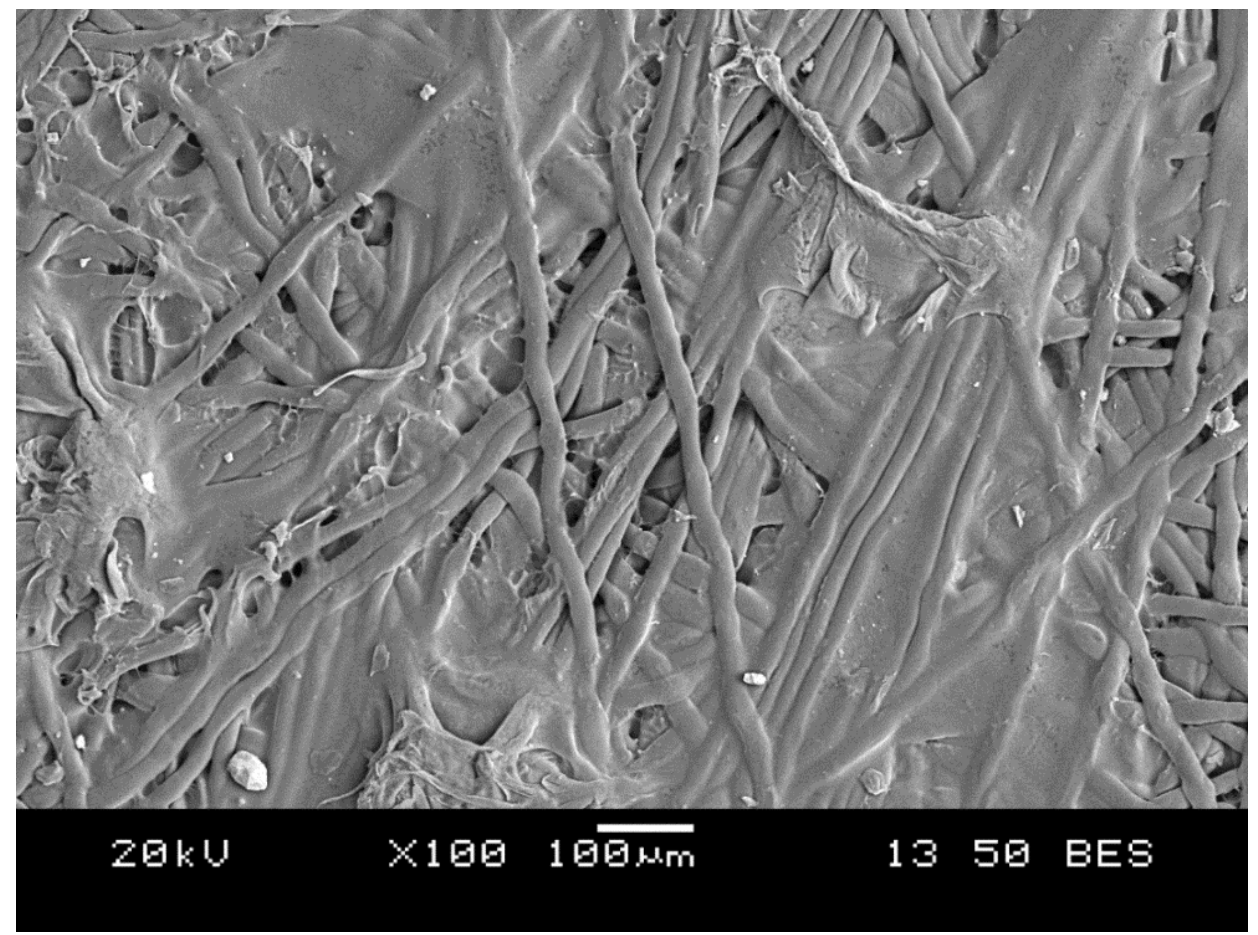

Figure 4.5 - SEM image of gaseous treated PVDF, ozone at 4.5\%wt., 30min

Comparing Figures 4.2, 4.3, 4.4 and 4.5, the damage after 30 minutes of ozonation at $4.5 \%$ wt. as well as after 1 hour at $2.5 \%$ wt. is clear. However, 30 minutes of ozonation at $2.5 \%$ wt., did not cause a significant texture difference. Thus, the maximum ozone concentration and the longest exposure time were chosen to be $2.5 \% \mathrm{wt}$. and 30 minutes, respectively, in the present study. Tensile strength drop is another obstacle of applying long time and intense ozone exposure. Thus, in order to evaluate the damage caused by ozonation, tensile strength measurements were also carried out. While the tensile strength of the untreated fresh membrane was measured as 26.25 MPa, Figure 4.6 shows that gaseous ozonation at $2.5 \%$ wt. and 30 minutes resulted in almost $65 \%$ decline of the membrane mechanical strength. According to Figures 4.6 and 4.7, further increase in the ozone concentration or ozonation time led to more reduction of the membrane tensile strength, which is not desirable for the filtration process. All the tensile strength measurements have been repeated 5 times (ASTM, 2009). The complete data sets could be found in Appendix V. 


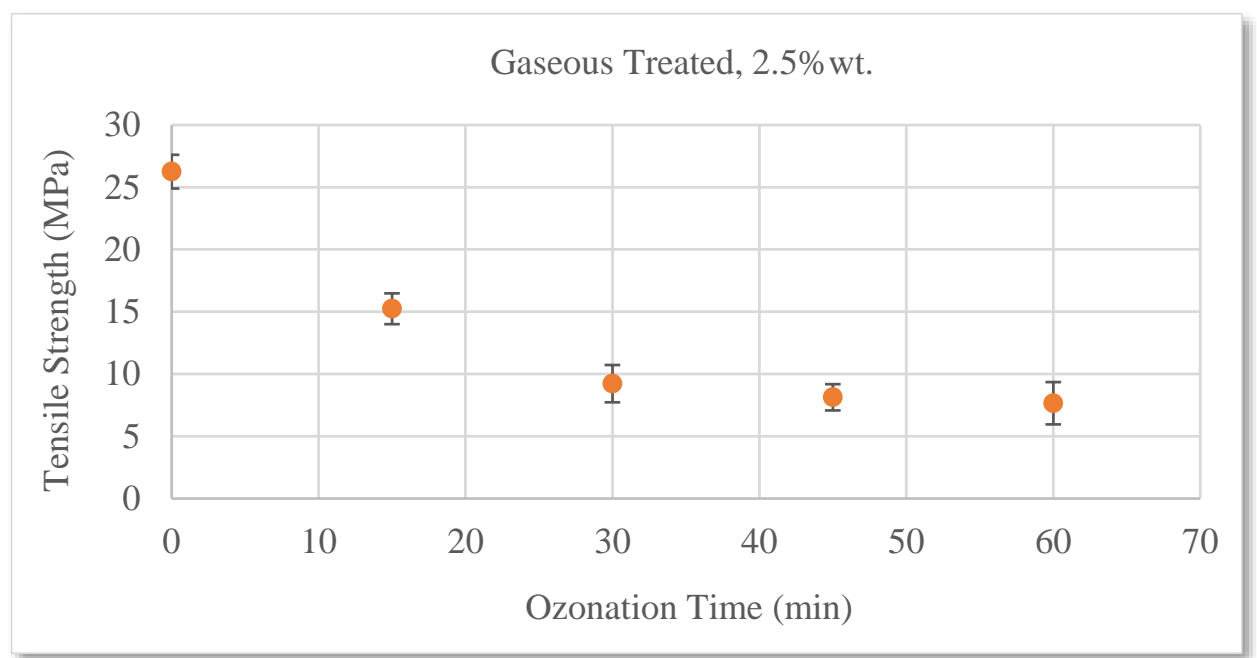

Figure 4.6 - Effect of ozonation time on tensile strength

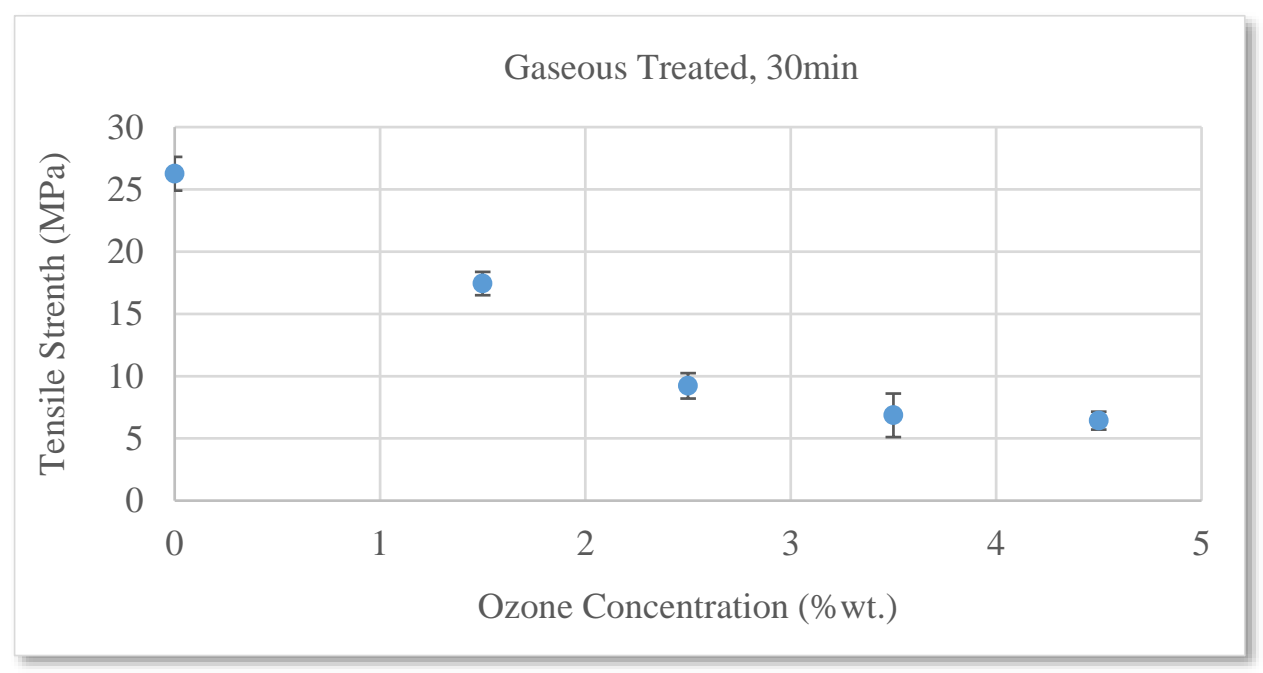

Figure 4.7- Effect of ozone concentration on tensile strength

The peroxide formation has been reported in literature as an exothermic process, thus, temperature could affect the rate of reaction and the mechanical strength of the ozonated membrane directly. Therefore, the temperature of the reactor was measured before and after gaseous ozonation at $2.5 \%$ wt. and 30 minutes, which was the longest and the most intense exposure. 


\subsection{Effect of Catalyst}

One of the advantages of the aqueous medium over the gaseous one is the capacity of catalyst addition which could increase the rate of peroxide formation. Homogenous catalysts have been studied by some researchers. $\mathrm{Cu}^{2+}$ and $\mathrm{Fe}^{3+}$ have been reported to be effective in increasing the peroxide concentration on PE and PP polymers (Gu et al., 2012; Mastan et al., 2013). However, heterogeneous catalysts in general are more industrially desirable due to their easier separation from liquid after the completion of the reaction step. Significantly higher cost of those metal salts, in addition to the recovery costs, in comparison to that of heterogeneous AC was the main reason to investigate the effect of $\mathrm{AC}$ on peroxide formation in the present study.

Since no information could be found in the literature regarding the usage of $\mathrm{AC}$ as a catalyst for polymer ozonation reaction, at first $\mathrm{AC}$ was tried with different concentrations to inquire its effectiveness. Also, in order to compare its functionality with that of metal salts in the same conditions, $\mathrm{Fe}^{3+}$ and $\mathrm{Cu}^{2+}$ were also tested as homogenous catalysts. The results of catalytic aqueous ozonation at $\mathrm{pH}=7,2 \%$ wt. ozone and after 10 minutes could be found in Figure 4.8 below. Each data is the average of two individual results. More details could be found in Appendix VI.

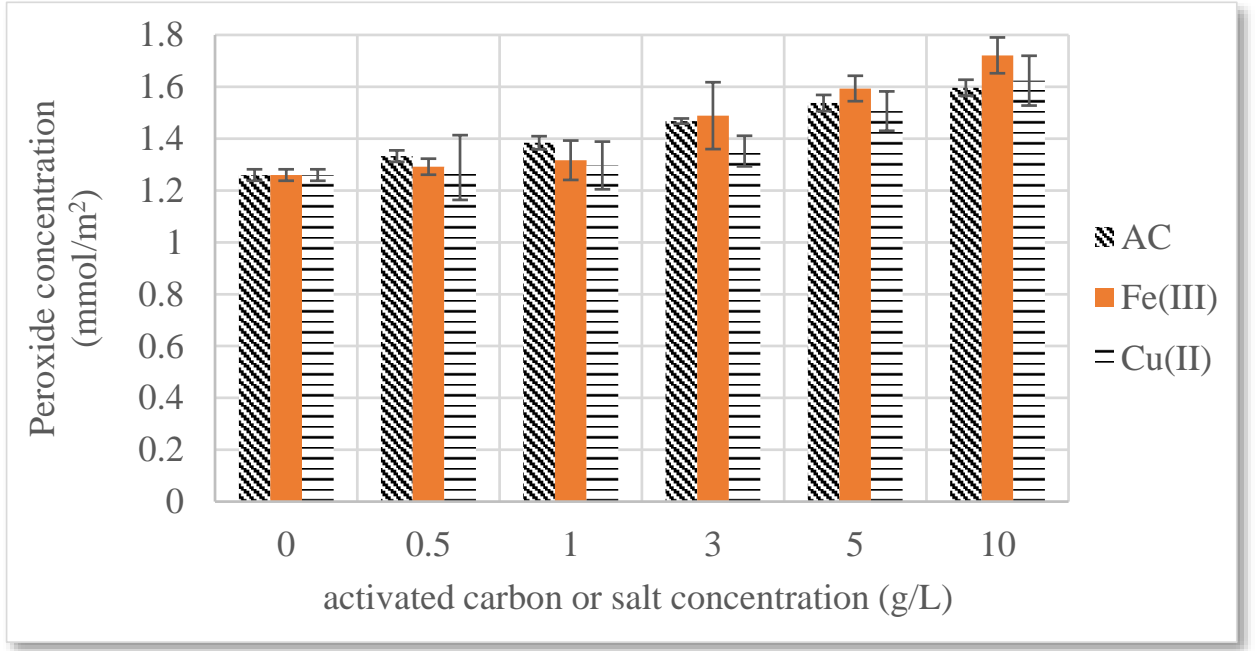

Figure 4.8 - Effect of different catalysts on the concentration of peroxide formed on the membrane surface $(\mathrm{pH}=7,2 \%$ wt. ozone, $10 \mathrm{~min})$ 
According to Figure 4.8, $\mathrm{Cu}^{2+}$ and $\mathrm{Fe}^{3+}$ led to higher peroxide concentrations at higher catalyst concentrations. However, at concentrations of $3 \mathrm{~g} / \mathrm{L}$ or lower, AC was notably more effective. Considering the significantly lower cost of $\mathrm{AC}$, this catalyst has been chosen for further investigations. Also, since after $1 \mathrm{~g} / \mathrm{L}$ of $\mathrm{AC}$, the slope of the curve of peroxide concentration vs. concentration of $\mathrm{AC}$ started to decrease, which is demonstrated in Figure 4.9 below, the mentioned concentration was chosen as the optimum one.

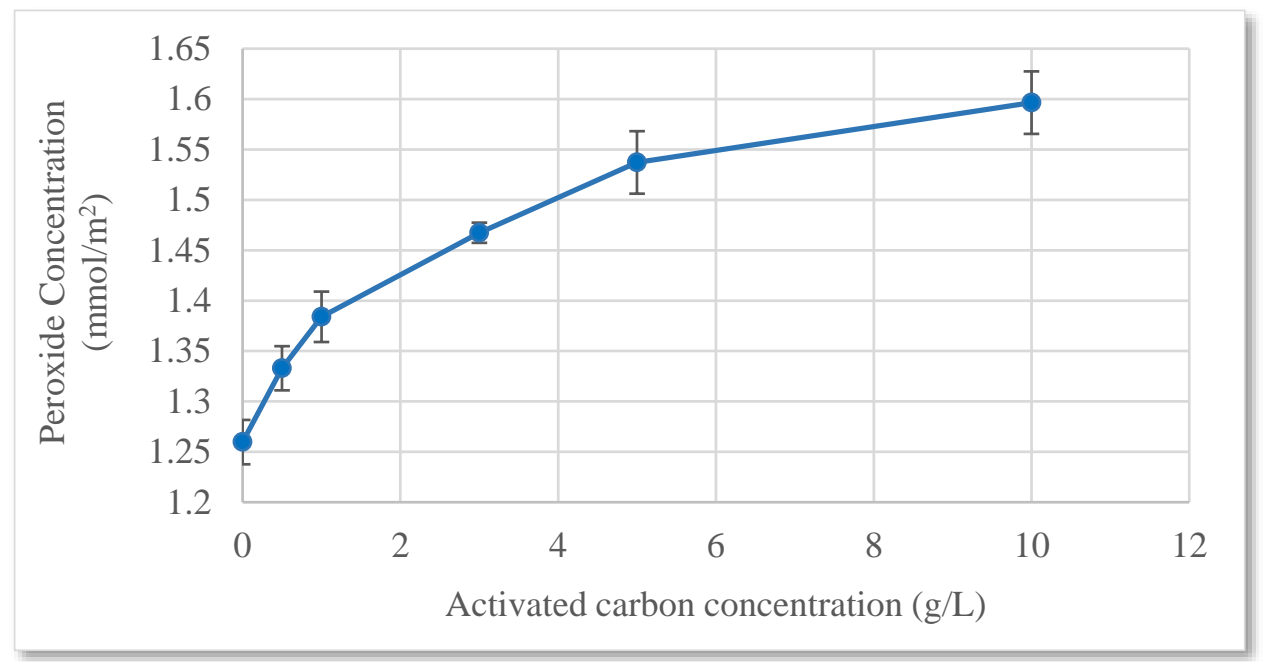

Figure 4.9 - Effect of activated carbon concentration (pH=7, 2\%wt. ozone, 10min)

\subsection{Effect of Ozone Concentration}

The effect of ozone concentration has been reported in the literature. It was observed that higher ozone concentration led to higher peroxide concentration and lower tensile strength (Ozen et al., 2002). In the present study three ozone concentrations have been investigated in both gaseous and aqueous media, in either the presence or the absence of $\mathrm{AC}$ as a heterogeneous catalyst. The results are presented in Figure 4.10. 


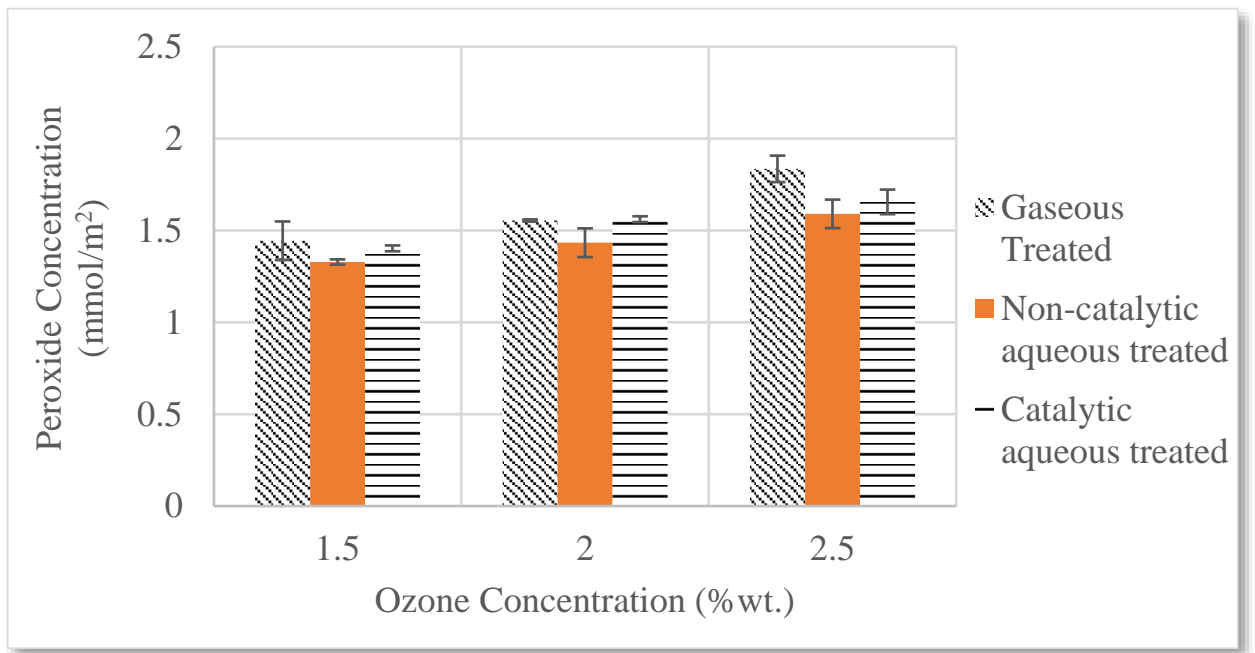

Figure 4.10 - Effect of ozone concentration on peroxide formation after 20 minutes of gaseous ozonation, non-catalytic aqueous ozonation and catalytic aqueous ozonation at $\mathrm{pH}=7$

Ozone concentration was varied from $1.5 \% \mathrm{wt}$. to $2.5 \% \mathrm{wt}$. in gaseous phase, catalytic and non-catalytic aqueous phase. For all of the experiments, ozone concentration had a positive effect on peroxide formation. Although similar trends could be observed for all the treatments, increasing the ozone concentration from $1.5 \%$ wt. to $2.5 \%$ wt. had the most effect on the gaseous phase treatment which led to $27 \%$ increase in peroxide concentration on the gaseous treated sample. This increase was $20 \%$ and $18 \%$ for non-catalytic aqueous and catalytic aqueous treatment, respectively. That might be due to the fact that in the gaseous phase treatment samples were more exposed to the ozone molecules in comparison to the aqueous phase treatment where ozone is involved in several aqueous reactions in addition to the direct oxidation of polymers. Thus, gaseous phase treatment would be more sensitive to ozone concentration variation. Nonetheless, in all the cases, the significant effect of ozone concentration could be observed due to the more intense attack of ozone molecules to the polymer's bonds. All the experiments were repeated 2 times. The complete sets of data could be found in Appendix VI.

\subsection{Effect of Ozonation Time}

Longer ozonation time led to more peroxides formed on the surface of the membrane samples. The ozonation time from 5 to 30 minutes were tested with different ozonation media. The maximum ozonation time of 30 minutes was used in the present study in order not to lose the 
mechanical strength significantly. Figure 4.11 below shows the effect of exposure time on the peroxide formation for gaseous and aqueous ozonation treatments.

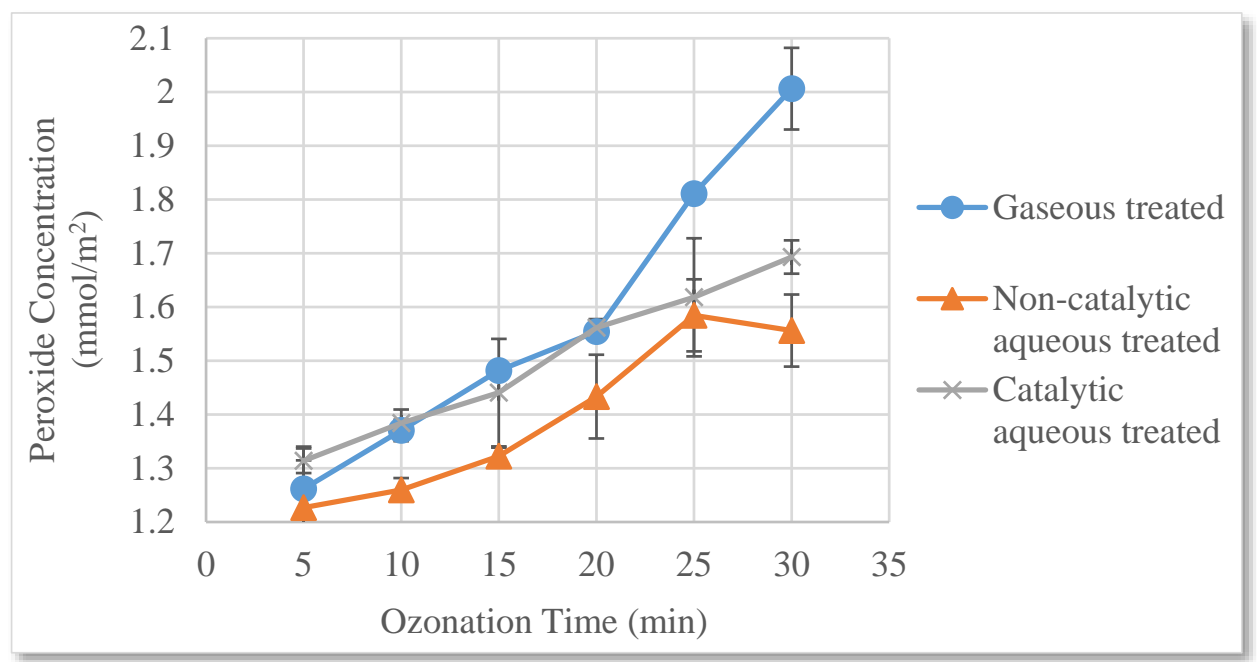

Figure 4.11 - Effect of ozonation time on peroxide formation at 2\%wt. in gaseous ozonation, noncatalytic and catalytic aqueous ozonation at $\mathrm{pH}=7$

According to Figure 4.11, the linear trend of peroxide concentration versus ozonation time could be observed in all three cases. At all ozonation times from 5 minutes to 30 minutes, gaseous treatment and catalytic aqueous ozonation had better yields in terms of peroxide formation in comparison to non-catalytic aqueous treatment. Although only insignificant difference could be observed after the short time treatments, longer ozone exposure revealed a significant margin between the different media. This might be due to the solubility limit of ozone in the aqueous medium. That in turns limited the amount of ozone that could reach the membrane surface. Figures 4.12 to 4.14 show the effect of ozone concentration and ozonation time in gaseous, non-catalytic aqueous and catalytic aqueous phase, respectively. 


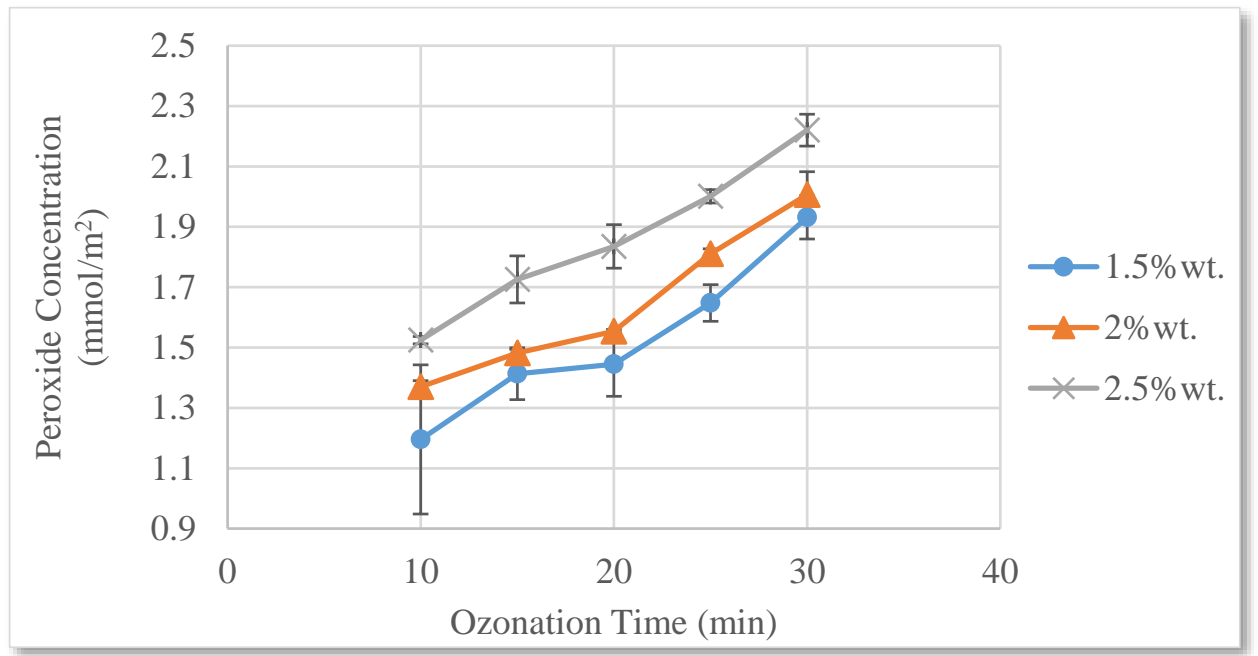

Figure 4.12 - Effect of ozonation time at different ozone concentrations in gaseous treatment

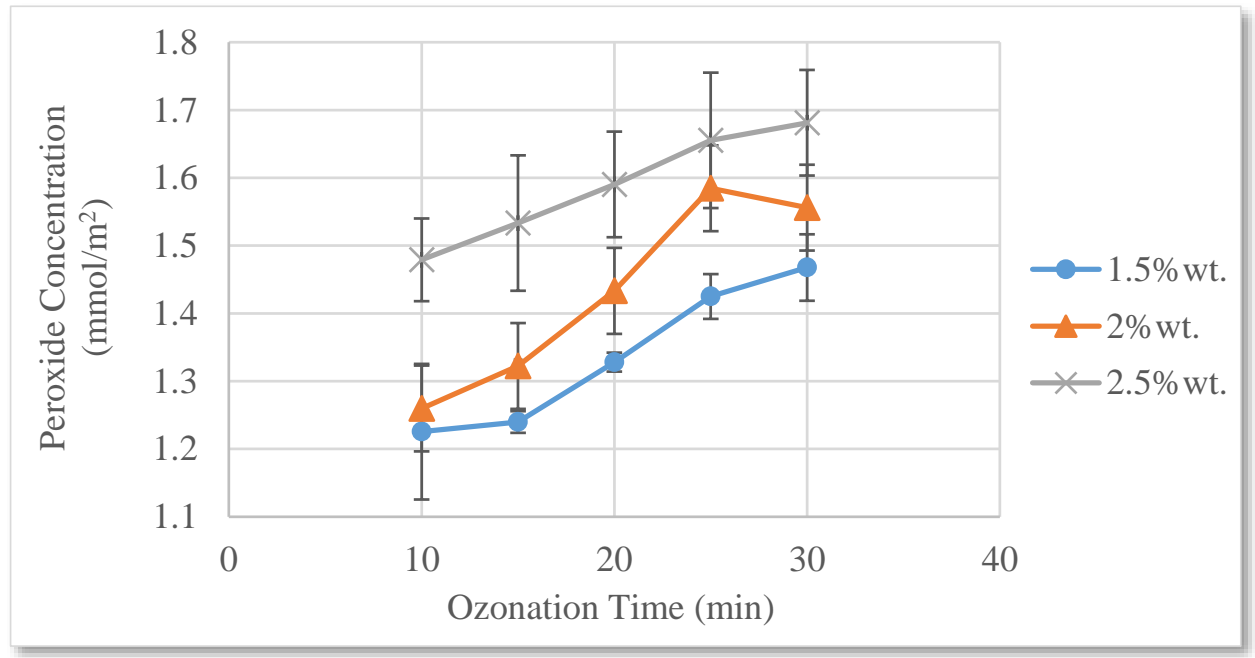

Figure 4.13 - Effect of ozonation time at different ozone concentrations in non-catalytic aqueous treatment $(\mathrm{pH}=7)$ 


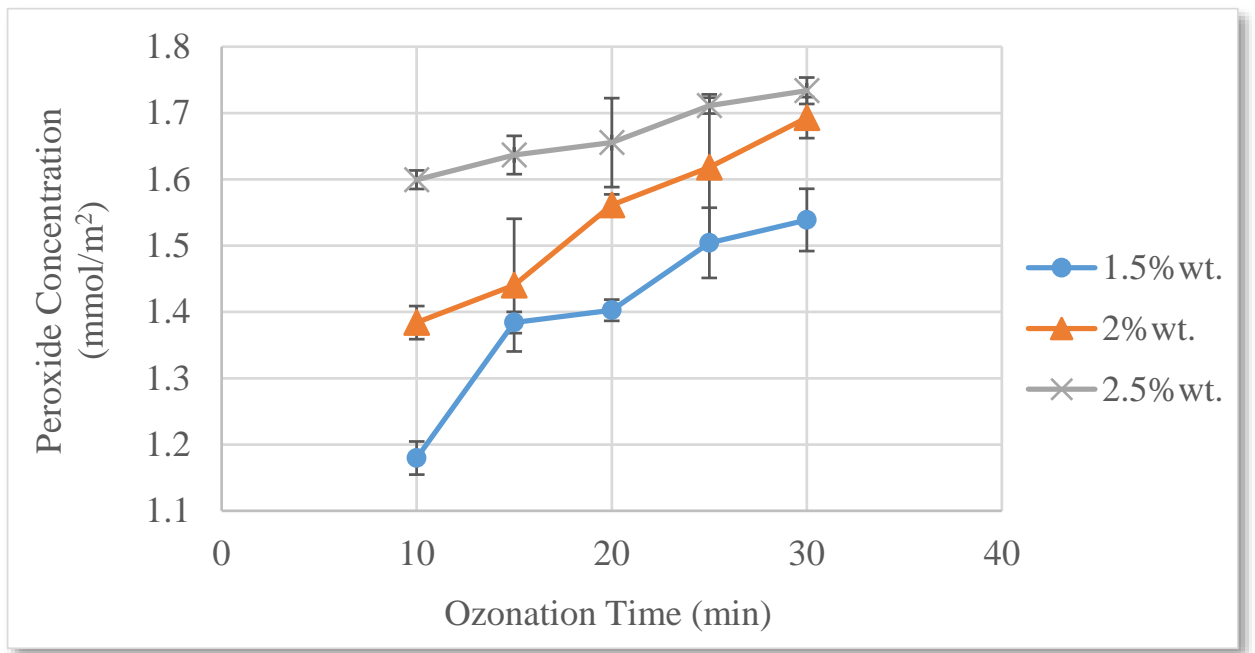

Figure 4.14 - Effect of ozonation time at different ozone concentrations in catalytic aqueous treatment $(\mathrm{pH}=7)$

According to Figures 4.12 to 4.14, within the range used in the present study, both ozone concentration and ozonation time were effective in terms of peroxide formation on the samples. Although some researchers observed peroxide formation rate decreasing over time, that trend was not observed in the present study within the chosen range of exposure times. Using gaseous phase treatment, higher peroxide concentration was achieved in comparison to aqueous phase ozonation. Adding $\mathrm{AC}$ to the aqueous medium was also effective in elevating the peroxide concentration on the membrane's surface in comparison to non-catalytic one.

\subsection{Effect of pH}

In an aqueous phase, $\mathrm{pH}$ is one of the most important factors because of the complex chain of reactions that ozone participates in. In the present study, the effect of $\mathrm{pH}$ was investigated in the absence and presence of AC acting as a catalyst.

Experimental data obtained in the present study showed that the maximum peroxide concentration on the surface of the samples was obtained around $\mathrm{pH}=6$, as could be seen in Figure 4.15. All the experiments were repeated twice and the complete data set could be found in Appendix VI. 


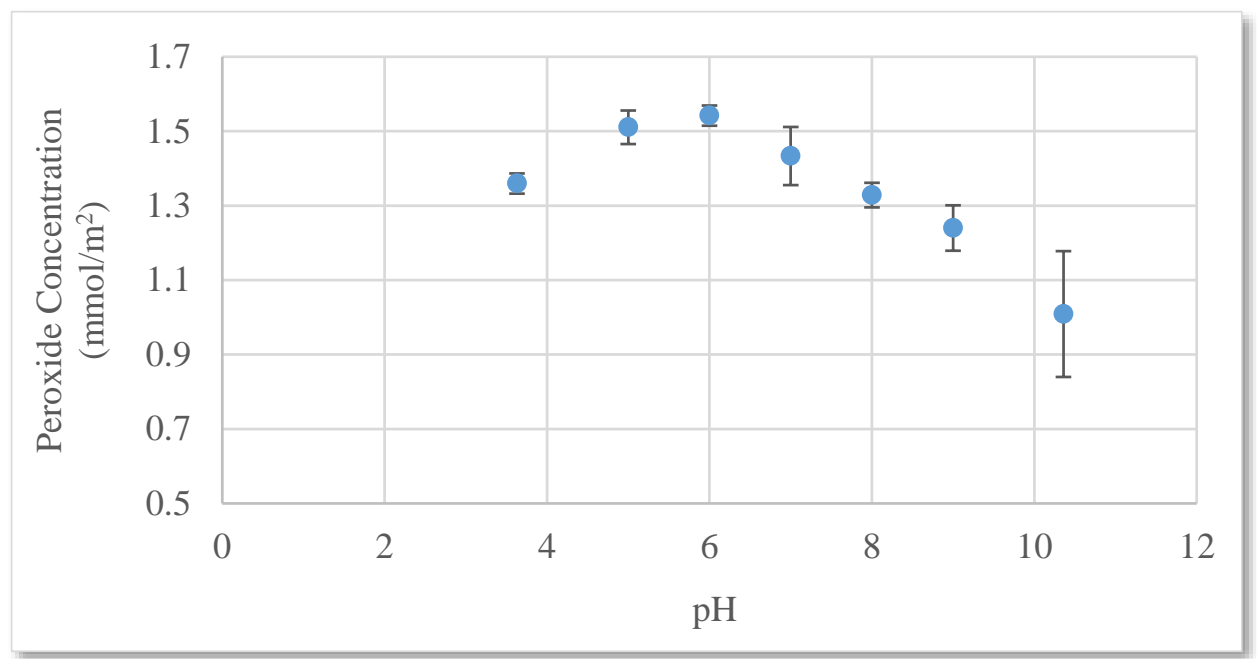

Figure 4.15 - Effect of $\mathrm{pH}$ on peroxide concentration during non-catalytic aqueous ozonation at $2 \%$ wt. and $20 \mathrm{~min}$

Although, according to the literature, increasing the $\mathrm{pH}$ would increase the rate of ozone self-decomposition into radicals which are stronger oxidizers, this speculation did not actually translate to a higher peroxide concentration at the surface of the ozonated membrane at the conditions used in this research (Sotelo et al., 1989; Staehelin and Hoigne, 1982). This might be due to the instability and the short life of radicals, which made them impossible to reach to the surface of the membrane in a limited time. Hence, further increases in the $\mathrm{pH}$ beyond 6 reduced the direct oxidation by high rate of ozone decomposition while the indirect oxidation did not have enough time to proceed, resulting in a lower peroxide concentration, as shown in Figure 4.15.

Activated carbon could completely change the trend. The way how activated carbon reacts in an aqueous medium is still unknown. There are many suggested mechanisms with a wide disagreement. However, all the proposed mechanisms suggested that the alkalinity of the solution could increase the rate of ozone decomposition in the presence of AC even though the efficiency depends on its chemical and textural properties (Alvarez et al., 2006; Faria et al., 2006; Guiza et al., 2004).

According to Beltran et al. (2002), under an acidic condition, although AC would participate in some reactions as shown in Equations 2.23 to 2.25, it could not help producing radicals. The observation in the present study supported the mentioned trend that at lower $\mathrm{pH}$, 
there was no significant difference between the amount of peroxide generated by catalytic ozonation and non-catalytic ozonation. Catalytic ozonation even led to less peroxide formed since ozone was consumed in undesirable reactions. However, Beltran et al. (2002) suggested that at $\mathrm{pH}>6$ the chain reactions, which involved activated carbon, would lead to radical formation. The reactions are provided in Equations 2.16 to 2.22. The experimental data illustrated in Figure 4.16 shows that increasing $\mathrm{pH}$ clearly helped oxidation process with the presence of AC. The complete data set could be found in Appendix VI.

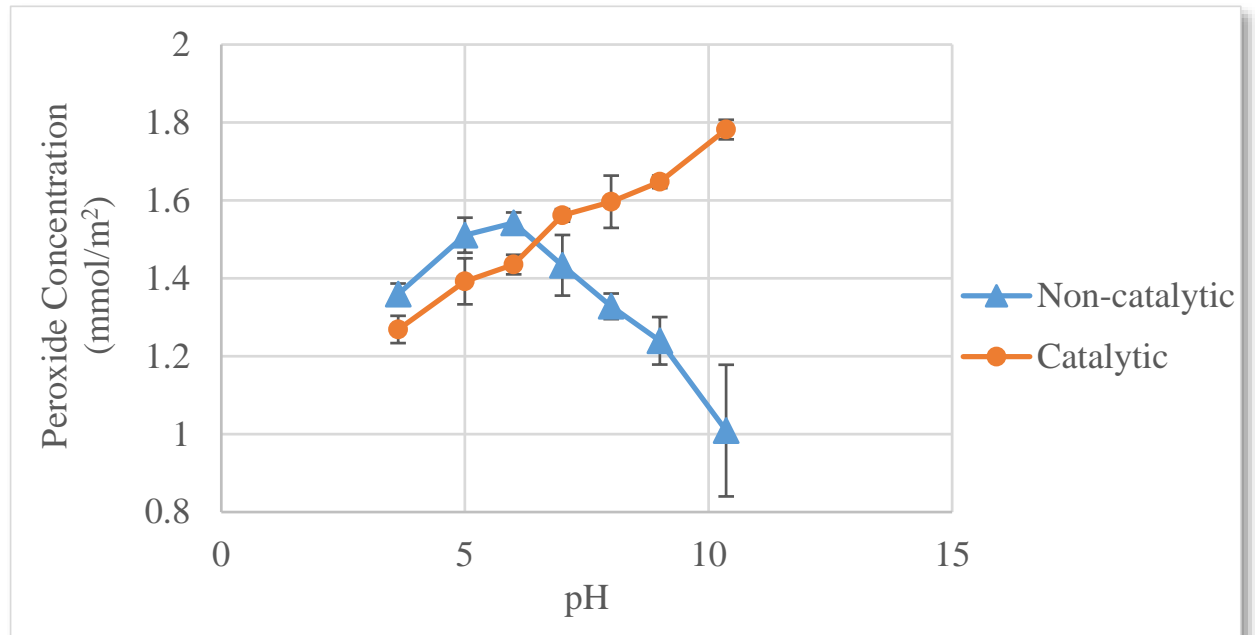

Figure 4.16 - Effect of $\mathrm{pH}$ on aqueous phase ozonation at $2 \% \mathrm{wt}$. and 20min

Although radicals were considered as the reason of increasing peroxide formation during catalytic ozonation in contrast to non-catalytic one, it also would be worthwhile noticing that the movement of activated carbon granular particles might help transporting and delivering the radicals from liquid to the membrane surface.

In conclusion, based on the data plotted in Figure 4.16, under acidic conditions, activated carbon would consume the main reactant, ozone, as indicated by reactions shown in Equations 2.23 to 2.25 rather than participate in the oxidation reaction, resulting in lower peroxide concentration on PVDF samples. The linear trend of peroxide concentration in the presence of activated carbon crossed the non-catalytic trend at $\mathrm{pH}$ around 6. Any further increase in the alkalinity of the medium, resulted in elevating the catalytic peroxide yield in comparison to that of the non-catalytic treatment. Although more investigation may be required to ascertain the 
main cause of the observed trend, suspended catalyst particles could help delivering the unstable but strong radical oxidizers from the bulk liquid to the surface of the samples.

\subsection{Modelling}

RSM and CCRD, have been used to find the optimum conditions for the highest amount of peroxide generated, based on concentration. Using RSM necessitates the user to specify the extreme values. These values are translated into the coded values as $+1,0$ and -1 which represent the maximum, the neutral and the minimum amount, respectively. Design Expert- 8 software was applied to find the models and plots in this part.

For gaseous ozonation, the peroxide concentration was considered as the response and the ozone concentration and the ozonation time were the parameters. Table 4.1 below shows the translation of actual parameters into the coded ones.

Table 4.1 - Actual and coded parameters of gaseous ozonation

\begin{tabular}{ccccccc}
\hline & Coded Value & $\mathbf{- 1 . 4 1}$ & $\mathbf{- 1}$ & $\mathbf{0}$ & $\mathbf{1}$ & $\mathbf{1 . 4 1}$ \\
\hline \multirow{2}{*}{ Actual Value } & Ozone Concentration (\%wt.) - A & 1.29 & 1.5 & 2 & 2.5 & 2.70 \\
& Time (min) - B & 5.86 & 10 & 20 & 30 & 34.14 \\
\hline
\end{tabular}

To get the model for the mentioned system, 13 runs were required by the software. The runs have been carried out randomly and each was repeated twice. More details could be found in Appendix VII. The average of each two runs, however, is provided in Table 4.2. 
Table 4.2 - Required runs of gaseous treatment

\begin{tabular}{ccccc}
\hline order & $\#$ & $\begin{array}{r}\text { Ozone concentration } \\
(\% \text { wt. })-\mathbf{A}\end{array}$ & $\begin{array}{c}\text { Ozonation Time } \\
(\mathbf{m i n})-\mathbf{B}\end{array}$ & $\begin{array}{c}\text { Peroxide Concentration } \\
\left(\mathbf{m m o l} / \mathbf{m}^{\mathbf{2}}\right)\end{array}$ \\
\hline 2 & 1 & 1 & -1 & 1.5248 \\
7 & 2 & 0 & -1.41421 & 1.2894 \\
1 & 3 & -1 & -1 & 1.1957 \\
10 & 4 & 0 & 0 & 1.4980 \\
9 & 5 & 0 & 0 & 1.5087 \\
3 & 6 & -1 & 1 & 1.9314 \\
4 & 7 & 1 & 1 & 2.2203 \\
12 & 8 & 0 & 0 & 1.5943 \\
5 & 9 & -1.41421 & 0 & 1.4590 \\
8 & 10 & 0 & 1.41421 & 2.1895 \\
13 & 11 & 0 & 0 & 1.6104 \\
6 & 12 & 1.41421 & 0 & 2.0555 \\
11 & 13 & 0 & 0 & 1.5426 \\
\hline
\end{tabular}

Catalytic and non-catalytic ozonation cases had an additional parameter, the $\mathrm{pH}$ of the aqueous solution, which made a difference in the required number of runs. In Table 4.3 below, the coded values for a system with 3 parameters are presented.

Table 4.3 - Actual and coded parameters of aqueous ozonation

\begin{tabular}{ccccccc}
\hline & Coded Value & $\mathbf{- 1 . 6 8}$ & $\mathbf{- 1}$ & $\mathbf{0}$ & $\mathbf{1}$ & $\mathbf{1 . 6 8}$ \\
\hline \multirow{3}{*}{ Actual Value } & Ozone Concentration (\%wt.) - A & 1.16 & 1.5 & 2 & 2.5 & 2.84 \\
& Time (min) - B & 3.18 & 10 & 20 & 30 & 36.81 \\
& $\mathrm{pH}-\mathrm{C}$ & 3.63 & 5 & 7 & 9 & 10.36 \\
\hline
\end{tabular}

In the same way as that for the gaseous phase, catalytic and non-catalytic aqueous runs were repeated twice. More details could be found in Appendix VII. The runs were carried out randomly and the results are shown in Tables 4.4 and 4.5 below. 
Table 4.4 - Required runs of non-catalytic aqueous treatment

\begin{tabular}{|c|c|c|c|c|c|}
\hline Order & $\#$ & $\begin{array}{c}\text { Ozone } \\
\text { Concentration } \\
(\% \text { wt. }) \text { - A }\end{array}$ & $\begin{array}{c}\text { Ozonation } \\
\text { Time (min) - B }\end{array}$ & pH - C & $\begin{array}{c}\text { Peroxide } \\
\text { Concentration } \\
\left(\mathbf{m m o l} / \mathbf{m}^{2}\right)\end{array}$ \\
\hline 9 & 1 & -1.68179 & 0 & 0 & 1.1371 \\
\hline 8 & 2 & 1 & 1 & 1 & 1.3960 \\
\hline 13 & 3 & 0 & 0 & -1.68179 & 1.3594 \\
\hline 17 & 4 & 0 & 0 & 0 & 1.4504 \\
\hline 4 & 5 & 1 & 1 & -1 & 1.653 \\
\hline 3 & 6 & -1 & 1 & -1 & 1.4592 \\
\hline 16 & 7 & 0 & 0 & 0 & 1.4732 \\
\hline 15 & 8 & 0 & 0 & 0 & 1.3991 \\
\hline 11 & 9 & 0 & -1.68179 & 0 & 1.1941 \\
\hline 10 & 10 & 1.68179 & 0 & 0 & 1.6331 \\
\hline 2 & 11 & 1 & -1 & -1 & 1.4734 \\
\hline 18 & 12 & 0 & 0 & 0 & 1.4447 \\
\hline 12 & 13 & 0 & 1.68179 & 0 & 1.6077 \\
\hline 19 & 14 & 0 & 0 & 0 & 1.3934 \\
\hline 5 & 15 & -1 & -1 & 1 & 1.0394 \\
\hline 14 & 16 & 0 & 0 & 1.68179 & 1.0089 \\
\hline 7 & 17 & -1 & 1 & 1 & 1.2882 \\
\hline 20 & 18 & 0 & 0 & 0 & 1.4276 \\
\hline 1 & 19 & -1 & -1 & -1 & 1.0802 \\
\hline 6 & 20 & 1 & -1 & 1 & 1.2877 \\
\hline
\end{tabular}


Table 4.5 - Required runs of catalytic aqueous treatment

\begin{tabular}{|c|c|c|c|c|c|}
\hline Order & $\#$ & $\begin{array}{c}\text { Ozone } \\
\text { Concentration } \\
(\% \text { wt. }) \text { - A }\end{array}$ & $\begin{array}{c}\text { Ozonation } \\
\text { Time (min) - B }\end{array}$ & pH - C & $\begin{array}{c}\text { Peroxide } \\
\text { Concentration } \\
\left(\mathbf{m m o l} / \mathbf{m}^{2}\right)\end{array}$ \\
\hline 9 & 1 & -1.68179 & 0 & 0 & 1.2939 \\
\hline 8 & 2 & 1 & 1 & 1 & 1.9214 \\
\hline 13 & 3 & 0 & 0 & -1.68179 & 1.2740 \\
\hline 17 & 4 & 0 & 0 & 0 & 1.5695 \\
\hline 4 & 5 & 1 & 1 & -1 & 1.5718 \\
\hline 3 & 6 & -1 & 1 & -1 & 1.5467 \\
\hline 16 & 7 & 0 & 0 & 0 & 1.5534 \\
\hline 15 & 8 & 0 & 0 & 0 & 1.5315 \\
\hline 11 & 9 & 0 & -1.68179 & 0 & 1.2875 \\
\hline 10 & 10 & 1.68179 & 0 & 0 & 1.7380 \\
\hline 2 & 11 & 1 & -1 & -1 & 1.3491 \\
\hline 18 & 12 & 0 & 0 & 0 & 1.5175 \\
\hline 12 & 13 & 0 & 1.68179 & 0 & 1.7535 \\
\hline 19 & 14 & 0 & 0 & 0 & 1.5180 \\
\hline 5 & 15 & -1 & -1 & 1 & 1.2470 \\
\hline 14 & 16 & 0 & 0 & 1.68179 & 1.7817 \\
\hline 7 & 17 & -1 & 1 & 1 & 1.6844 \\
\hline 20 & 18 & 0 & 0 & 0 & 1.5232 \\
\hline 1 & 19 & -1 & -1 & -1 & 1.0124 \\
\hline 6 & 20 & 1 & -1 & 1 & 1.6482 \\
\hline
\end{tabular}

The governing equations for all the three systems were obtained from linear regression of the experimental data, which was performed by the software. The parameters with p-values greater than 0.05 were omitted since the $95 \%$ level of confidence was chosen as the limit.

The models for the different treatment methods are provided below. A, B and C are the coded values of the parameters. Peroxide concentration is in $\mathrm{mmol} / \mathrm{m}^{2}$.

- $\quad$ Gaseous Phase, R-squared=0.9815, Adjusted R-squared=0.9682:

Peroxide Conc. $=1.551+0.183 \times \mathrm{A}+0338 \times \mathrm{B}+0.096 \times \mathrm{A}^{2}+0.087 \times \mathrm{B}^{2}$ 
- $\quad$ Non-catalytic Aqueous Phase, R-squared=0.9836, Adjusted R-squared=0.9689:

Peroxide Conc. $=1.431+0.130 \times \mathrm{A}+0.118 \times \mathrm{B}-0.091 \times \mathrm{C}-0.042 \times \mathrm{AB}-0.029 \times \mathrm{AC}-0.084 \times \mathrm{C}^{2}$

- $\quad$ Catalytic Aqueous Phase, R-squared=0.9792, Adjusted R-squared=0.9695:

Peroxide Conc. $=1.516+0.128 \times \mathrm{A}+0.165 \times \mathrm{B}+0.137 \times \mathrm{C}-0.060 \times \mathrm{AB}+0.034 \times \mathrm{AC}$

Also, the models have been provided based on the actual parameters below. In the following equations, $\mathrm{A}, \mathrm{B}$ and $\mathrm{C}$ represent ozone concentration (\%wt.), ozonation time $(\mathrm{min})$ and $\mathrm{pH}$, respectively. Peroxide concentration would be calculated in $\mathrm{mmol} / \mathrm{m}^{2}$.

- Gaseous Phase:

Peroxide Conc. $=1.941-1.125 \times \mathrm{A}+2.122 \mathrm{E}-003 \times \mathrm{B}+0.383 \times \mathrm{A}^{2}+8.675 \mathrm{E}-004 \times \mathrm{B}^{2}$

- Non-catalytic Aqueous Phase:

Peroxide Conc. $=-0.945+0.632 \times \mathrm{A}+0.038 \times \mathrm{B}-0.324 \times \mathrm{C}-8.497 \mathrm{E}-003 \times \mathrm{AB}-0.029 \times \mathrm{AC}-$ $0.020 \times C^{2}$

- $\quad$ Catalytic Aqueous Phase:

Peroxide Conc. $=0.162+0.252 \times \mathrm{A}+0.042 \times \mathrm{B}+5.341 \mathrm{E}-003 \times \mathrm{C}-0.012 \times \mathrm{AB}+0.034 \times \mathrm{AC}$

From the high R-squared and adjusted R-squared values, which were calculated for each model, low error could be interpreted. Thus, the three models have good fit with the experimental data.

According to the models obtained, ozone concentration and ozonation time have greater effects on the gaseous treatment comparing with the aqueous treatments, which could be noted as a higher sensitivity of the gaseous phase reaction to the variation of the mentioned parameters. Also, AC mainly affected the trend of the peroxide formation versus the medium $\mathrm{pH}$, which happened due to different dominant reactions taking place in the aqueous phase in the absence or the presence of the catalyst.

Tables 4.6 to 4.8 demonstrate the ANOVA used in the present study in order to investigate the accuracy of the models. 
Table 4.6 - ANOVA table for gaseous ozonation

\begin{tabular}{cccccc}
\hline Source & SS & D.F & MS & F & p-value \\
\hline Model & 1.27 & 5 & 0.25 & 84.01 & $<0.0001$ \\
A & 0.27 & 1 & 0.27 & 87.35 & $<0.0001$ \\
B & 0.91 & 1 & 0.91 & 298.99 & $<0.0001$ \\
AB & $4.04 \mathrm{E}-004$ & 1 & $4.04 \mathrm{E}-004$ & 0.13 & 0.7269 \\
$\mathbf{A}^{\mathbf{2}}$ & 0.06 & 1 & 0.06 & 20.82 & 0.0026 \\
$\mathbf{B}^{\mathbf{2}}$ & 0.05 & 1 & 0.05 & 17.12 & 0.0044 \\
Residual & 0.02 & 7 & $3.06 \mathrm{E}-003$ & & \\
Total & 1.31 & 12 & & & \\
\hline
\end{tabular}

Table 4.7 - ANOVA table for non-catalytic aqueous ozonation

\begin{tabular}{cccccc}
\hline Source & SS & D.F. & MS. & F & p-value \\
\hline Model & 0.66 & 9 & 0.07 & 66.68 & $<0.0001$ \\
A & 0.23 & 1 & 0.23 & 209.65 & $<0.0001$ \\
B & 0.19 & 1 & 0.19 & 172.32 & $<0.0001$ \\
C & 0.11 & 1 & 0.11 & 102.71 & $<0.0001$ \\
AB & 0.01 & 1 & 0.01 & 13.09 & 0.0047 \\
AC & $6.66 \mathrm{E}-003$ & 1 & $6.66 \mathrm{E}-003$ & 6.04 & 0.0338 \\
BC & $5.07 \mathrm{E}-003$ & 1 & $5.07 \mathrm{E}-003$ & 4.60 & 0.0576 \\
$\mathbf{A}^{2}$ & $2.29 \mathrm{E}-003$ & 1 & $2.29 \mathrm{E}-003$ & 2.08 & 0.1800 \\
$\mathbf{B}^{2}$ & $7.11 \mathrm{E}-004$ & 1 & $7.11 \mathrm{E}-004$ & 0.64 & 0.4406 \\
$\mathbf{C}^{2}$ & 0.1 & 1 & 0.1 & 91.42 & $<0.0001$ \\
Residuals & 0.01 & 10 & $1.10 \mathrm{E}-003$ & & \\
Total & 0.67 & 19 & & & \\
\hline
\end{tabular}

Table 4.8 - ANOVA table for catalytic aqueous ozonation

\begin{tabular}{cccccc}
\hline Source & SS & D.F. & MS. & F & p-value \\
\hline Model & 0.89 & 6 & 0.15 & 101.79 & $<0.0001$ \\
A & 0.22 & 1 & 0.22 & 153.33 & $<0.0001$ \\
B & 0.37 & 1 & 0.37 & 254.66 & $<0.0001$ \\
C & 0.26 & 1 & 0.26 & 176.61 & $<0.0001$ \\
AB & 0.03 & 1 & 0.03 & 19.42 & 0.0007
\end{tabular}




\begin{tabular}{cccccc} 
AC & $9.55 \mathrm{E}-003$ & 1 & $9.55 \mathrm{E}-003$ & 6.55 & 0.0237 \\
BC & $2.69 \mathrm{E}-004$ & 1 & $2.69 \mathrm{E}-004$ & 0.18 & 0.6744 \\
Residuals & 0.02 & 13 & $1.46 \mathrm{E}-003$ & & \\
Total & 0.91 & 19 & & & \\
\hline
\end{tabular}

High F-values and low p-values $(<0.05)$ are the criteria that can be used to reject the null hypothesis (non-significant changes of the peroxide concentration with a specific parameter, such as: ozone concentration, ozonation time or $\mathrm{pH}$ ). According the ANOVA tables, the main parameters, ozone concentration, ozonation time and $\mathrm{pH}$ were all significantly relevant to the peroxide concentration for gaseous, non-catalytic aqueous and catalytic aqueous ozonation. Also, some of the interactions owned a considerable relevancy. The ones with p-value greater than 0.05 were deleted from the models.

In addition to the R-squared value and ANOVA, the accuracy of models could be evaluated based on the linearity of the normal plot of residuals and actual-versus-predicted plots. In the following figures (Figures 4.17 to 4.22), these plots were shown for gaseous, non-catalytic and catalytic ozonation.

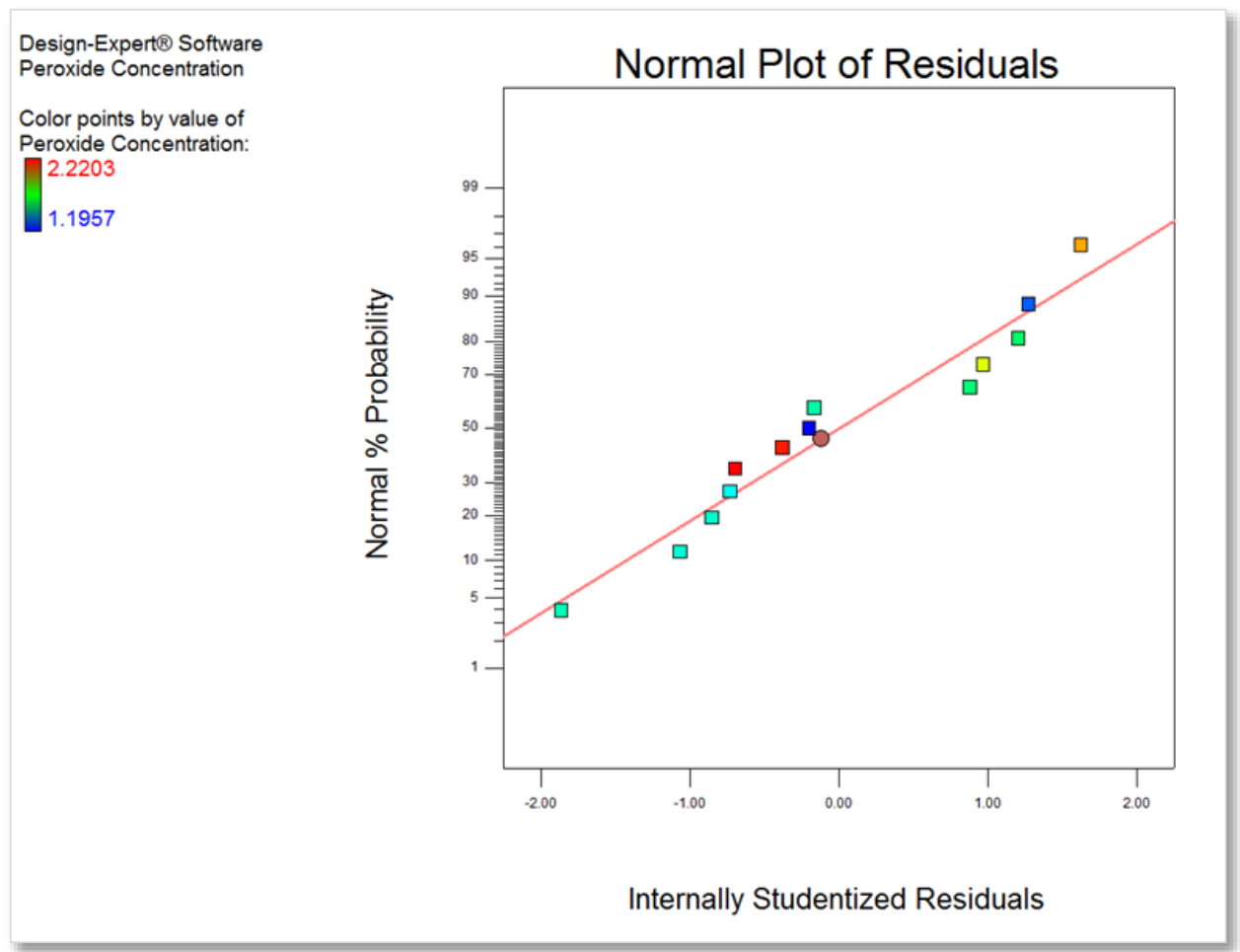

Figure 4.17 - Normal plot of residuals, gaseous ozonation 


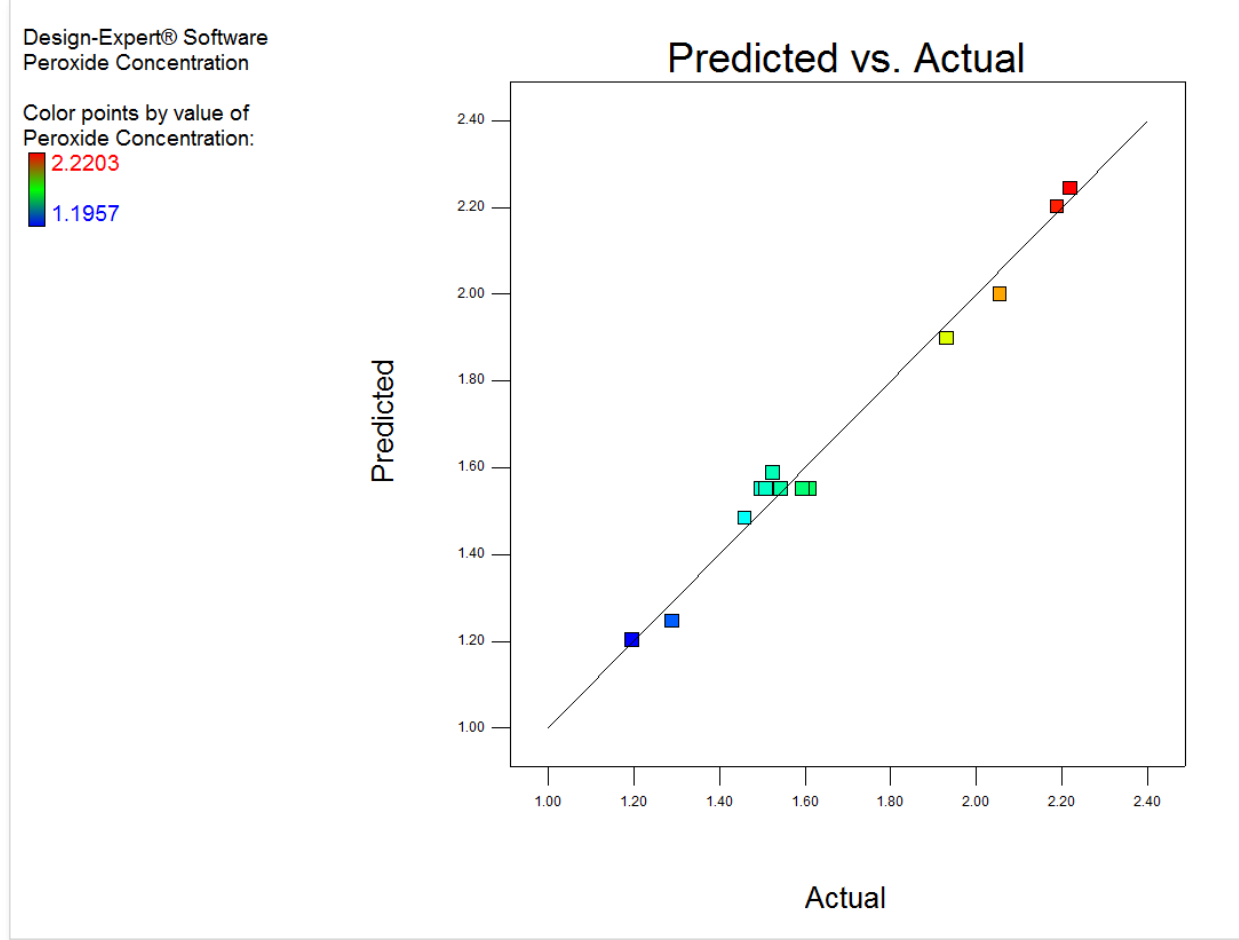

Figure 4.18 - Predicted and actual peroxide concentrations, gaseous phase

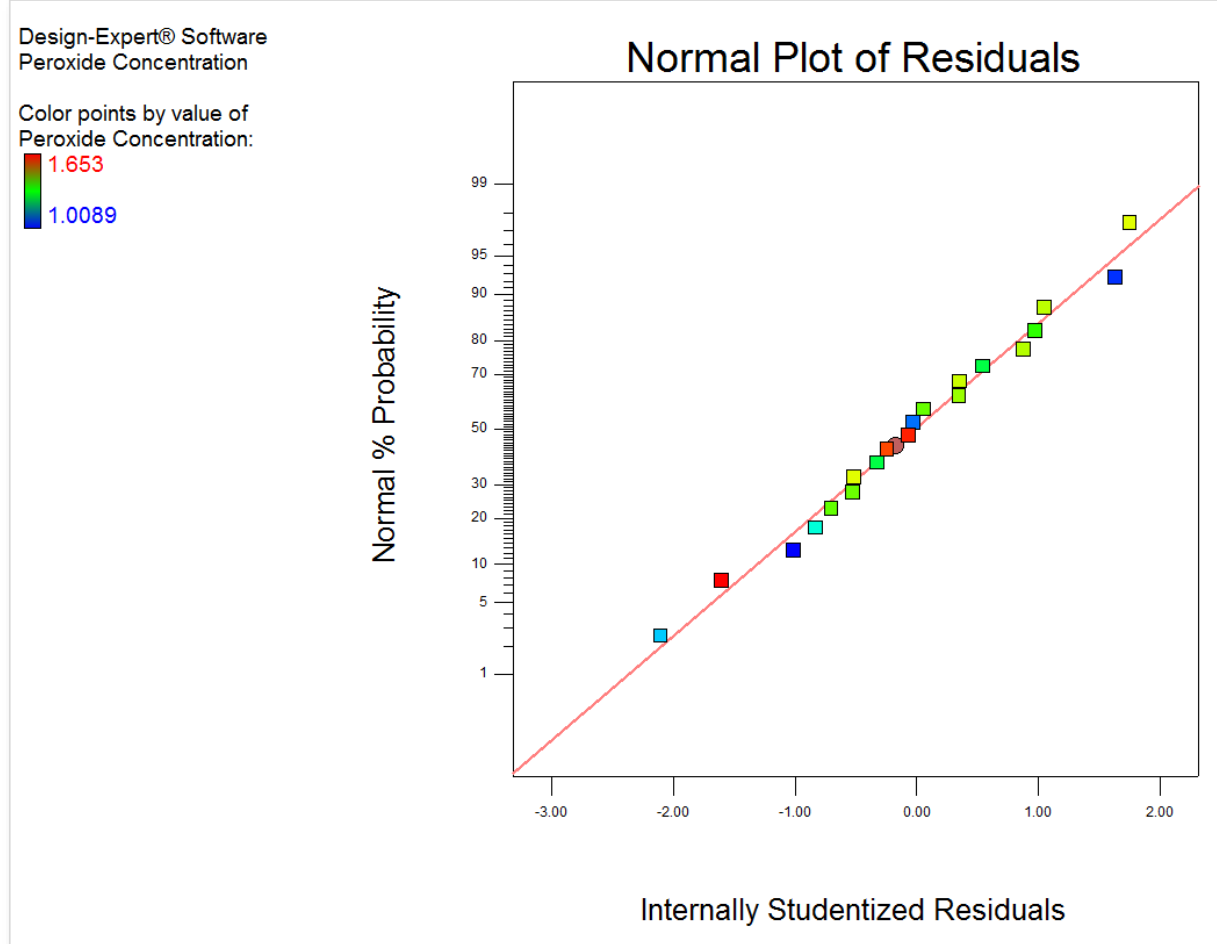

Figure 4.19 - Normal plot of resuals, non-catalytic aqueous ozonation 


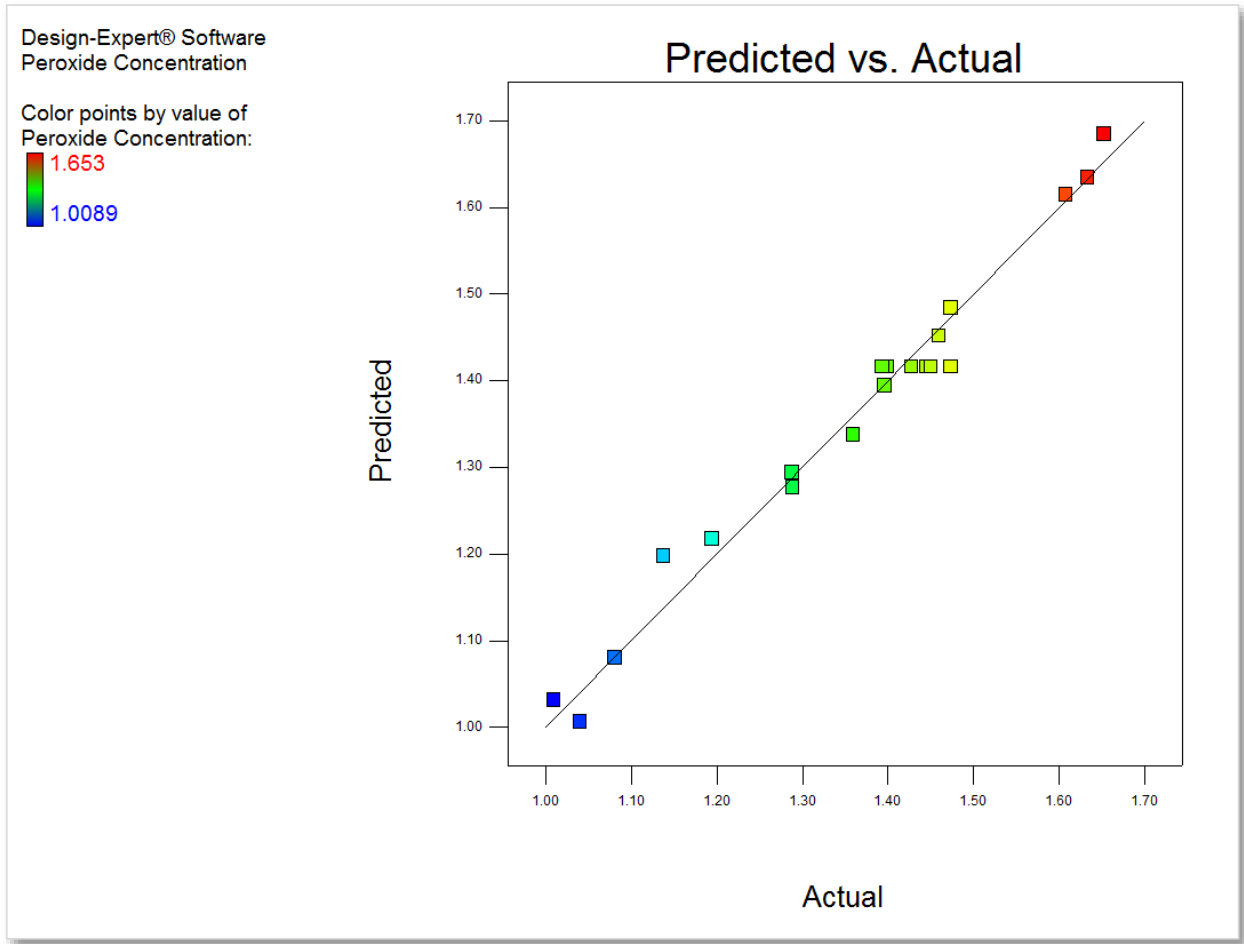

Figure 4.20 - Predicted and actual peroxide concentrations, non-catalytic aqueous phase

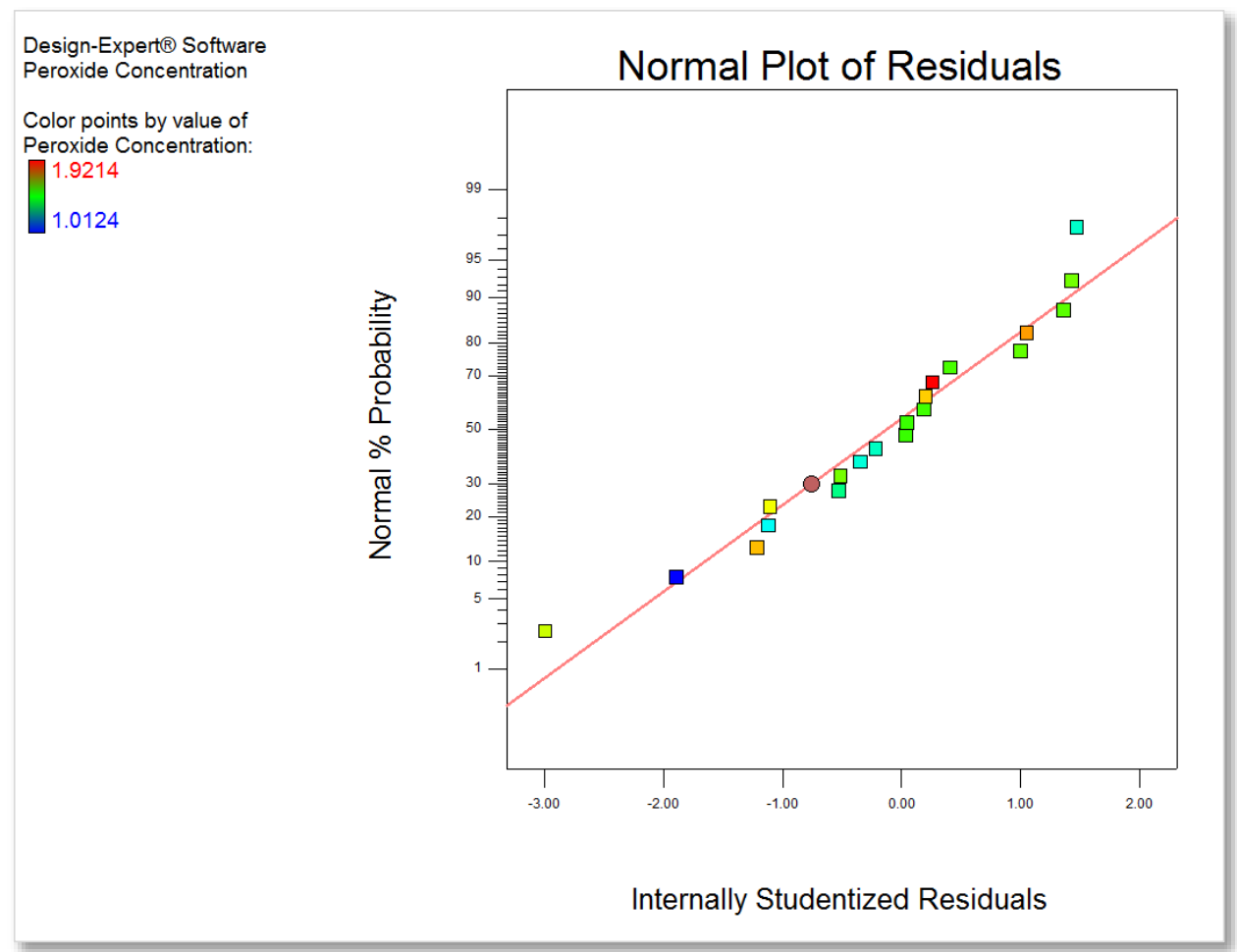

Figure 4.21 - Normal plot of resuals, catalytic aqueous ozonation 


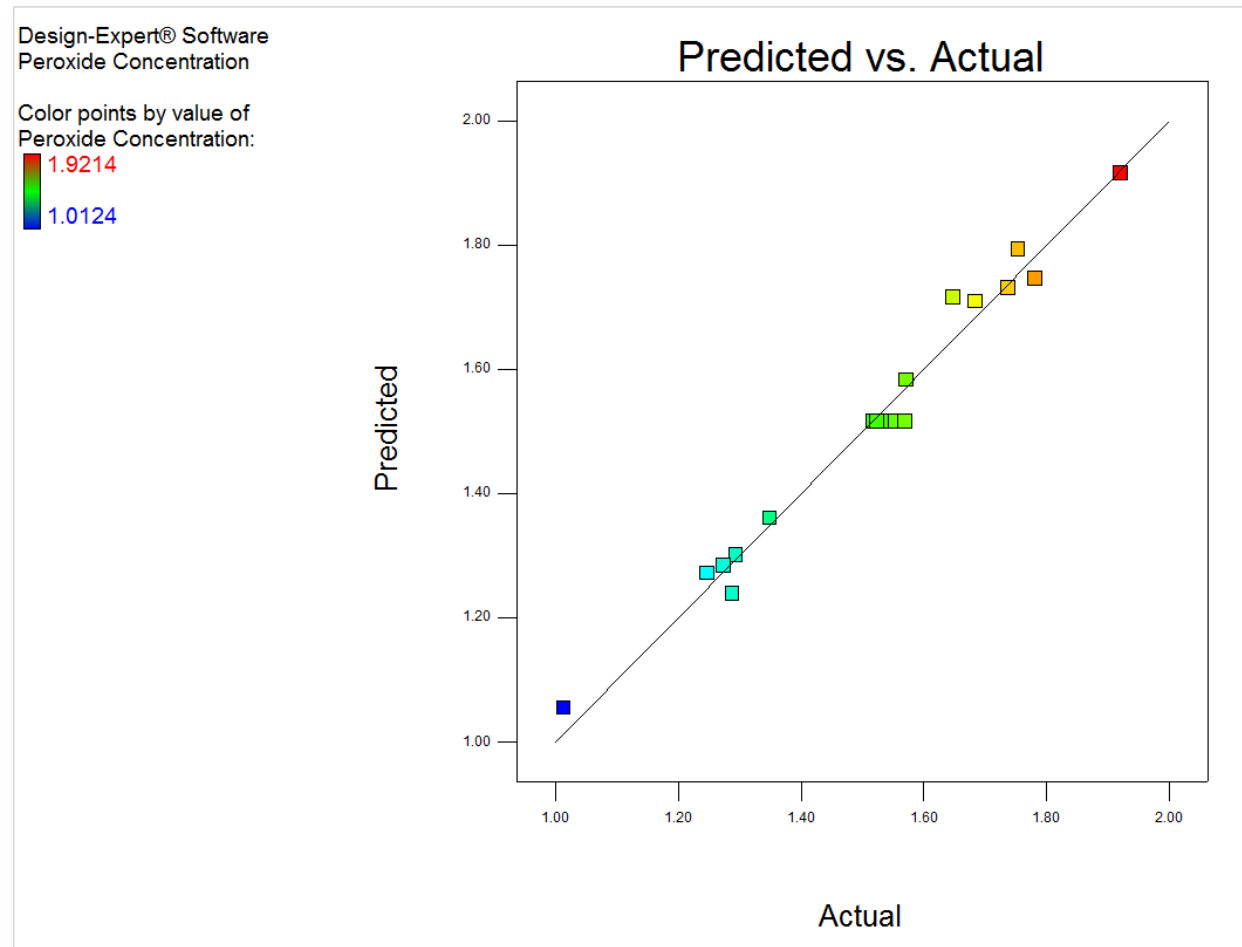

Figure 4.22 - Predicted and actual peroxide concentrations, catalytic aqueous phase

Since the normal plots of residuals demonstrated an acceptable linearity, normal error distributions could be interpreted for gaseous and aqueous treatments. This supports the accuracy of the provided peroxide concentration models.

\subsection{Optimization}

Increasing the amount of peroxide on the surface of the samples was the main goal of the present study since formation of more peroxide would lead to a higher hydrophilicity of the membrane surface, and hence, a lower contact angle and less fouling during the filtration process. Therefore, optimization of the membrane treatment parameters would be helpful in order to find the conditions leading to the highest amount of peroxide generated on the PVDF membrane surface. Therefore, using the models obtained earlier in this chapter, optimization was carried out. The peroxide concentration profiles were generated and plotted in Figures 4.23-4.25, using Design Expert-8 software. 


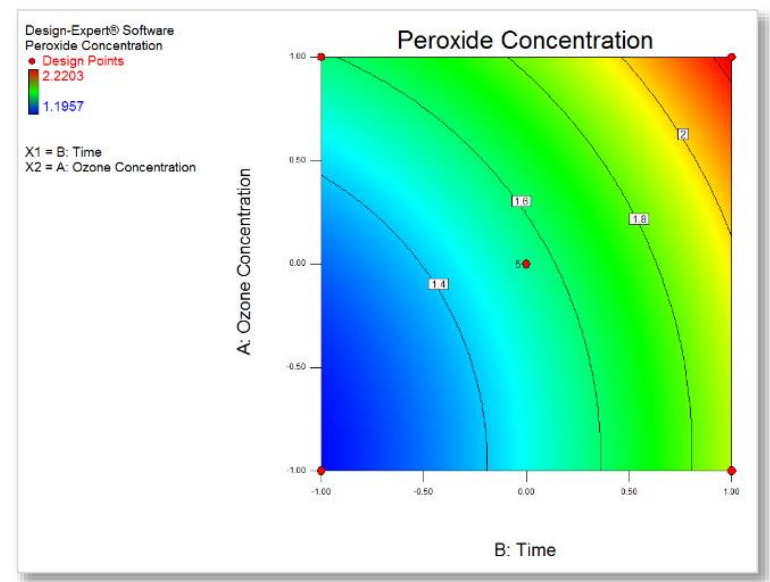

Figure 4.23 - Peroxide concentration profile, gaseous ozonation
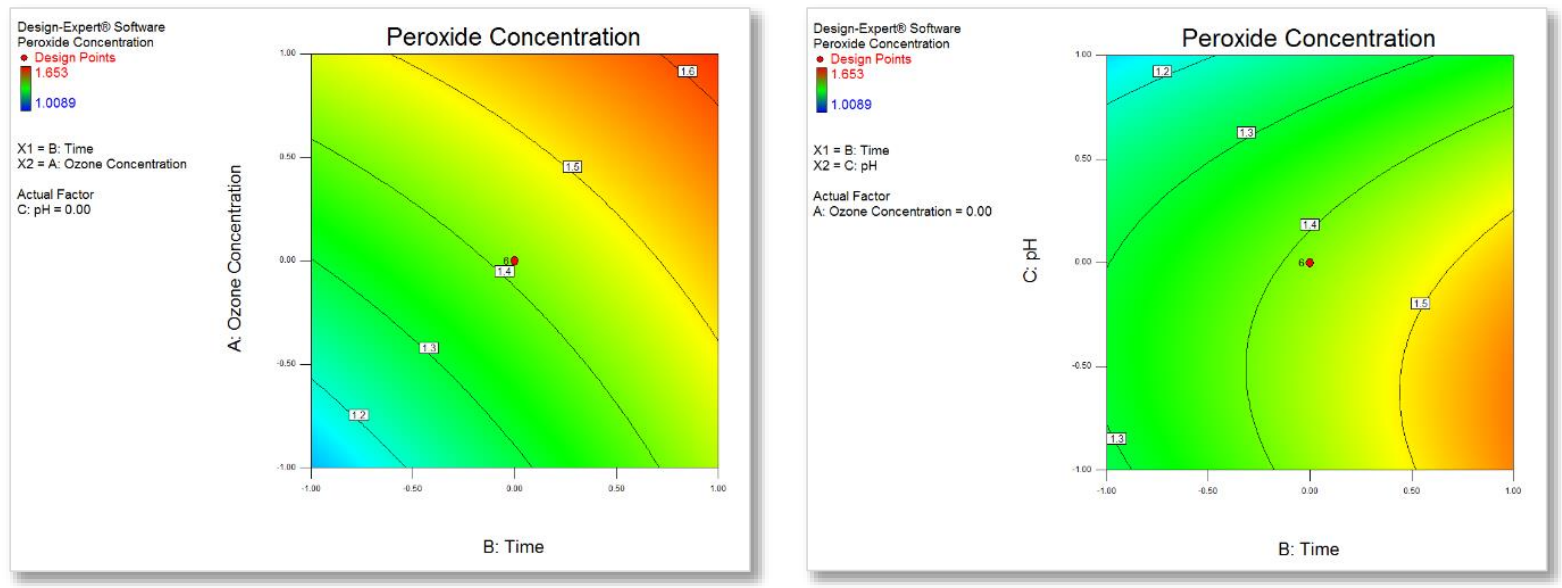

Figure 4.24 - Peroxide concentration profile, non-catalytic aqueous ozonation
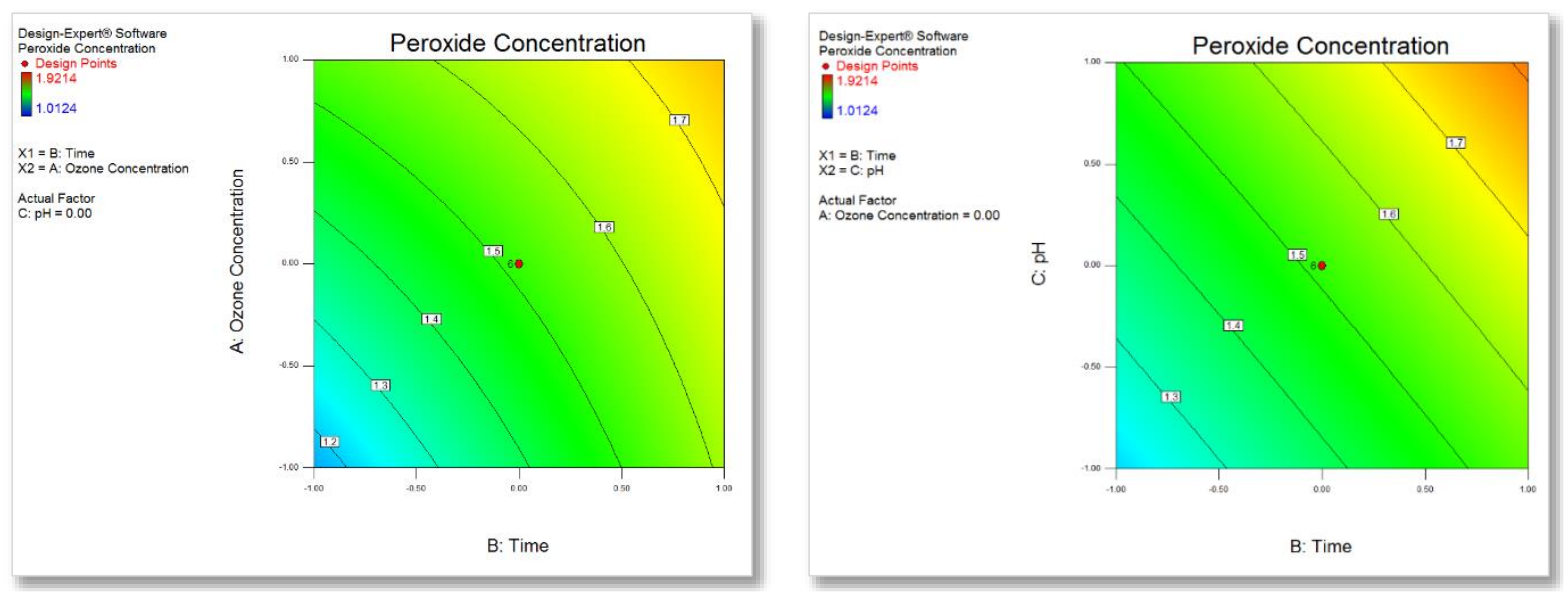

Figure 4.25 - Peroxide concentration profile, catalytic aqueous ozonation 
The 2-D peroxide concentration profiles of gaseous and aqueous treated samples, clearly illustrate that longer and more intense ozone exposure would result in a higher peroxide concentration in the studied range. However, for non-catalytic aqueous treatment, the peroxide concentration appeared to be dependent on $\mathrm{pH}$ with a second-order behavior, as could be seen on the right-hand-side graph of Figure 4.24; and the maximum concentration happened at $\mathrm{pH}$ around 6, 2.5\%wt. ozone and 30 minutes ozonation. On the other hand, a linear trend of the variation of the peroxide concentration with $\mathrm{pH}$ was observed for catalytic treatments, as could be seen on the right-hand-side graph of Figure 4.25.

According to the peroxide concentration profiles and the governing equations, the optimal conditions, in the studied range, in order to reach the maximum peroxide generated on the membrane surface were found and shown in Table 4.9 below. The details of mechanical strength tests and peroxide concentrations could be found in Appendix V and VI, respectively.

Table 4.9 - Optimal conditions of ozonation

\begin{tabular}{cccc} 
Sample & Parameters & $\begin{array}{c}\text { Peroxide } \\
\text { Concentration } \\
\left(\mathbf{m m o l} / \mathbf{m}^{2}\right)\end{array}$ & $\begin{array}{c}\text { Mechanical } \\
\text { Strength } \\
(\mathbf{M P a})\end{array}$ \\
\hline Untreated Sample & - & 0 & 26.25 \\
Gaseous Ozonation & $2.5 \% \mathrm{wt} ., 30 \mathrm{~min}$ & 2.2202 & 9.22 \\
Non-Catalytic Aqueous Ozonation & $2.5 \% \mathrm{wt} ., 30 \mathrm{~min}, \mathrm{pH}=5.5$ & 1.7556 & 11.04 \\
Catalytic Aqueous Ozonation & $2.5 \% \mathrm{wt} ., 30 \mathrm{~min}$, & 1.9214 & 11.15 \\
\hline
\end{tabular}

\subsection{Contact Angle}

Contact angle measurements were carried out to demonstrate the effect of ozonation on increasing the membrane hydrophilicity. The measurements were carried out for the untreated sample and the ones optimally treated in gaseous or aqueous phase. During the ozonation process, since peroxides were formed on the membrane surface, the hydrophilicity and thereupon the wettability of the membrane increased. For each sample, the contact angle was measured at 3 different spots. More details could be found in Appendix VIII. The average contact angles are presented below. 
The drop of distilled water on the fresh untreated sample formed a contact angle of $73.5 \pm 0.2$ degree, as shown in Figure 4.26.

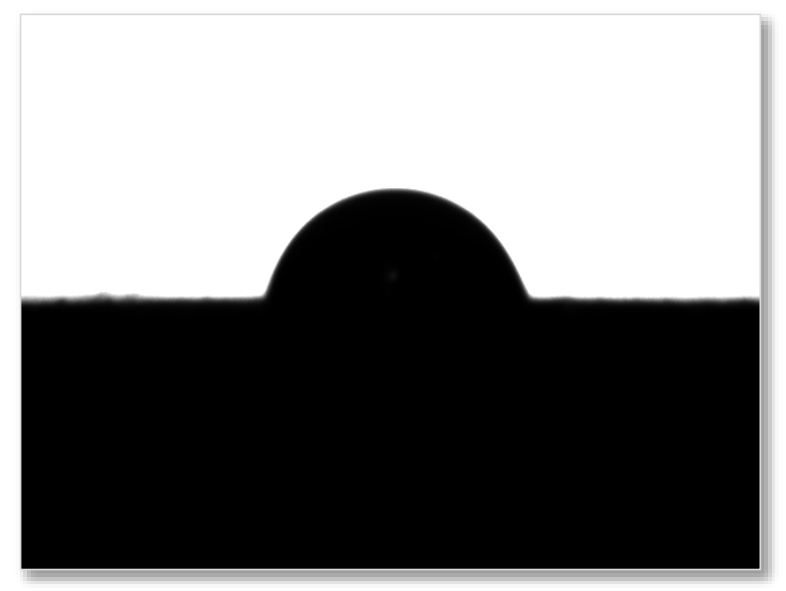

Figure 4.26 - Contact angle image, untreated PVDF

Ozonation was proved to be significantly effective in increasing the hydrophilicity of the membrane surface. The contact angle dropped to $50.4 \pm 0.3$ degree for the membrane subjected to gaseous ozonation. 30 minutes at an ozone concentration of $2.5 \%$ wt., as indicated in Figure 4.27 below.

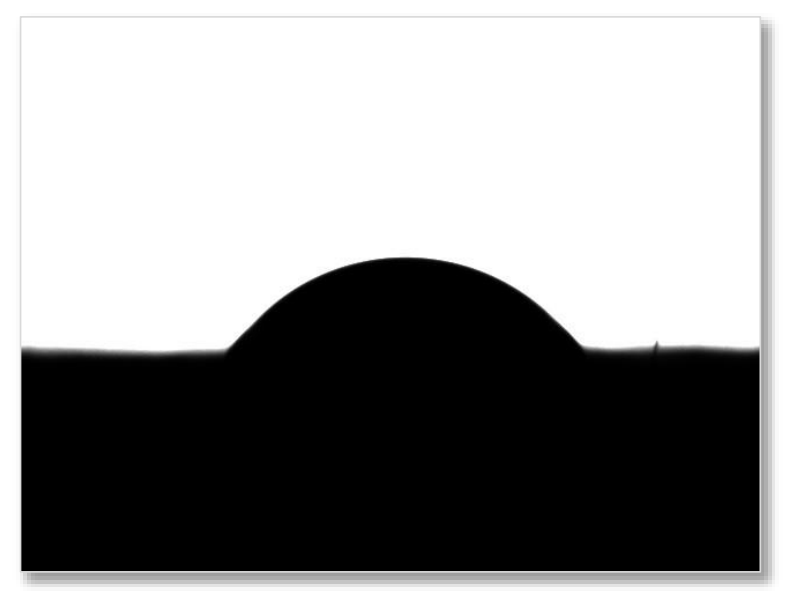

Figure 4.27 - Contact angle image, optimal gaseous treated PVDF

Although aqueous treatment was also quite effective in enhancing the hydrophilicity of the treated membrane, the contact angle did not decrease as much as that with the gaseous ozonation. Non-catalytic aqueous ozonation at $2.5 \%$ wt., $\mathrm{pH}=5.5$ and 30 minutes treatment, the 
conditions that led to the maximum peroxide concentration shown earlier, was able to lessen the contact angle to $65.1 \pm 0.7$ degree. Figure 4.28 below shows the contact angle of the drop of water on the surface of the non-catalytic aqueous treated membrane.

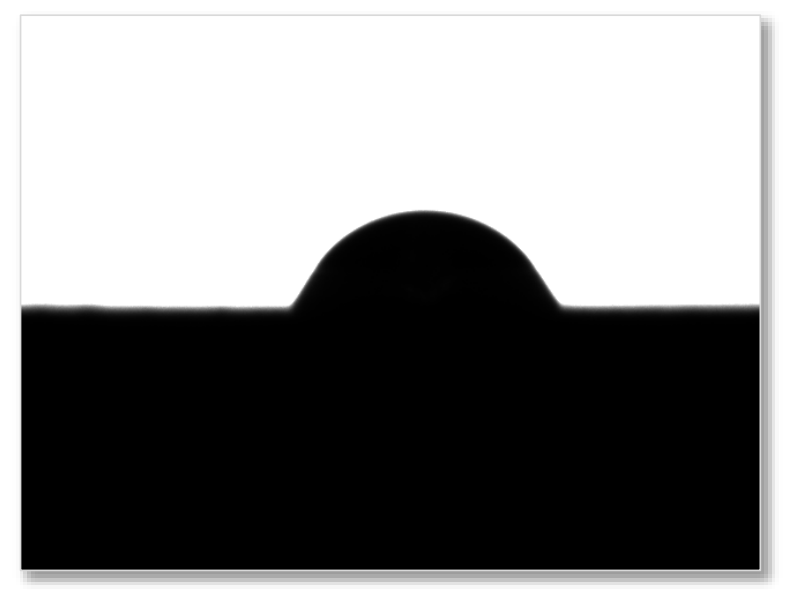

Figure 4.28 - Contact angle image, optimal non-catalytic aqueous treated PVDF

Catalytic aqueous ozonation was able to increase the hydrophilicity of the PVDF membrane more than the non-catalytic one. The contact angle of the optimal catalytic treated sample was measured as 56.4 \pm 0.5 degree, shown in Figure 4.29, which could approve the effectiveness of using $\mathrm{AC}$ as the catalyst of surface modification treatment. Also, the attachment of small particles of AC to the membrane surface, could increase the surface heterogeneity and roughness leading to lower contact angle according to the Wenzel equation (Equation 2.3).

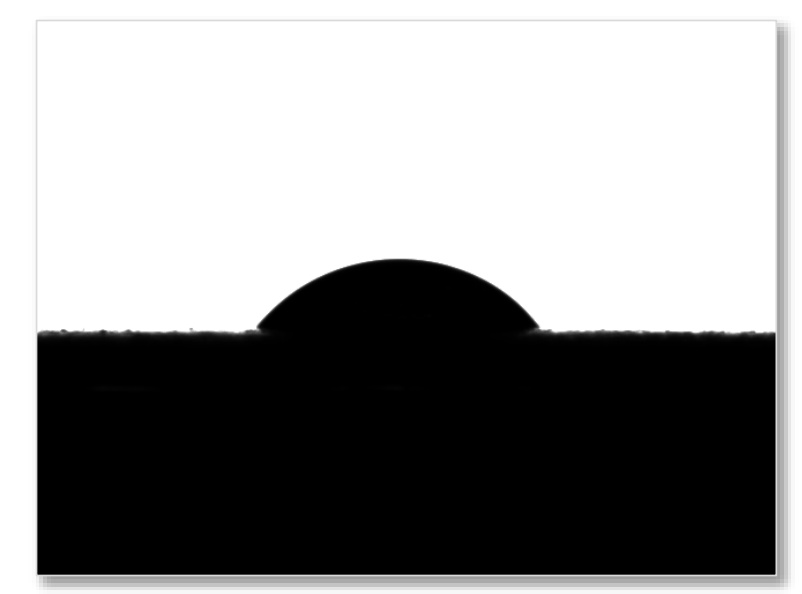

Figure 4.29 - Contact angle image, optimal catalytic aqueous treated PVDF 


\subsection{Filtration Test}

Using water as the feed, the permeate flux through the membrane was measured before and after fouling with milk proteins for the untreated membrane sample, the optimal gaseous, noncatalytic and catalytic treated PVDF samples over 5 minutes of filtration in order to investigate the effect of ozone treatment on filtration performance of PVDF membrane. Filtration runs were carried out under constant pressure in a cross-flow filtration unit. The pressure difference was kept at $18 \mathrm{psig}$. The membranes were rinsed with distilled water after the skim milk filtration to remove the formed cake layer from the membrane surface. The rinsed membranes were used again to find distilled water flux through the fouled samples. All the runs have been duplicated and the individual results could be found in Appendix IX.

According to the results showed in Figure 4.30, ozonation increased water flux before fouling. This observation might be due to the material deterioration caused by the treatment which led to larger pore size of the treated samples.

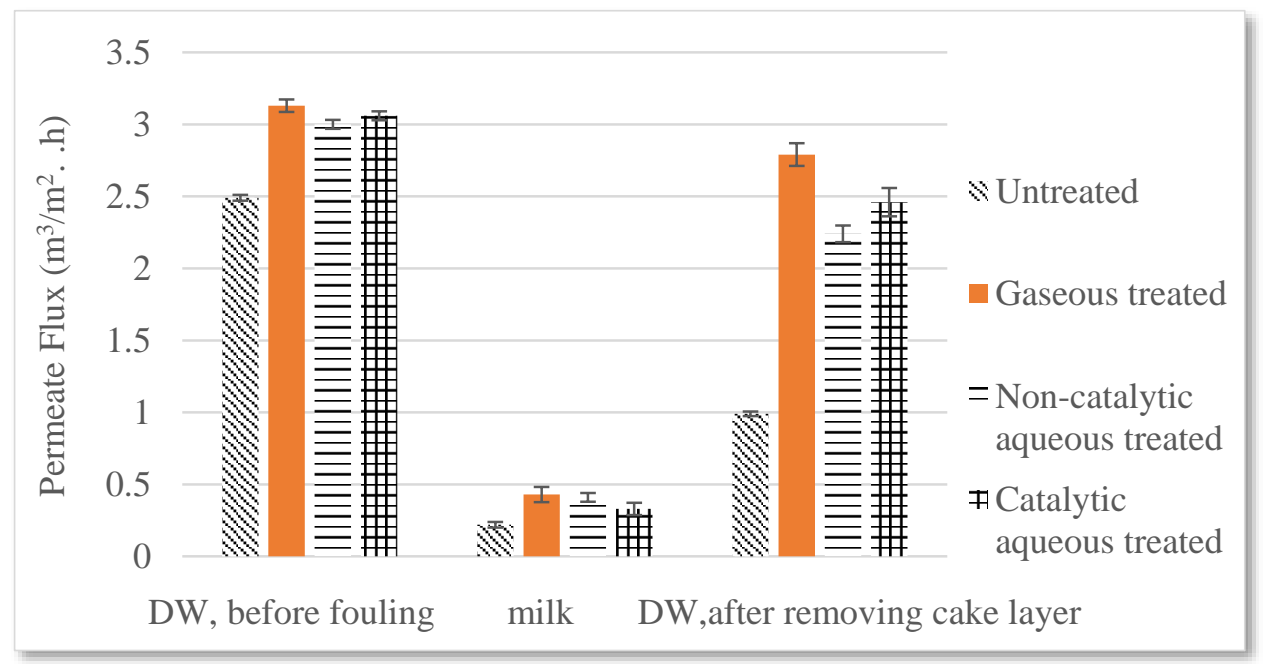

Figure 4.30 - Effect of ozonation on flux reduction

For filtration of skim milk, the permeate flux increased significantly with membranes which were treated by ozonation in all media. However, the permeate flux in skim milk filtration was much lower than that with distilled water feed. This was due to different viscosities of fluids and the resistance of cake layer formed during milk filtration, which was not present in filtration using distilled water. 
In order to quantify the effect of pore fouling on the permeate flux, the cake layer was washed off the membrane. Distilled water filtration was then carried out, using the washed membrane. The results obtained showed the effectiveness of ozonation in alleviating the permeate flux decline due to pore fouling. Untreated membrane experienced a flux decline of almost $60 \%$ while the distilled water flux decrease was only about 11 percent for the gaseous treated membrane. Membranes treated with the catalytic and non-catalytic aqueous ozonation had 19\% and $25 \%$ flux decline, respectively.

Also, peroxide titration was carried out after filtration runs to evaluate the stability of peroxides on the membrane surface. The results showed that the amount of attached peroxides changed only few percent after 5 minutes skim milk filtration under a constant pressure of 4 psig.

Resistance-in-series model of filtration was applied to find the membrane, the cake layer and the fouling resistances for untreated, optimal gaseous treated, optimal catalytic and noncatalytic aqueous treated membranes. The results are shown in Table 4.10. The sample calculation could be found in Appendix X.

Table 4.10 - Effect of ozonation on membrane and fouling resistances

\begin{tabular}{cccc}
\hline Sample & $\mathbf{R}_{\mathbf{M}}$ & $\mathbf{R}_{\mathbf{F}}$ & $\mathbf{R}_{\mathbf{C}}$ \\
\hline Untreated PVDF & $1.495 \times 10^{11} \mathrm{~m}^{-1}$ & $2.266 \times 10^{11} \mathrm{~m}^{-1}$ & $5.069 \times 10^{11} \mathrm{~m}^{-1}$ \\
Optimal Gaseous Treated & $1.189 \times 10^{11} \mathrm{~m}^{-1}$ & $1.455 \times 10^{10} \mathrm{~m}^{-1}$ & $3.181 \times 10^{11} \mathrm{~m}^{-1}$ \\
PVDF & & & \\
Optimal Non-catalytic & $1.241 \times 10^{11} \mathrm{~m}^{-1}$ & $4.211 \times 10^{10} \mathrm{~m}^{-1}$ & $3.076 \times 10^{11} \mathrm{~m}^{-1}$ \\
Aqueous Treated PVDF & & & \\
Optimal Catalytic Aqueous & $1.217 \times 10^{11} \mathrm{~m}^{-1}$ & $2.965 \times 10^{10} \mathrm{~m}^{-1}$ & $4.373 \times 10^{11} \mathrm{~m}^{-1}$ \\
Treated PVDF & & & \\
\hline
\end{tabular}

According to Table 4.10, although the resistance of the membrane itself (represented by $\mathrm{R}_{\mathrm{M}}$ ) was reduced about $20 \%$, surface fouling (due to cake layer represented by $\mathrm{R}_{\mathrm{C}}$ ) and pore fouling resistances (represented by $\mathrm{R}_{\mathrm{F}}$ ) declined significantly for all the treated samples. For 
example, $\mathrm{R}_{\mathrm{F}}$ and $\mathrm{R}_{\mathrm{C}}$ decreased almost 10 times and 2.5 times, respectively, for PVDF catalytically ozonated in an aqueous medium, as compared with the untreated PVDF. Also, the gaseous phase treated membrane showed lower fouling resistances in comparison to those of PVDF catalytically and non-catalytically treated in an aqueous medium which represents a better surface treatment occurrence in gaseous phase.

Backwash tests were also carried out to investigate the effect of ozonation on the flux recovery of PVDF membranes. Backwash appeared to remove all the reversible fouling attachments including the cake layer and part of pore foulants. Milk filtration was done using untreated and gaseous treated membranes. After performing the backwash process, the membranes were used again for milk filtration. Three filtration-backwash cycles carried out for each membrane sample. The permeate fluxes obtained are shown in Figures 4.31 and 4.32 below and the details could be found in Appendix XI.

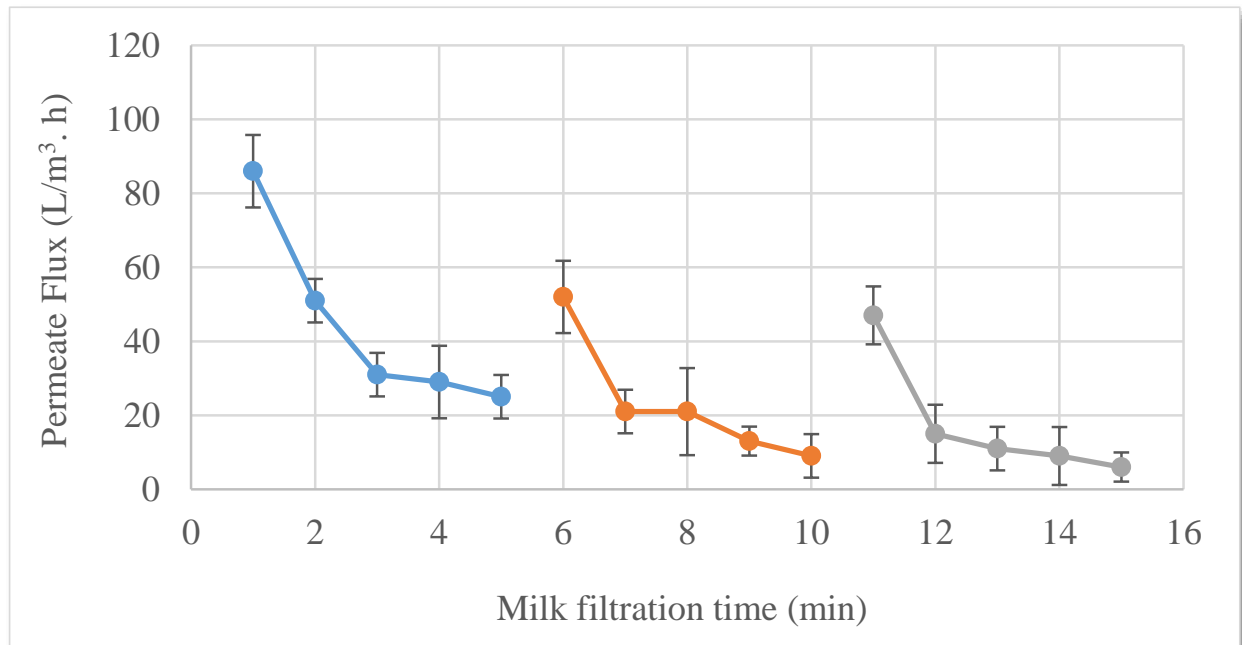

Figure 4.31 - Effect of backwash on milk permeate flux using untreated PVDF 


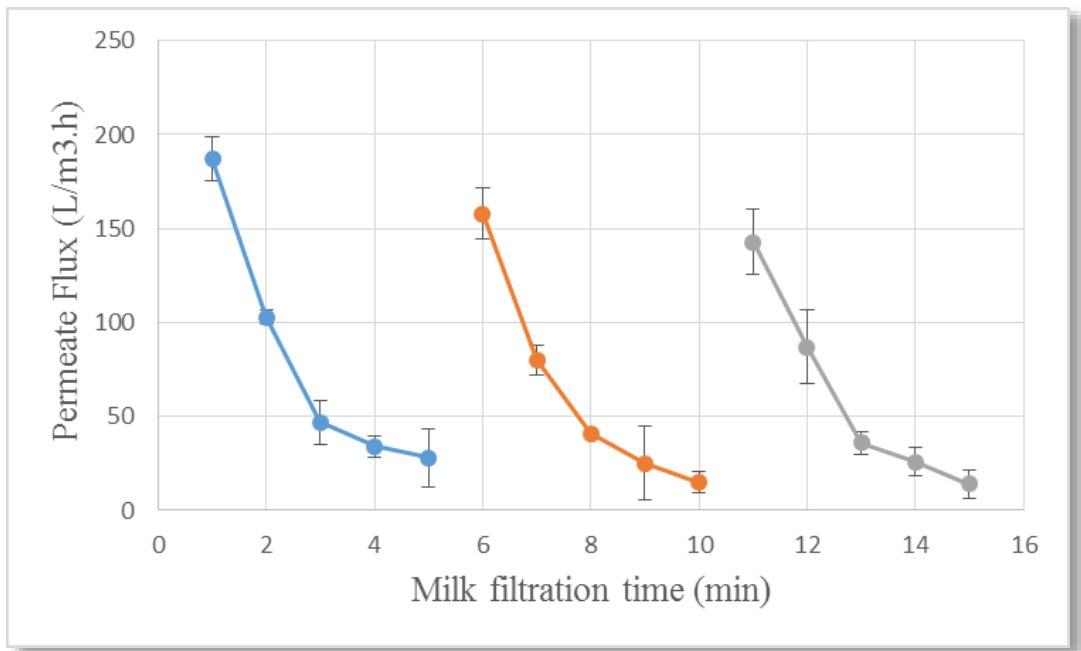

Figure 4.32 - Effect of backwash on milk permeate flux using optimal gaseous treated PVDF

Using backwash, although the milk permeate flux did not return completely to the initial value, an acceptable membrane functionality recovery was observed with both untreated and optimal gaseous treated samples. The first backwash cycle helped recovering 60 percent of the initial permeate flux for the untreated sample while the flux recovery ratio was around 84 percent for the gaseous treated sample. Since backwash removes the reversible fouling, both on the membrane surface and in the membrane pores, this could be inferred as less irreversible fouling formation on the membrane that underwent the ozonation treatment. The first reason for the flux recovery improvement could be due to the occurrence of pores enlargement during ozonation process, which was confirmed by a higher flux of distilled water through the clean ozone treated PVDF, as compared with that of the clean untreated PVDF (Figure 4.30). Larger pores would hinder depth fouling, which is categorized as irreversible fouling, by providing wider paths for particles to pass through the membrane. Secondly, peroxides have been reported to be formed not only on the surface, but also in pores of the membranes (Fujimoto et al., 1993). Thus, less protein would attach to the pores of the membrane leading to less irreversible pore fouling for the ozone treated membrane. This observation demonstrates the enhancement of the anti-fouling capability of the membranes by ozonation during a filtration process.

The second backwash cycle was more effective in both cases. The second flux recovery ratio was about 90 percent for both samples. The early sharp flux reduction was mainly attributed to pore blocking rather than the cake layer formation on the membrane surface. Most 
of irreversible fouling would be formed early during the first filtration cycle with the fresh membrane. Backwash of the membrane for the first time after the first filtration cycle could only remove the reversible fouling. Therefore, the flux recovery ratio after the first backwash was relatively low. However, after the second filtration cycle, the amount of irreversible only increased slightly; and the reversible fouling could be easily washed off in the second backwash, resulting in the much higher flux recovery ratio between the third and the second filtration cycles. 


\section{Chapter rive - Conclusion}

Ozonation treatment was conducted on PVDF membranes in both gaseous and aqueous phase in the presence and absence of $\mathrm{AC}$ as the heterogeneous catalyst. Peroxide concentration determination showed that despite of the parameters used, ozonation was effective in producing peroxides on the membrane surface. While ozone concentration, in the range of 1.5 to $2.5 \%$ wt., and exposure time, in the range of 5 to 30 minutes, resulted in increasing trends in terms of peroxide formation on the membrane surface, the optimum $\mathrm{pH}$ of 5.5 and 9 were obtained for non-catalytic and catalytic aqueous treatments, respectively.

Although gaseous ozonation showed a better performance yield in comparison to the aqueous ozonation, the tensile strength reduced more in the gaseous phase. While $1 \mathrm{~g} / \mathrm{L}$ of $\mathrm{AC}$ was effective in increasing peroxide concentration on the membrane surface in comparison to the non-catalytic ozonation, adding AC did not affect the mechanical strength which could be considered as the advantage of catalytic ozonation over gaseous and non-catalytic treatments.

The efficiency of ozonation was tested using contact angle measurements. The gaseous ozonation was able to reduce the contact angle of the membrane from $73.5^{\circ}$ to $50.4^{\circ}$. Noncatalytic aqueous ozonation decreased the contact angle to $65.1^{\circ}$. However, adding $\mathrm{AC}$ resulted in a significantly lower contact angle which was measured to be $56.4^{\circ}$.

Having lower fouling on the membrane surface and in the pores of the membrane was proved with conducting filtration runs using distilled water and milk through both clean and fouled membranes. It was found that the decline of distilled water flux through PVDF membrane after fouling with milk proteins decreased from $60 \%$ for the untreated membrane to $10 \%$ after the optimal gaseous treatment. The flux reduction due to fouling was about $25 \%$ and $20 \%$ for non-catalytic and catalytic aqueous ozonation, respectively.

Backwash tests showed that less irreversible fouling happened after the optimal gaseous ozonation in comparison to the untreated membrane since milk permeate flux recovery ratio increased from $61 \%$ to $84 \%$ with the optimal gaseous ozonation. 


\section{Chapter Six - Recommendations}

Activated carbon has a good potential to catalyze PVDF membrane ozonation in an aqueous phase. However, there are various issues that could be investigated in further studies. The AC preparation method affects its final properties such as the activity and the zeta potential. Thus, studying different commercial activated carbons might result in finding the most appropriate one to be used in this field. Also, catalytic ozonation could be tested on PVDF polymer while the polymer is dissolved in a solvent solution. Changing the solid phase of the membrane into an aqueous phase might result in a better uniform treatment on the polymer surface after casting.

Another parameter of ozonation is the temperature which was assumed to be constant in the present study. However, the temperature affects the rate of the reactions and the mechanical strength of the membranes simultaneously. Thus, finding an optimum temperature which maximizes the peroxide concentration on the membrane surface would be helpful.

Furthermore, using scavengers and radical trappers would be a field of study to determine the effect of ozone molecules and radicals separately on peroxide formation on the membrane surface. Having the required information in this field would be necessary to find the mechanism which predicts the peroxide formation behavior on the PVDF membrane surface.

Although ozonation is considered as an effective hydrophilicity enhancement treatment, pairing ozonation with graft polymerization of various monomers could boost the yield of this surface modification process in terms of fouling reduction. 


\section{Appendices}




\section{Appendix I - Peroxide determination method}

Hydrogen peroxide reacts with iodide in acetic media:

$\mathrm{H}_{2} \mathrm{O}_{2}+2 \mathrm{I}^{-}+2 \mathrm{H}^{+} \rightarrow \mathrm{I}_{2}+2 \mathrm{H}_{2} \mathrm{O}$

The created $\mathrm{I}_{2}$ can be investigated by the titration of a standard $\mathrm{S}_{2} \mathrm{O}_{3}{ }^{2-}$ solution:

$\mathrm{I}_{2}+2 \mathrm{~S}_{2} \mathrm{O}_{3}^{2-} \rightarrow 2 \mathrm{I}^{-}+\mathrm{S}_{4} \mathrm{O}_{6}{ }^{2-}$

Iodine in water solutions is usually colored strong enough so that its presence can be detected visually. However, close to the end point, when the iodine concentration is very low, its yellowish color is very pale and can be easily overlooked. Thus for the end point detection starch solutions are used. Continue titration until blue color disappears.

We assume R-OOH has the same function as hydrogen peroxide.

$$
\Rightarrow \quad 1 \mathrm{mmol} \mathrm{ROOH}=2 \mathrm{mmol} \mathrm{S}_{2} \mathrm{O}_{3}^{2-}
$$

Sodium thiosulfate solution 0.1 Normal $(0.1 \mathrm{M})$ :

Dissolve $25 \mathrm{~g} \mathrm{Na} \mathrm{S}_{2} \mathrm{O}_{4} .5 \mathrm{H}_{2} \mathrm{O}(\mathrm{MW}=248.18 \mathrm{~g} / \mathrm{mol})$ in $1 \mathrm{~L}$ freshly boiled distilled water and standardize against $\mathrm{K}_{2} \mathrm{Cr}_{2} \mathrm{O}_{7}$ after at least 10days.

Standard potassium dichromate $0.1 \mathrm{~N}(0.0167 \mathrm{M})$ :

Precisely dissolve $4.9042 \mathrm{~g}$ in $1 \mathrm{~L}$ solution distilled water to get $0.1 \mathrm{~N}$ which is equal to $0.0167 \mathrm{M}$. Keep the solution in a stopper bottle. 
For standardization of $0.1 \mathrm{~N}$ sodium thiosulphate solution with potassium dichromate:

$\mathrm{Cr}_{2} \mathrm{O}_{7}^{2-}+6 \mathrm{I}^{-}+14 \mathrm{H}^{+} \rightarrow 2 \mathrm{Cr}^{3+}+3 \mathrm{I}_{2}+7 \mathrm{H}_{2} \mathrm{O}$

$2 \mathrm{~S}_{2} \mathrm{O}_{3}{ }^{2-}+\mathrm{I}_{2} \rightarrow \mathrm{S}_{4} \mathrm{O}_{6}{ }^{2-}+2 \mathrm{I}^{-}$

Add $10 \mathrm{ml} \mathrm{K} 2 \mathrm{Cr}_{2} \mathrm{O}_{7}$, add $10 \mathrm{ml} 10 \% \mathrm{KI}$ solution, add $10 \mathrm{ml} \mathrm{H}_{2} \mathrm{SO}_{4} 1 \mathrm{M}$. Leave it in dark for 10 minutes. Titrate sample with sodium thiosulfate until it becomes pale yellow. Add 5 drops of starch indicator. Continue titration until blue color disappears.

$N_{S T} . V_{S T}=N_{P D} . V_{P D}$

Procedure:

Place ozonated samples in $25 \mathrm{ml}$ IPA. Add $1 \mathrm{ml}$ saturated KI solution. Add $1 \mathrm{ml}$ glacial acetic acid. Heating to about $80{ }^{\circ} \mathrm{C}$ (boiling point which was found using trial and error) and keep at that temperature for 7 minutes. Without cooling titrate with $0.001 \mathrm{~N}$ standard sodium thiosulphate until the yellow color disappears. 


\section{Appendix II - Sample calculation of peroxide determination}

If $\mathrm{m}$ milliliter of sodium thiosulfate solution which is $\mathrm{n}$ Normal gets consumed in a titration, it means mn normality of sodium thiosulfate which is equal to $\mathrm{mn}$ mol of sodium thiosulphate would be detected $\rightarrow \mathrm{mn} / 2 \mathrm{mmol}$ of peroxide would be exist. This amount could be divided by the nominal samples' area to find the surface density.

Below the sample calculation has been provided for one of the runs which has been conducted in gas phase, at $2 \%$ wt. ozone for 10 minutes.

Using the standard potassium dichromate solution, $9.2 \mathrm{ml}$ of the sodium thiosulfate solution was consumed.

$10 \times 0.1=9.2 \times N_{\text {sodium thiosulfate }}$

$N_{\text {sodium thiosulfate }}=0.1086$

The sodium thiosulfate solution then was diluted 100 times. Thus the consuming solution in titration procedure has the normality of 0.001086 .

For an ozonated sample, $2.42 \mathrm{ml}$ of the sodium thiosulfate solution was consumed.

$$
\begin{aligned}
& 2.42 \times 0.001086=2 \times \mathrm{mmol}_{\text {peroxide }} \\
& \text { mmol }_{\text {peroxide }}=1.3141 \times 10^{-3} \mathrm{mmol}
\end{aligned}
$$

The samples were cut as $2 \mathrm{~cm} \times 5 \mathrm{~cm}$ strips. Thus, the nominal surface density could be found.

Peroxide Concentration $=\frac{1.3032 \times 10^{-3} \mathrm{mmol}}{2 \times 5 \times 10^{-4} \mathrm{~m}^{2}}=1.3141 \mathrm{mmol} / \mathrm{m}^{2}$ 


\section{Appendix III - Required time of boiling for peroxide determination}

After heating the solution to its boiling point, it is necessary to keep the temperature constant in order to provide enough energy for the reactions. However, the exact required time has been obtained using trial and error method in gaseous media.

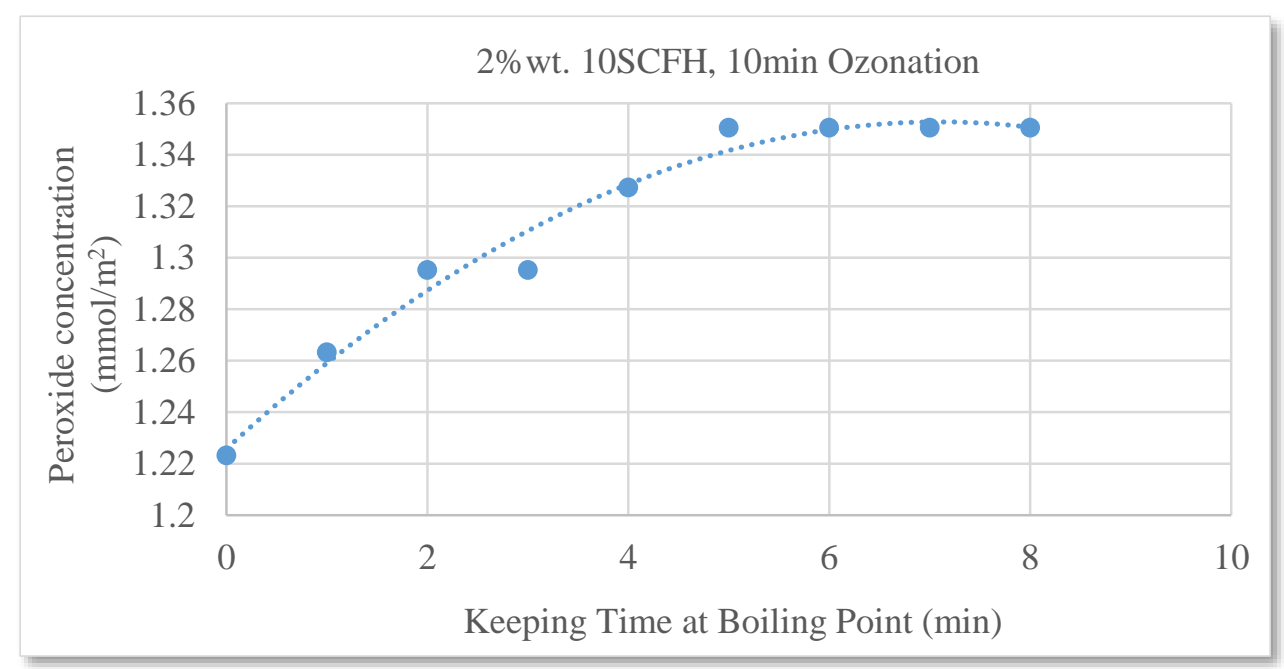

Figure A.1 - The required time of boiling for the peroxide determination process

Based on Figure A.1, after 7 minutes, the system had been reached to its steady state condition. Thus, for all the titration experiments, 7 minutes has been chosen in this study. 


\section{Appendix IV - Time of vacuuming}

Putting samples under vacuum is necessary to remove the attached ozone molecules on the membrane surface since molecular ozone might interfere with the titration process to find the peroxide amount. In order to find the optimum vacuuming time, some runs have been carried out in gas phase. The pressure of the vacuum was measured as 20 inch of $\mathrm{Hg}$.

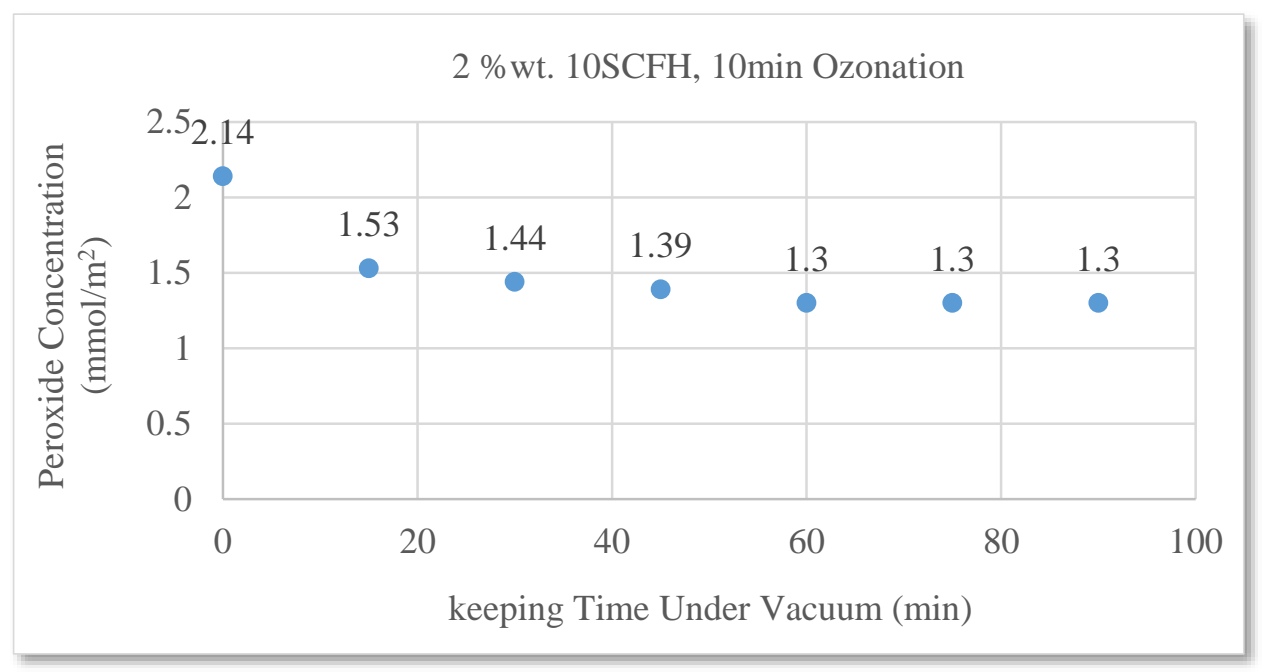

Figure A.2 - The required time of vacuuming before peroxide concentration determination

According to the Figure A.2, 1 hour vacuuming is enough since the peroxide concentration did not change after 1 hour. 


\section{Appendix V - Details of runs, mechanical strength}

According to ASTM (2009), all the measurements are required to be repeated five times. The individual values have been shown in the tables below.

Following equations are used for error analysis.

Standard Deviation $=\sqrt{\frac{\sum_{i}\left(x_{i}-X\right)^{2}}{N-1}}$

Standard Error $=($ Standard Deviation $) / \sqrt{N}$

Error $($ with $95 \%$ confidence $)=1.96 \times($ Standard Error $)$

$x_{i}$ : value of $i-$ th trial

$X:$ average of all trials

$N$ : number of trials

Table A.1 - Tensile strength of untreated membrane in different orientations

\begin{tabular}{cccccccccc}
\hline \multirow{2}{*}{ Orientation } & \multicolumn{4}{c}{ Tensile Strength (MPa) } & \multicolumn{2}{c}{ Standard } & Standard & \multirow{2}{*}{ Error } \\
\cline { 2 - 7 } & Test 1 & Test 2 & Test 3 & Test 4 & Test 5 & Average & Deviation & Error & \\
\hline Vertical & 25.96 & 24.13 & 27.32 & 25.73 & 28.14 & 26.25 & 1.546 & 0.691 & 1.354 \\
Horizontal & 24.01 & 27.42 & 25.73 & 26.69 & 25.80 & 25.93 & 1.279 & 0.572 & 1.121 \\
\hline
\end{tabular}

Table A.2 - Tensile strength of gaseous treated PVDF membranes at 2.5\%wt.

\begin{tabular}{cccccccccc}
\hline $\begin{array}{c}\text { Ozonation } \\
\text { Time (min) }\end{array}$ & \multicolumn{4}{c}{ Tensile Strength (MPa) } & \multicolumn{2}{c}{$\begin{array}{c}\text { Standard } \\
\text { Deviation }\end{array}$} & $\begin{array}{c}\text { Standard } \\
\text { Error }\end{array}$ & Error \\
\cline { 2 - 7 } & Test 1 & Test 2 & Test 3 & Test 4 & Test 5 & Average & \\
\hline 0 & 25.96 & 24.13 & 27.32 & 25.73 & 28.14 & 26.25 & 1.546 & 0.691 & 1.354 \\
15 & 17.28 & 16.14 & 13.91 & 14.45 & 14.42 & 15.24 & 1.417 & 0.634 & 1.243 \\
30 & 9.76 & 10.11 & 11.08 & 8.51 & 6.64 & 9.22 & 1.711 & 0.765 & 1.499 \\
45 & 10.11 & 7.52 & 7.18 & 8.38 & 7.46 & 8.13 & 1.194 & 0.534 & 1.047 \\
60 & 6.53 & 7.71 & 7.12 & 7.86 & 9.03 & 7.65 & 0.934 & 0.865 & 1.695 \\
\hline
\end{tabular}


Table A.3 - Tensile strength of gaseous treated PVDF membranes after $30 \mathrm{~min}$

\begin{tabular}{|c|c|c|c|c|c|c|c|c|c|}
\hline \multirow{2}{*}{$\begin{array}{c}\text { Ozone } \\
\text { Concentration } \\
\text { (\%wt.) }\end{array}$} & \multicolumn{6}{|c|}{ Tensile Strength (MPa) } & \multirow{2}{*}{$\begin{array}{l}\text { Standard } \\
\text { Deviation }\end{array}$} & \multirow{2}{*}{$\begin{array}{c}\text { Standard } \\
\text { Error }\end{array}$} & \multirow[b]{2}{*}{ Error } \\
\hline & Test 1 & Test 2 & Test 3 & Test 4 & Test 5 & Average & & & \\
\hline 0 & 25.96 & 24.13 & 27.32 & 25.73 & 28.14 & 26.25 & 1.546 & 0.691 & 1.354 \\
\hline 1.5 & 18.14 & 18.46 & 16.49 & 16.08 & 17.98 & 17.43 & 1.069 & 0.478 & 0.937 \\
\hline 2.5 & 9.37 & 10.88 & 8.40 & 9.58 & 7.87 & 9.22 & 1.162 & 0.520 & 1.019 \\
\hline 3.5 & 5.87 & 5.97 & 7.28 & 8.27 & 6.91 & 6.86 & 0.992 & 0.891 & 1.746 \\
\hline 4.5 & 6.09 & 5.73 & 5.79 & 6.92 & 7.62 & 6.43 & 0.817 & 0.365 & 0.715 \\
\hline
\end{tabular}

Table A.4 - Tensile Strength of optimal treated samples after $30 \mathrm{~min}$ at 2.5\%wt.

\begin{tabular}{|c|c|c|c|c|c|c|c|c|c|}
\hline \multirow{2}{*}{ Condition } & \multicolumn{6}{|c|}{ Tensile Strength (MPa) } & \multirow{2}{*}{$\begin{array}{l}\text { Standard } \\
\text { Deviation }\end{array}$} & \multirow{2}{*}{$\begin{array}{c}\text { Standard } \\
\text { Error }\end{array}$} & \multirow{2}{*}{ Error } \\
\hline & Test 1 & Test 2 & Test 3 & Test 4 & Test 5 & Average & & & \\
\hline $\begin{array}{c}\text { Gaseous } \\
\text { Phase }\end{array}$ & 9.37 & 10.88 & 8.40 & 9.58 & 7.87 & 9.22 & 1.162 & 0.520 & 1.019 \\
\hline $\begin{array}{c}\text { Non-catalytic } \\
\text { Aqueous } \\
\text { Phase } \\
(\mathrm{pH}=5.5)\end{array}$ & 11.83 & 9.48 & 10.67 & 11.90 & 11.32 & 11.04 & 1.002 & 0.448 & 0.878 \\
\hline $\begin{array}{c}\text { Catalytic } \\
\text { Aqueous } \\
\text { Phase }(\mathrm{pH}=9)\end{array}$ & 10.23 & 11.26 & 10.78 & 12.08 & 11.40 & 11.15 & 0.693 & 0.310 & 0.608 \\
\hline
\end{tabular}




\section{Appendix VI - Details of runs, peroxide concentration}

Following equations are used for error analysis.

Standard Deviation $=\sqrt{\frac{\sum_{i}\left(x_{i}-X\right)^{2}}{N-1}}$

Standard Error $=($ Standard Deviation $) / \sqrt{N}$

Error $($ with $95 \%$ confidence $)=1.96 \times($ Standard Error $)$

$x_{i}$ : value of $i-$ th trial

$X:$ average of all trials

$N$ : number of trials

Table A.5 - Peroxide concentration of gaseous treated samples at different conditions

\begin{tabular}{cccccccc}
\hline $\begin{array}{c}\text { Ozone } \\
\text { Concentration } \\
\text { (\%wt.) }\end{array}$ & $\begin{array}{c}\text { Ozonation } \\
\text { Time (min) }\end{array}$ & \multicolumn{3}{c}{$\begin{array}{c}\text { Peroxide Concentration } \\
\left(\mathbf{m m o l} / \mathbf{m}^{2}\right)\end{array}$} & $\begin{array}{c}\text { Standard } \\
\text { Deviation }\end{array}$ & $\begin{array}{c}\text { Standard } \\
\text { Error }\end{array}$ & Error \\
\cline { 3 - 6 } & & Test 1 & Test 2 & Average & & & \\
\hline 1.5 & 10 & 1.3214 & 1.0700 & 1.1957 & 0.178 & 0.126 & 0.247 \\
1.5 & 15 & 1.4568 & 1.3696 & 1.4132 & 0.062 & 0.044 & 0.086 \\
1.5 & 20 & 1.4980 & 1.3910 & 1.4445 & 0.076 & 0.054 & 0.106 \\
1.5 & 25 & 1.6799 & 1.6157 & 1.6478 & 0.044 & 0.031 & 0.061 \\
1.5 & 30 & 1.8939 & 1.9689 & 1.9314 & 0.053 & 0.037 & 0.072 \\
2 & 5 & 1.2211 & 1.3017 & 1.2614 & 0.057 & 0.040 & 0.079 \\
2 & 10 & 1.3803 & 1.3606 & 1.3704 & 0.014 & 0.010 & 0.020 \\
2 & 15 & 1.4873 & 1.4766 & 1.4819 & 0.008 & 0.006 & 0.012 \\
2 & 20 & 1.5508 & 1.5576 & 1.5542 & 0.005 & 0.003 & 0.006 \\
2 & 25 & 1.8190 & 1.8029 & 1.8109 & 0.011 & 0.008 & 0.016 \\
2 & 30 & 2.047 & 1.9688 & 2.0063 & 0.055 & 0.039 & 0.076 \\
2.5 & 10 & 1.5194 & 1.5302 & 1.5248 & 0.008 & 0.006 & 0.012 \\
2.5 & 15 & 1.6853 & 1.7655 & 1.7254 & 0.057 & 0.040 & 0.078 \\
2.5 & 20 & 1.8725 & 1.7976 & 1.8351 & 0.053 & 0.037 & 0.072 \\
2.5 & 25 & 1.9902 & 2.0116 & 2.0009 & 0.015 & 0.011 & 0.022 \\
2.5 & 30 & 2.2470 & 2.1935 & 2.2203 & 0.038 & 0.027 & 0.053 \\
\hline & & & & & &
\end{tabular}


Table A.6 - Peroxide concentration of non-catalytic aqueous treated samples at different conditions

\begin{tabular}{|c|c|c|c|c|c|c|c|c|}
\hline \multirow{2}{*}{$\begin{array}{c}\text { Ozone } \\
\text { Concentration } \\
\text { (\%wt.) }\end{array}$} & \multirow{2}{*}{$\begin{array}{l}\text { Ozonation } \\
\text { Time (min) }\end{array}$} & \multirow[t]{2}{*}{ pH } & \multicolumn{3}{|c|}{$\begin{array}{l}\text { Peroxide Concentration } \\
\qquad\left(\mathbf{m m o l} / \mathbf{m}^{2}\right)\end{array}$} & \multirow{2}{*}{$\begin{array}{l}\text { Standard } \\
\text { Deviation }\end{array}$} & \multirow{2}{*}{$\begin{array}{l}\text { Standard } \\
\text { Error }\end{array}$} & \multirow[t]{2}{*}{ Error } \\
\hline & & & Test 1 & Test 2 & Average & & & \\
\hline 1.5 & 10 & 7 & 1.2768 & 1.1742 & 1.2255 & 0.072 & 0.051 & 0.100 \\
\hline 1.5 & 15 & 7 & 1.2312 & 1.2482 & 1.2397 & 0.012 & 0.008 & 0.016 \\
\hline 1.5 & 20 & 7 & 1.4022 & 1.2540 & 1.3281 & 0.105 & 0.074 & 0.145 \\
\hline 1.5 & 25 & 7 & 1.4421 & 1.4079 & 1.4250 & 0.024 & 0.017 & 0.033 \\
\hline 1.5 & 30 & 7 & 1.4934 & 1.4421 & 1.4678 & 0.036 & 0.025 & 0.049 \\
\hline 2 & 5 & 7 & 1.1812 & 1.2718 & 1.2265 & 0.064 & 0.045 & 0.088 \\
\hline 2 & 10 & 7 & 1.2711 & 1.2483 & 1.2597 & 0.016 & 0.011 & 0.022 \\
\hline 2 & 15 & 7 & 1.4022 & 1.2426 & 1.3224 & 0.113 & 0.080 & 0.157 \\
\hline 2 & 20 & 3.6 & 1.3737 & 1.3452 & 1.3594 & 0.020 & 0.014 & 0.027 \\
\hline 2 & 20 & 5 & 1.4877 & 1.5333 & 1.5105 & 0.032 & 0.023 & 0.045 \\
\hline 2 & 20 & 6 & 1.5561 & 1.5276 & 1.5419 & 0.020 & 0.014 & 0.027 \\
\hline 2 & 20 & 7 & 1.4732 & 1.3934 & 1.4333 & 0.056 & 0.040 & 0.078 \\
\hline 2 & 20 & 8 & 1.3452 & 1.3110 & 1.3281 & 0.024 & 0.017 & 0.033 \\
\hline 2 & 20 & 9 & 1.2084 & 1.2711 & 1.2397 & 0.044 & 0.031 & 0.061 \\
\hline 2 & 20 & 10.4 & 0.9236 & 1.0944 & 1.0089 & 0.121 & 0.086 & 0.169 \\
\hline 2 & 25 & 7 & 1.5504 & 1.6188 & 1.5846 & 0.048 & 0.034 & 0.067 \\
\hline 2 & 30 & 7 & 1.5903 & 1.5219 & 1.5561 & 0.048 & 0.034 & 0.067 \\
\hline 2.5 & 10 & 7 & 1.4478 & 1.5105 & 1.4791 & 0.044 & 0.031 & 0.061 \\
\hline 2.5 & 15 & 7 & 1.4820 & 1.5846 & 1.5333 & 0.072 & 0.051 & 0.100 \\
\hline 2.5 & 20 & 7 & 1.5504 & 1.6302 & 1.5903 & 0.056 & 0.040 & 0.078 \\
\hline 2.5 & 25 & 7 & 1.6072 & 1.7084 & 1.6553 & 0.072 & 0.051 & 0.100 \\
\hline 2.5 & 30 & 7 & 1.7212 & 1.6414 & 1.6813 & 0.056 & 0.040 & 0.078 \\
\hline
\end{tabular}


Table A.7 - Peroxide concentration of catalytic aqueous treated samples at different conditions

\begin{tabular}{|c|c|c|c|c|c|c|c|c|}
\hline \multirow{2}{*}{$\begin{array}{c}\text { Ozone } \\
\text { Concentration } \\
\text { (\%wt.) }\end{array}$} & \multirow{2}{*}{$\begin{array}{l}\text { Ozonation } \\
\text { Time (min) }\end{array}$} & \multirow[t]{2}{*}{$\mathbf{p H}$} & \multicolumn{3}{|c|}{$\begin{array}{l}\text { Peroxide Concentration } \\
\qquad\left(\mathrm{mmol} / \mathrm{m}^{2}\right)\end{array}$} & \multirow{2}{*}{$\begin{array}{l}\text { Standard } \\
\text { Deviation }\end{array}$} & \multirow{2}{*}{$\begin{array}{c}\text { Standard } \\
\text { Error }\end{array}$} & \multirow[t]{2}{*}{ Error } \\
\hline & & & Test 1 & Test 2 & Average & & & \\
\hline 1.5 & 10 & 7 & 1.1672 & 1.1923 & 1.1797 & 0.018 & 0.013 & 0.025 \\
\hline 1.5 & 15 & 7 & 1.3765 & 1.3919 & 1.3842 & 0.011 & 0.008 & 0.016 \\
\hline 1.5 & 20 & 7 & 1.3953 & 1.4103 & 1.4028 & 0.011 & 0.008 & 0.016 \\
\hline 1.5 & 25 & 7 & 1.4773 & 1.5314 & 1.5043 & 0.038 & 0.027 & 0.053 \\
\hline 1.5 & 30 & 7 & 1.5632 & 1.5145 & 1.5388 & 0.034 & 0.024 & 0.047 \\
\hline 2 & 5 & 7 & 1.3014 & 1.3262 & 1.3138 & 0.017 & 0.012 & 0.023 \\
\hline 2 & 10 & 7 & 1.3975 & 1.3706 & 1.3841 & 0.019 & 0.013 & 0.025 \\
\hline 2 & 15 & 7 & 1.3897 & 1.4913 & 1.4405 & 0.072 & 0.051 & 0.100 \\
\hline 2 & 20 & 3.6 & 1.2506 & 1.2864 & 1.2685 & 0.025 & 0.018 & 0.035 \\
\hline 2 & 20 & 5 & 1.3619 & 1.4223 & 1.3921 & 0.043 & 0.030 & 0.059 \\
\hline 2 & 20 & 6 & 1.4478 & 1.4224 & 1.4351 & 0.018 & 0.013 & 0.025 \\
\hline 2 & 20 & 7 & 1.5695 & 1.5534 & 1.5615 & 0.011 & 0.008 & 0.016 \\
\hline 2 & 20 & 8 & 1.5625 & 1.6301 & 1.5963 & 0.048 & 0.034 & 0.067 \\
\hline 2 & 20 & 9 & 1.6555 & 1.6394 & 1.6475 & 0.011 & 0.008 & 0.016 \\
\hline 2 & 20 & 10.4 & 1.7952 & 1.7683 & 1.7817 & 0.019 & 0.013 & 0.025 \\
\hline 2 & 25 & 7 & 1.6739 & 1.5623 & 1.6181 & 0.079 & 0.056 & 0.110 \\
\hline 2 & 30 & 7 & 1.7092 & 1.6770 & 1.6931 & 0.023 & 0.016 & 0.031 \\
\hline 2.5 & 10 & 7 & 1.6064 & 1.5924 & 1.5994 & 0.010 & 0.007 & 0.014 \\
\hline 2.5 & 15 & 7 & 1.6221 & 1.6516 & 1.6368 & 0.021 & 0.015 & 0.029 \\
\hline 2.5 & 20 & 7 & 1.6214 & 1.6896 & 1.6555 & 0.048 & 0.034 & 0.067 \\
\hline 2.5 & 25 & 7 & 1.7176 & 1.7050 & 1.7113 & 0.009 & 0.006 & 0.012 \\
\hline 2.5 & 30 & 7 & 1.7436 & 1.7239 & 1.7337 & 0.014 & 0.010 & 0.020 \\
\hline
\end{tabular}


Table A.8 - Peroxide concentration of catalytic aqueous treated samples using different catalysts, at $\mathrm{pH}=7,2 \%$ wt. ozone and 10 minutes

\begin{tabular}{lccccccc}
\hline \multirow{2}{*}{ Catalyst } & $\begin{array}{c}\text { Concentration } \\
(\mathbf{g} / \mathbf{L})\end{array}$ & \multicolumn{3}{c}{$\begin{array}{c}\text { Peroxide Concentration } \\
(\mathbf{m m o l} / \mathbf{m} 2)\end{array}$} & $\begin{array}{c}\text { Standard } \\
\text { Deviation }\end{array}$ & $\begin{array}{c}\text { Standard } \\
\text { Error }\end{array}$ & Error \\
\cline { 3 - 6 } & & Test 1 & Test 2 & Average & & \\
\hline $\mathrm{AC}$ & 0.5 & 1.3222 & 1.3437 & 1.3330 & 0.015 & 0.011 & 0.022 \\
$\mathrm{AC}$ & 1 & 1.3975 & 1.3706 & 1.3841 & 0.019 & 0.013 & 0.025 \\
$\mathrm{AC}$ & 3 & 1.4624 & 1.4723 & 1.4674 & 0.007 & 0.005 & 0.010 \\
$\mathrm{AC}$ & 5 & 1.5533 & 1.5211 & 1.5372 & 0.023 & 0.016 & 0.031 \\
$\mathrm{AC}$ & 10 & 1.6125 & 1.5803 & 1.5964 & 0.023 & 0.016 & 0.031 \\
$\mathrm{Cu}^{2+}$ & 0.5 & 1.2246 & 1.3520 & 1.2883 & 0.090 & 0.064 & 0.125 \\
$\mathrm{Cu}^{2+}$ & 1 & 1.3437 & 1.2491 & 1.2964 & 0.067 & 0.047 & 0.092 \\
$\mathrm{Cu}^{2+}$ & 3 & 1.3816 & 1.3218 & 1.3517 & 0.042 & 0.030 & 0.059 \\
$\mathrm{Cu}^{2+}$ & 5 & 1.4666 & 1.5452 & 1.5059 & 0.055 & 0.039 & 0.076 \\
$\mathrm{Cu}^{2+}$ & 10 & 1.6729 & 1.5739 & 1.6234 & 0.070 & 0.049 & 0.096 \\
$\mathrm{Fe}^{3+}$ & 0.5 & 1.2763 & 1.3073 & 1.2918 & 0.022 & 0.016 & 0.031 \\
$\mathrm{Fe}^{3+}$ & 1 & 1.3555 & 1.2783 & 1.3169 & 0.055 & 0.039 & 0.076 \\
$\mathrm{Fe}^{3+}$ & 3 & 1.5550 & 1.4224 & 1.4887 & 0.094 & 0.066 & 0.129 \\
$\mathrm{Fe}^{3+}$ & 5 & 1.6183 & 1.5683 & 1.5933 & 0.035 & 0.025 & 0.049 \\
$\mathrm{Fe}^{3+}$ & 10 & 1.6859 & 1.7563 & 1.7211 & 0.050 & 0.035 & 0.069 \\
\hline
\end{tabular}




\section{Appendix VII - Details of runs, modelling}

In order to use Response Surface Methodology, different runs were required for gaseous and aqueous phase. Each run was repeated twice and the average was reported in Results and Discussion part. In the table below, the exact amount of peroxide found on the surface was demonstrated for all the replicates.

Table A.9 - Details of runs for gaseous ozonation

\begin{tabular}{cccccc}
\hline Ozone & $\begin{array}{c}\text { Peroxide } \\
\text { concentration } \\
(\% \text { wt. })\end{array}$ & $\begin{array}{c}\text { Time } \\
(\mathbf{m i n})\end{array}$ & $\begin{array}{c}\text { Peroxide } \\
\text { Concentration } \\
\left(\mathbf{m m o l} / \mathbf{m}^{2}\right)\end{array}$ & $\begin{array}{c}\text { Peroxide } \\
\text { Concentration } \\
\left(\mathbf{m m o l} / \mathbf{m}^{2}\right)\end{array}$ & $\begin{array}{c}\text { Concentration } \\
\left(\mathbf{m m o l} / \mathbf{m}^{2}\right)\end{array}$ \\
\hline 1 & 1 & -1 & 1.5194 & 1.5302 & 1.5248 \\
First Replicate & Second Replicate & 1.2894 \\
2 & 0 & -1.41421 & 1.3375 & 1.2412 & 1.1957 \\
3 & -1 & -1 & 1.3214 & 1.0699 & 1.4980 \\
4 & 0 & 0 & 1.4631 & 1.5329 & 1.5087 \\
5 & 0 & 0 & 1.5361 & 1.4814 & 1.9314 \\
6 & -1 & 1 & 1.8939 & 1.9689 & 2.2203 \\
7 & 1 & 1 & 2.2470 & 2.1935 & 1.5943 \\
8 & 0 & 0 & 1.5287 & 1.6599 & 1.4590 \\
9 & -1.41421 & 0 & 1.3482 & 1.8832 & 2.1895 \\
10 & 0 & 1.41421 & 2.1983 & 2.1806 & 1.6104 \\
11 & 0 & 0 & 1.6419 & 1.5789 & 2.0555 \\
12 & 1.41421 & 0 & 2.0437 & 2.0672 & 1.5426 \\
\hline 13 & 0 & 0 & 1.4768 & 1.6084 & \\
\hline
\end{tabular}


Table A.10 - Details of runs for non-catalytic aqueous ozonation

\begin{tabular}{|c|c|c|c|c|c|c|}
\hline$\#$ & $\begin{array}{c}\text { Ozone } \\
\text { Concentration } \\
\text { (\%wt.) }\end{array}$ & $\begin{array}{l}\text { Ozonation } \\
\text { Time } \\
\text { (min) }\end{array}$ & pH & $\begin{array}{c}\text { Peroxide } \\
\text { Concentration } \\
\left(\mathbf{m m o l} / \mathbf{m}^{2}\right)- \\
\text { First } \\
\text { Replicate }\end{array}$ & $\begin{array}{c}\text { Peroxide } \\
\text { Concentration } \\
\left(\mathbf{m m o l} / \mathbf{m}^{2}\right)- \\
\text { Second } \\
\text { Replicate }\end{array}$ & $\begin{array}{c}\text { Peroxide } \\
\text { Concentration } \\
\left(\mathbf{m m o l} / \mathbf{m}^{2}\right) \text { - } \\
\text { Average }\end{array}$ \\
\hline 1 & -1.68179 & 0 & 0 & 1.1115 & 1.1628 & 1.1371 \\
\hline 2 & 1 & 1 & 1 & 1.3561 & 1.4359 & 1.396 \\
\hline 3 & 0 & 0 & -1.68179 & 1.3737 & 1.3452 & 1.3594 \\
\hline 4 & 0 & 0 & 0 & 1.3987 & 1.5021 & 1.4504 \\
\hline 5 & 1 & 1 & -1 & 1.6131 & 1.6929 & 1.653 \\
\hline 6 & -1 & 1 & -1 & 1.4934 & 1.0602 & 1.4592 \\
\hline 7 & 0 & 0 & 0 & 1.4983 & 1.4481 & 1.4732 \\
\hline 8 & 0 & 0 & 0 & 1.4251 & 1.3731 & 1.3991 \\
\hline 9 & 0 & -1.68179 & 0 & 1.1685 & 1.2198 & 1.1941 \\
\hline 10 & 1.68179 & 0 & 0 & 1.6587 & 1.6074 & 1.6331 \\
\hline 11 & 1 & -1 & -1 & 1.482 & 1.4649 & 1.4734 \\
\hline 12 & 0 & 0 & 0 & 1.3874 & 1.502 & 1.4447 \\
\hline 13 & 0 & 1.68179 & 0 & 1.5909 & 1.6245 & 1.6077 \\
\hline 14 & 0 & 0 & 0 & 1.3499 & 1.4369 & 1.3934 \\
\hline 15 & -1 & -1 & 1 & 1.0413 & 1.0374 & 1.0394 \\
\hline 16 & 0 & 0 & 1.68179 & 0.9234 & 1.0944 & 1.0089 \\
\hline 17 & -1 & 1 & 1 & 1.3680 & 1.2084 & 1.2882 \\
\hline 18 & 0 & 0 & 0 & 1.4665 & 1.3887 & 1.4276 \\
\hline 19 & -1 & -1 & -1 & 1.1001 & 1.0602 & 1.0802 \\
\hline 20 & 1 & -1 & 1 & 1.3162 & 1.2592 & 1.2877 \\
\hline
\end{tabular}


Table A.11 - Details of runs for catalytic aqueous ozonation

\begin{tabular}{|c|c|c|c|c|c|c|}
\hline \# & $\begin{array}{c}\text { Ozone } \\
\text { Concentration } \\
\text { (\%wt.) }\end{array}$ & $\begin{array}{c}\text { Ozonation } \\
\text { Time } \\
\text { (min) }\end{array}$ & pH & $\begin{array}{c}\text { Peroxide } \\
\text { Concentration } \\
\left(\mathbf{m m o l} / \mathbf{m}^{2}\right) \text { - } \\
\text { First } \\
\text { Replicate }\end{array}$ & $\begin{array}{c}\text { Peroxide } \\
\text { Concentration } \\
\left(\mathbf{m m o l} / \mathbf{m}^{2}\right) \text { - } \\
\text { Second } \\
\text { Replicate }\end{array}$ & $\begin{array}{c}\text { Peroxide } \\
\text { Concentration } \\
\left(\mathbf{m m o l} / \mathbf{m}^{2}\right) \text { - } \\
\text { Average }\end{array}$ \\
\hline 1 & -1.68179 & 0 & 0 & 1.2279 & 1.3599 & 1.2939 \\
\hline 2 & 1 & 1 & 1 & 1.9771 & 1.8657 & 1.9214 \\
\hline 3 & 0 & 0 & -1.68179 & 1.2506 & 1.2974 & 1.2740 \\
\hline 4 & 0 & 0 & 0 & 1.5124 & 1.6266 & 1.5695 \\
\hline 5 & 1 & 1 & -1 & 1.6841 & 1.4595 & 1.5718 \\
\hline 6 & -1 & 1 & -1 & 1.6880 & 1.4054 & 1.5467 \\
\hline 7 & 0 & 0 & 0 & 1.6231 & 1.4837 & 1.5534 \\
\hline 8 & 0 & 0 & 0 & 1.5643 & 1.4987 & 1.5315 \\
\hline 9 & 0 & -1.68179 & 0 & 1.3008 & 1.2742 & 1.2875 \\
\hline 10 & 1.68179 & 0 & 0 & 1.7668 & 1.7092 & 1.7380 \\
\hline 11 & 1 & -1 & -1 & 1.3670 & 1.3312 & 1.3491 \\
\hline 12 & 0 & 0 & 0 & 1.4623 & 1.5727 & 1.5175 \\
\hline 13 & 0 & 1.68179 & 0 & 1.7924 & 1.7146 & 1.7535 \\
\hline 14 & 0 & 0 & 0 & 1.5483 & 1.4877 & 1.5180 \\
\hline 15 & -1 & -1 & 1 & 1.1801 & 1.3929 & 1.2470 \\
\hline 16 & 0 & 0 & 1.68179 & 1.7952 & 1.7683 & 1.7817 \\
\hline 17 & -1 & 1 & 1 & 1.6231 & 1.7457 & 1.6844 \\
\hline 18 & 0 & 0 & 0 & 1.4631 & 1.5833 & 1.5232 \\
\hline 19 & -1 & -1 & -1 & 1.1018 & 0.230 & 1.0124 \\
\hline 20 & 1 & -1 & 1 & 1.5566 & 1.7398 & 1.6482 \\
\hline
\end{tabular}




\section{Appendix VIII - Details of runs, contact angle}

Following equations are used for error analysis.

Standard Deviation $=\sqrt{\frac{\sum_{i}\left(x_{i}-X\right)^{2}}{N-1}}$

Standard Error $=($ Standard Deviation $) / \sqrt{N}$

Error $($ with $95 \%$ confidence $)=1.96 \times($ Standard Error $)$

$x_{i}$ : value of $i-$ th trial

$X$ : average of all trials

$N$ : number of trials

Table A.12 - Contact angle of untreated and optimal treated samples

\begin{tabular}{|c|c|c|c|c|c|c|c|}
\hline \multirow{2}{*}{ Condition } & \multicolumn{4}{|c|}{ Contact Angle ( ${ }^{\circ}$ ) } & \multirow{2}{*}{$\begin{array}{l}\text { Standard } \\
\text { Deviation }\end{array}$} & \multirow{2}{*}{$\begin{array}{c}\text { Standard } \\
\text { Error }\end{array}$} & \multirow{2}{*}{ Error } \\
\hline & Test 1 & Test 2 & Test 3 & Average & & & \\
\hline Untreated & 73.5 & 73.8 & 73.2 & 71.3 & 0.173 & 0.100 & 0.196 \\
\hline Gaseous Phase & 50.1 & 50.6 & 50.5 & 50.4 & 0.265 & 0.153 & 0.300 \\
\hline $\begin{array}{c}\text { Non-catalytic Aqueous } \\
\text { Phase }(\mathrm{pH}=5.5)\end{array}$ & 65.3 & 65.7 & 64.5 & 65.1 & 0.611 & 0.353 & 0.692 \\
\hline $\begin{array}{c}\text { Catalytic Aqueous } \\
\text { Phase }(\mathrm{pH}=9)\end{array}$ & 56.1 & 56.2 & 56.9 & 56.4 & 0.436 & 0.252 & 0.494 \\
\hline
\end{tabular}




\section{Appendix IX - Details of runs, filtration}

Following equations are used for error analysis.

Standard Deviation $=\sqrt{\frac{\sum_{i}\left(x_{i}-X\right)^{2}}{N-1}}$

Standard Error $=($ Standard Deviation $) / \sqrt{N}$

Error $($ with $95 \%$ confidence $)=1.96 \times($ Standard Error $)$

$x_{i}$ : value of $i-$ th trial

$X:$ average of all trials

$N$ : number of trials

Table A.13 - Distilled water permeate flux through clean untreated and optimal treated samples

\begin{tabular}{|c|c|c|c|c|c|c|}
\hline \multirow{2}{*}{ Condition } & \multicolumn{3}{|c|}{ Permeate Flux $\left(\mathrm{m}^{3} / \mathrm{m}^{2} . h\right)$} & \multirow{2}{*}{$\begin{array}{l}\text { Standard } \\
\text { Deviation }\end{array}$} & \multirow{2}{*}{$\begin{array}{c}\text { Standard } \\
\text { Error }\end{array}$} & \multirow{2}{*}{ Error } \\
\hline & Test 1 & Test 2 & Average & & & \\
\hline Untreated & 2.50 & 2.48 & 2.49 & 0.014 & 0.010 & 0.020 \\
\hline Gaseous Phase & 3.11 & 3.15 & 3.13 & 0.031 & 0.022 & 0.043 \\
\hline $\begin{array}{c}\text { Non-catalytic Aqueous Phase } \\
\qquad(\mathrm{pH}=5.5)\end{array}$ & 3.02 & 2.90 & 3.00 & 0.022 & 0.016 & 0.031 \\
\hline $\begin{array}{c}\text { Catalytic Aqueous Phase } \\
\qquad(\mathrm{pH}=9)\end{array}$ & 3.05 & 3.08 & 3.06 & 0.022 & 0.016 & 0.031 \\
\hline
\end{tabular}

Table A.14 - Milk permeate flux through clean untreated and optimal treated samples

\begin{tabular}{|c|c|c|c|c|c|c|}
\hline \multirow{2}{*}{ Condition } & \multicolumn{3}{|c|}{ Permeate Flux $\left(\mathrm{m}^{3} / \mathrm{m}^{2} . h\right)$} & \multirow{2}{*}{$\begin{array}{l}\text { Standard } \\
\text { Deviation }\end{array}$} & \multirow{2}{*}{$\begin{array}{c}\text { Standard } \\
\text { Error }\end{array}$} & \multirow{2}{*}{ Error } \\
\hline & Test 1 & Test 2 & Average & & & \\
\hline Untreated & 0.21 & 0.23 & 0.22 & 0.014 & 0.010 & 0.020 \\
\hline Gaseous Phase & 0.46 & 0.41 & 0.43 & 0.038 & 0.027 & 0.053 \\
\hline $\begin{array}{c}\text { Non-catalytic Aqueous Phase } \\
\qquad(\mathrm{pH}=5.5)\end{array}$ & 0.42 & 0.39 & 0.41 & 0.022 & 0.016 & 0.031 \\
\hline $\begin{array}{c}\text { Catalytic Aqueous Phase } \\
\qquad(\mathrm{pH}=9)\end{array}$ & 0.35 & 0.31 & 0.33 & 0.031 & 0.022 & 0.043 \\
\hline
\end{tabular}


Table A.15 - Distilled water permeate flux through fouled untreated and optimal treated samples, after removing cake layer

\begin{tabular}{ccccccc}
\hline \multirow{2}{*}{ Condition } & \multicolumn{3}{c}{ Permeate Flux $\left(\mathbf{m}^{\left.\mathbf{3} / \mathbf{m}^{\mathbf{2}} \mathbf{. h}\right)}\right.$} & $\begin{array}{c}\text { Standard } \\
\text { Deviation }\end{array}$ & $\begin{array}{c}\text { Standard } \\
\text { Error }\end{array}$ & Error \\
\cline { 2 - 6 } & Test 1 & Test 2 & Average & & \\
\hline $\begin{array}{c}\text { Untreated } \\
\text { Gaseous Phase }\end{array}$ & 1.07 & 0.91 & 0.99 & 0.113 & 0.080 & 0.016 \\
$\begin{array}{c}\text { Non-catalytic Aqueous Phase } \\
(\mathrm{pH}=5.5)\end{array}$ & 2.75 & 2.83 & 2.79 & 0.057 & 0.040 & 0.079 \\
$\begin{array}{c}\text { Catalytic Aqueous Phase } \\
(\mathrm{pH}=9)\end{array}$ & 2.51 & 2.27 & 2.24 & 0.042 & 0.030 & 0.058 \\
\hline
\end{tabular}




\section{Appendix X - Sample calculation of membrane resistances}

The sample calculation of finding resistances has been provided for the untreated membrane.

Resistance Model: $J=\frac{T M P}{\mu \cdot\left(R_{M}+R_{C}+R_{F}\right)}$

$$
\begin{aligned}
& R_{M}=\frac{T M P}{J_{\text {initial }} \cdot \mu_{\text {distilled water }}}=\frac{18 p s i \times \frac{6894.76 \mathrm{~Pa}}{1 p s i}}{\left(2.49 \frac{\mathrm{m}^{3}}{\mathrm{~m}^{2} \times h} \times \frac{1 \mathrm{~h}}{3600 \mathrm{~s}}\right) \times 1.2 \mathrm{cp} \times \frac{10^{-3} \mathrm{~Pa} . \mathrm{s}}{1 \mathrm{cp}}} \\
& R_{M}=1.495 \times 10^{11} \mathrm{~m}^{-1}
\end{aligned}
$$

$$
R_{F}=\frac{T M P}{J_{\text {final }} \cdot \mu_{\text {distilled water }}}-R_{M}
$$

$$
=\frac{18 p s i \times \frac{6894.76 P a}{1 p s i}}{\left(0.99 \frac{m^{3}}{m^{2} \times h} \times \frac{1 h}{3600 s}\right) \times 1.2 c p \times \frac{10^{-3} P a . s}{1 c p}}-1.495 \times 10^{11}
$$

$R_{F}=2.266 \times 10^{11} \mathrm{~m}^{-1}$

$$
\begin{aligned}
& R_{C}=\frac{T M P}{J_{m i l k} \cdot \mu_{m i l k}}-R_{M}-R_{F}=\frac{18 p s i \times \frac{6894.76 P a}{1 p s i}}{\left(o .22 \frac{m^{3}}{m^{2} \times h} \times \frac{1 h}{3600 s}\right) \times 2.3 c p \times \frac{10^{-3} P a . s}{1 c p}}-(1.495+2.266) \times 10^{11} \\
& R_{C}=5.069 \times 10^{11} m^{-1}
\end{aligned}
$$




\section{Appendix XI - Backwash}

Following equations are used for error analysis.

Standard Deviation $=\sqrt{\frac{\sum_{i}\left(x_{i}-X\right)^{2}}{N-1}}$

Standard Error $=($ Standard Deviation $) / \sqrt{N}$

Error $($ with $95 \%$ confidence $)=1.96 \times($ Standard Error $)$

$x_{i}$ : value of $i-$ th trial

$X:$ average of all trials

$N$ : number of trials

Table A.16 - Milk permeate flux through untreated membrane before and after backwashing

\begin{tabular}{cccccccc}
\hline \multirow{2}{*}{ Condition } & Time & \multicolumn{2}{c}{ Permeate Flux $\left(\mathbf{L} / \mathbf{m}^{2} \mathbf{. h}\right)$} & & $\begin{array}{c}\text { Standard } \\
\text { Deviation }\end{array}$ & $\begin{array}{c}\text { Standard } \\
\text { Error }\end{array}$ & Error \\
\cline { 3 - 4 } & $(\mathbf{m i n})$ & Test 1 & Test 2 & Average & Devion & \\
\hline First run & 2 & 81 & 91 & 86 & 7.071 & 5.000 & 9.800 \\
(before & 3 & 34 & 28 & 31 & 4.243 & 3.000 & 5.880 \\
backwash) & 4 & 22 & 36 & 29 & 9.900 & 7.000 & 9.800 \\
& 5 & 22 & 28 & 25 & 4.243 & 3.000 & 5.880 \\
Second run & 7 & 24 & 18 & 21 & 4.243 & 3.000 & 5.880 \\
(after first & 8 & 27 & 15 & 13 & 8.485 & 6.000 & 11.759 \\
backwash) & 9 & 11 & 15 & 13 & 2.829 & 2.000 & 3.921 \\
& 10 & 6 & 12 & 9 & 4.243 & 3.000 & 5.880 \\
& 11 & 51 & 43 & 47 & 5.657 & 4.000 & 7.840 \\
Third run & 12 & 11 & 19 & 15 & 5.657 & 4.000 & 7.840 \\
(after second & 13 & 8 & 14 & 11 & 4.243 & 3.000 & 5.880 \\
backwash) & 14 & 5 & 13 & 9 & 5.657 & 4.000 & 7.840 \\
& 15 & 8 & 4 & 6 & 2.829 & 2.000 & 3.921 \\
\hline
\end{tabular}


Table A.17 - Milk permeate flux through optimal gaseous treated membrane before and after backwashing

\begin{tabular}{|c|c|c|c|c|c|c|c|}
\hline \multirow{2}{*}{ Condition } & \multirow{2}{*}{$\begin{array}{l}\text { Time } \\
(\min )\end{array}$} & \multicolumn{3}{|c|}{ Permeate Flux $\left(\mathrm{L} / \mathrm{m}^{2} . h\right)$} & \multirow{2}{*}{$\begin{array}{l}\text { Standard } \\
\text { Deviation }\end{array}$} & \multirow{2}{*}{$\begin{array}{c}\text { Standard } \\
\text { Error }\end{array}$} & \multirow{2}{*}{ Error } \\
\hline & & Test 1 & Test 2 & Average & & & \\
\hline \multirow{5}{*}{$\begin{array}{l}\text { First run } \\
\text { (before } \\
\text { backwash) }\end{array}$} & 1 & 193 & 181 & 187 & 8.485 & 6.000 & 11.759 \\
\hline & 2 & 105 & 101 & 103 & 2.828 & 2.000 & 3.921 \\
\hline & 3 & 41 & 53 & 47 & 8.485 & 6.000 & 11.759 \\
\hline & 4 & 37 & 31 & 34 & 4.243 & 3.000 & 5.880 \\
\hline & 5 & 20 & 36 & 28 & 11.314 & 8.000 & 15.680 \\
\hline \multirow{5}{*}{$\begin{array}{l}\text { Second run } \\
\text { (after first } \\
\text { backwash) }\end{array}$} & 6 & 151 & 165 & 158 & 9.900 & 7.000 & 13.721 \\
\hline & 7 & 84 & 76 & 80 & 5.657 & 4.000 & 7.840 \\
\hline & 8 & 43 & 45 & 41 & 1.414 & 1.000 & 1.960 \\
\hline & 9 & 35 & 15 & 25 & 14.142 & 10.000 & 19.600 \\
\hline & 10 & 12 & 18 & 15 & 4.243 & 3.000 & 5.880 \\
\hline \multirow{5}{*}{$\begin{array}{l}\text { Third run } \\
\text { (after second } \\
\text { backwash) }\end{array}$} & 11 & 152 & 134 & 143 & 12.728 & 9.000 & 17.640 \\
\hline & 12 & 97 & 77 & 87 & 14.142 & 10.000 & 19.600 \\
\hline & 13 & 33 & 39 & 36 & 4.243 & 3.000 & 5.880 \\
\hline & 14 & 22 & 30 & 26 & 5.657 & 4.000 & 7.840 \\
\hline & 15 & 18 & 10 & 14 & 5.657 & 4.000 & 7.840 \\
\hline
\end{tabular}




\section{References}


Abdelrasoul, A. (2015), "Investigation on Membrane Fouling in Ultrafiltration of Latex Solution", PhD Thesis, Ryerson University.

Abdelrasoul, A., H. Doan and A. Lohi (2013), "A Mechanistic Model for Ultrafiltration Membrane Fouling by Latex", Journal of Membrane Science, 433, 99-99.

Adams, M. C. (2012), “Examination of Methods to Reduce Membrane Fouling during Dairy Microfiltration and Ultrafiltration", Master's Thesis, Cornell University.

Al Abdulal, E., A. Khot, A. Bailey, M. Mehan, T. Debies and G. A. Takacs (2015), "Surface Characterization of Polystyrene Treated with Ozone and Grafted with Poly(acrylic acid)", Journal of Adhesion Science and technology, 29(1), 1-11.

Alvarez, P. M., J. F. Garcia-Araya, F. J. Beltran, I. Giraldez, J. Jaramillo and V. Gomez-Serrano (2006), “The Influence of Various Factors on Aqueous Ozone Decomposition by Granular Activated Carbons and the Development of a Mechanistic Approach", Carbon 44, 31023112.

ASTM D882-09 (2009), "Standard Test Method for Tensile Properties of Thin Plastic Sheeting", West Conshohocken, PA: American Society of Testing and Materials. DOI: 10.1520/D0882-09.

Bae, T.-H. and T.-M. Tak (2005), "Effect of $\mathbf{T i O}_{2}$ Nanoparticles on Fouling Mitigation of Ultrafiltration Membranes for Activated Sludge Filtration", Journal of Membrane Science, 249 (1-2), 1-8.

Baker, R. W. (2004), "Membrane Technology and Applications", New York, NY: John Wiley \& Sons, Ltd.

Beicha, A. and R. Zaamouche (2012), "Mathematical Modeling of Flux in Ultrafiltration Membrane", Chemical Engineering, 5(2), 110-115. 
Beltran, F. J., J. Rivas, P. Alvarez and R. Montero-de-Espinosa (2002), "Kinetics of Heterogeneous Catalytic Ozone Decomposition in Water on an Activated Carbon”, Ozone: Science and Engineering, 24(4), 227-237.

Bhaduri, S. and D. Mukesh (2000), “Homogeneous Catalysis: Mechanism and industrial Applications", New York, NY: John Wiley and Sons, Inc.

Boutevin, B., J. J. Robin, N. Torres and J. Casteil (2002) "Synthesis and Characterization of Ozonized Polyethylene", Polymer Engineering and Science, 42(1), 78-89.

Cataldo, F., A. Rosati, E. Lilla and O. Ursini (2011), "On the Action of Ozone at High Concentration on Various Grades of Polyethylene and Certain Straight Chain Paraffins", Polymer Degradation and Stability, 96(5), 955-964.

Chang, I. S., C. H. Lee and K.H. Ahn (1999), "Membrane Filtration Characteristics in Membrane-Coupled Activated Sludge System: The effect of Floc Structure on Membrane Fouling", Separation Science and technology, 34(9), 1743-1758.

Chang, I.S., P. Le Clech, B. Jefferson and S. Judd (2002), "Membrane Fouling in Membrane Bioreactors For Wastewater Treatment", Journal of Environmental Engineering, 128(11), 1018-1029.

Chang, Y., C.-Y. Ko, Y.-J. Shih, D. Quemener, A. Deratani, T.-C. Wei, D.-M. Wang and J.-Y. Lai (2009), "Surface Grafting Control of PEGylated Poly(vinylidene fluoride) Antifouling Membrane via Surface Initiated Radical Graft Copolymerization", Journal of Membrane Science, 345(1), 160-169.

Chang, Y., Y.J. Shih, R.C. Ruaan, A. Higuchi, W.Y. Chen and J.Y. Lai (2008), “Preparation of Poly(vinylidene fluoride) Microfiltration Membrane with Uniform SurfaceCopolymerized Poly(Ethylene glycol) Methacrylate and Improvement of Blood Compatibility", Journal of Membrane Science, 309(1), 165-174. 
Chen, W., K. G. Neoh, E.T. Kang, K.L Tan, D.J. Liaw and C.C. Huang (1998), "Surface Modification and Adhesion Characteristics of Polycarbonate Films After Graft Polymerization”, Journal of Polymer Science: Part A: Polymer Chemistry, 36(2), 357-366.

Chen, Y., L. Ying, W. Yu, E. T. Kang and K. G. Neoh (2003), "Poly(vinylidene fluoride) with Grafted Poly(ethylene glycol) Side Chains via the RAFT-Mediated Process and Pore Size Control of the Copolymer Membranes”, Macromolecules, 36(25), 9451-9457.

Cheryan, M. (1998), “Ultrafiltration and Microfiltration Handbook", Technomic Publishing Company, Inc., Lancaster, PA, USA.

Chiang, H.-L., C. P. Huang and P.C. Chiang (2002), "The Surface Characteristics of Activated Carbon as Affected by Ozone and Alkaline Treatment”, Chemosphere, 47(3), 257-265.

Chiang, Y.-C., Y. Chang, A. Higuchi, W.-Y. Chen and R.-C. Ruaan (2009), "Sulfobetainegrafted Poly(vinylidene fluoride) Ultrafiltration Membranes Exhibit Excellent Antifouling Property”, Journal of Membrane Science, 339(1), 151-159.

Corapcioglu, M. O. and C.P. Huang (1987), "The Surface Acidity and Characterization of Some Commercial Activated Carbons", Carbon, 25(4), 569-578.

Cui, Z., E. Drioli, and Y. M. Lee (2014), "Recent Progress in Fluoropolymers for Membranes", Progress in Polymer Science, 39(1), 164-198.

Damodar, R.A., S.J. You and H.H. Chou (2009), "Study of Self Cleaning, Antibacterial and Photo Catalytic Properties of Ti02 Entrapped PVDF Membranes", Journal of Hazardous Materials, 172(2), 1321-1328.

Elovitz, M. S. and U. von Gunten (1999), "Hydroxyl Radical/Ozone Ratios during Ozonation Processes. I. The R $\mathbf{R}_{\mathrm{ct}}$ Concept”, Ozone: Science and Engineering, 21(3), 239-260.

Espina, V. S., M. Y. Jaffrin, M. Frappart and L. H. Ding (2008), "Separation of casein Micelles from Whey Proteins by High Shear Microfiltration of Skim Milk using Rotating Ceramic 
Membranes and Organic Membranes in a Rotating Disk Module", Journal of Membrane Science, 325(2), 872-879.

Faria, P. C. C., J. J. M. Orfao and M. F. R. Pereira (2006), “Ozone Decomposition in Water Catalyzed by Activated Carbon: Influence of Chemical and Textural Properties", Industrial and Engineering Chemistry Research, 45(8), 2715-2721.

Field, R. W., D. Wu, J.A. Howell and B.B. Gupta (1995), "Critical Flux Concept for Microfiltration Fouling”, Journal of Membrane Science, 100(3), 259-272.

Fujimoto, K., Y. Takebayashi, H. Inoue and Y. Ikada (1993), “Ozone-Induced Graft Polymerization onto Polymer Surface", Journal of Polymer Science, Polymer Chemistry, 31(4), 1035-1043.

Gatenholm, P., T. Ashida and A.S. Hoffman (1997), “Hybrid Biomaterials Prepared by Ozone-Induced Polymerization. I. Ozonation of Microporous Polypropylene", Journal of Polymeric Science A: Polym. Chem., 35(8), 1461-1467.

Genne, I., S. Kuypers and R. Leysen (1996), "Effect of the Addition of $\mathbf{Z r O}_{2}$ to Polysulfone Based UF Membranes", Journal of Membrane Science, 113(2), 343-350.

Gu, H. B. (2014), "Modification of Polypropylene Membranes and Films by Catalytic Ozonation", $\mathrm{PhD}$ thesis, Ryerson University.

Gu, H., J. Wu and H. Doan (2009), "Hydrophilicity Enhancement of High-Density Polyethylene Film by Ozonation”, Chemical Engineering Technology, 32(5), 726-731.

Gu, H., J. Wu, P. Chan. G. Turcotte and T. Ye (2012), "Hydrophilicity Modification of Polypropylene Microfiltration Membrane by Ozonation”, Chemical Engineering Research and Design, 90(2), 229-237.

Guiza, M., A. Ouederni and A. Ratel (2004), "Decomposition of Dissolved Ozone in the Presence of Activated Carbon: An Experimental Study", Ozone: Science and Engineering, 26(3), 299-397. 
Guzman-Perez, C.A., J. Soltan and J. Robertson (2011), "Kinetics of Catalytic Ozonation of atrazine in the presence of activated carbon", Separation and Purification Technology", 79(1), 8-14.

Hermia, J. (1982), “Constant Pressure Blocking Filtration Laws: Application to PowerLaw Non-Newtonian Fluids", Chemical Engineering Research and Design, 60, 183-186.

Hilal, N., M. Khayet and C. J. Wright (2012), "Membrane Modification, Technology and Applications", Taylor and Francis, ISBN: 978-1-4398-6635-1.

Ho, C. and A. L. Zydney (1999), "Effect of Membrane Morphology on the Initial Rate of Protein Fouling during Microfiltration”, Journal of Membrane Science, 155(2), 261-275.

Jans U. and J. Hoigne (1998), “Activated carbon and carbon black catalyzed transformation of aqueous ozone into OH-radicals", Ozone: Science and Engineering, 20(1), 67-90.

Kang, G. and Y. Cao (2014), “Application and Modification of Poly(vinylidene fluoride) (PVDF) Membranes - A Review", Journal of Membrane Science, 463, 145-165.

Kefeli, A.A., S. D. Razumovskii and G. Y. Zaikov (1971), "Interaction of Polyethylene with Ozone”, Polymer Science U.S.S.R., 13(4), 904-911.

Kim, J., and F.A. DiGiano (2009), “Fouling Models for Low-pressure Membrane Systems”, Separation and Purification Technology, 68(3), 293-304.

Ko, Y. G., Y. H. Kim, K. D. Park, H. J. Lee, W. K. Lee, H. D. Park, S. H. Kim, G. S. Lee and D. J. Ahn (2001), “Immobilization of Poly(ethylene glycol) or Its Sulfonate onto Polymer Surfaces by Ozone Oxidation”, Biomaterials, 22(15), 2115-2123.

Kokatnur, V. R., and M. Jelling (1941), "Iodometric Determination of Peroxygen in Organic Compounds" Journal of the American Chemical Society, 63(5), 1432-1433. 
Laitman, I, M. Natan, E. Banin and S. Margel (2014), "Synthesis and Characterization of Fluoro-modified Polypropylene Films for Inhibition of Biofilm Formation", Colloids and Surfaces B: Biointerfaces, 115, 8-14

Lazic, Z. R. (2004), “Design of Experiments in Chemical Engineering: A Practical Guide", Weinheim: Wiley-VCH.

Le Berre, O. and G. Daufin (1996), "Skimmilk Crossflow Microfiltration Performance versus Permeation Flux to Wall Shear Stress Ratio", Journal of Membrane Science, 117(12), 261-270.

Lee, Y. and M. M. Clark (1998) "Modeling of Flux Decline during Crossflow Ultrafiltration of Colloidal Suspensions”, Journal of Membrane Science, 149(2), 181-202.

Liang, S., K. Xiao, Y.H. Mo and X. Huang (2012), “A Novel ZnO Nanoparticle Blended Polyvinylidene Fluoride Membrane for Anti-irreversible Fouling", Journal of Membrane Science, 394, 184-192.

Liu, Y., J.Y. Lee, E. T. Kand, P. Wand and K.L. Tan (2001), "Synthesis, Characterization and Electrochemical Transport Properties of the Poly(Ethyleneglycol)-grafted Poly(vinylidenefluoride) Nanoporous Membranes", Reactive and Functional Polymers, 47(3), 201-213.

Mahfoudh, A., F. Poncin-Epaillard, M. Moisan and J. Barbeau (2010), "Effect of Dry-Ozone

Exposure on Different Polymer Surfaces and Their Resulting Biocidal Action on Sporulated Bacteria", Surface Science, 604(17), 1487-1493.

Mastan, E. (2010), “Surface Modification of Polyethylene Film by Catalytic Ozonation", Masters's Thesis, Ryerson University.

Mastan, E., J. Wu and H. Doan (2013), “An Investigation into Surface Modification of Polyethylene Films for Hydrophilicity Enhancement by Catalytic Ozonation", Journal of Applied Polymer, 128(1), 828-835. 
McSweeney, P. L. H. and P. F. Fox (2013), "Advanced Dairy Chemistry, Volume 1A: Proteins: Basic Aspects", 4 ${ }^{\text {th }}$ edition, New York, NY: Springer. DOI 10.1007/978-1-46144714-6

Merten, U. (1963), "Flow Relationships in Reverse Osmosis", Industrial and Engineering Chemistry Fundamentals, 2(3), 229-232.

Montgomery, D. C. (2005), "Design and analysis of Experiments", $6{ }^{\text {th }}$ edition, Hoboken, NJ: John Wiley and Sons, Ltd.

Murakami, T. N., .Y Fukushima, Y. Hirano, Y. Tokuoka, M. Takahashi and N. Kawashima (2003), "Surface Modification of Polystyrene and Poly(methylmethacrylate) by Active Oxygen Treatment", Colloids and Surfaces B: Biointerfaces, 29(2), 171-179.

Obvintseva, L.A., M.P Dmitrieva, A.I. Klimul, A.D. Shepelev, N.V. Kozlova, N.V. Sadovskaya, Yu.A. Tomashpol'skii and A.K. Avetisov (2010), "Action of Ozone on Polysulfone-Based Microfibrous Filters", Russian Journal of Applied Chemistry, 83(6), 1069-1073.

Ozen, B. F., L. J. Mauer and J. D. Floros (2002), "Effects of Ozone Exposure on the Structural, Mechanical and barrier Properties of Select Plastic Packaging Films", Packaging Technology and Science, 15(6), 301-311.

Pan, K., P. Fang and B. Cao (2012), “Novel Composite Membranes Prepared by Interfacial Polymerization on Polypropylene Fiber Supports Pretreated by Ozone-Induced Polymerization", Desalination, 294, 36-43.

Park, J.-C., Y.-S. Hwang, J.-E. Lee, K. D. Park, K. Matsumura, S.-H. Hyon and H. Suh (2000), "Type I Atelocollagen Grafting onto Ozone-Treated Polyurethane Films: Cell Attachment, Proliferation and Collagen Synthesis", Journal of Biomedical Materials Research, 52 (4), 669-677.

Patel, D. P. (2008), “An Investigation into Surface Modification of Polyethylene Film by Ozonation", Masters's Thesis, Ryerson University. 
Patel, D., J. Wu, P. Chan, S. Upreti, G. Turcotte and T. Ye (2012), "Surface Modification of Low Density Polyethylene Films by Homogeneous Catalytic Ozonation", Chemical Engineering Research and Design, 90(11), 1800-1806.

Puspitasari, V., A. Granville, P. Le-Clech and V. Chen (2010), "Cleaning and Ageing Effect of Sodium Hypochlorite on Polyvinylidene Fluoride (PVDF) Membrane", Separation and Purification Technology, 72 (3), 301-308.

Rahimpour, A., S. S. Madaeni, M. Amirnejad, Y, Mansourpanah and S. Zereshki (2009), "The Effect of Heat Treatment of PES and PVDF Ultrafiltration Membranes on Morphology and Performance for milk Filtration”, Journal of Membrane Science, 330(1), 189-204.

Rashid, A. N., K. Tsuru and K. Ishikawa (2015), "Effect of Calcium-ozone Treatment on Chemical and Biological Properties of Polyethylene Terephthalate", Journal of Biomedical Materials Research Part B: Applied Biomaterials, 103(4), 853-860.

Rice, G, A. Barber, A. O’Conner, G. Stevens and S. Kentish (2009), "Fouling of NF Membranes by Dairy Ultrafiltration Permeates", Journal of Membrane Science, 330(1), 117126.

Robin, J. J. (2004), "The Use of Ozone in the Synthesis of New Polymers and the Modification of Polymers", Advances in Polymer Science, 167, 35-79.

Sanchez-Polo, M., U. von Gunten and J. Rivera-Utrilla (2005), "Efficiency of Activated Carbon to Transform Ozone into •OH radicals: Influence of Operational Parameters", Water Research, 39(14), 3189-3198.

Saxena, A., B. P. Tripathi, M. Kumar and V. K. Shahi (2009), "Membrane-Based Techniques for the Separation and Purification of Proteins", Advanced in Colloid and Interface Science, $145(1), 1-22$.

Shen, X., X. Yin, Y. Zhao and L. Chen (2015), "Improved Protein Fouling Resistance of PVDF Membrane Grafted with the Polyampholyte Layers", Colloid and Polymer Science, 293(4), 1205-1213. 
Shi, X., G. Tal, N. P. Hankins and V. Gitis (2014), "Fouling and Cleaning of Ultrafiltration Membranes: A Review”, Journal of Water Process Engineering, 1, 121-138.

Singh, Harjinder Boland and Mike Thompson, Abby (2014) "Milk Proteins - From Expression to Food (2nd Edition)". Elsevier. Online version available at: http://app.knovel.com/hotlink/toc/id:kpMPFEFE09/milk-proteins-from-expression/milkproteins-from-expressPion

Sotelo, J. L., F. J. Beltran, F. J. Benitez and J. Beltran-Heredia (1989), “Henry's Law Constant for the Ozone-Water System", Water Research, 23(10), 1239-1246.

Sotelo, J. L., F. J. Beltran, F. J. Benitez and J. Beltran-Heredia (1987), “Ozone Decomposition in Water: Kinetic Study”, Industrial and Engineering Chemistry Research, 26(1), 39-43.

Staehelin, J. and J. Hoigne (1982), "Decomposition of Ozone in Water: Rate of Initiation by Hydroxide Ions and Hydrogen Peroxide", Environmental Science and Technology, 16(10), 676-681.

Tamime, A.Y (2012), "Society of Dairy Technology Series- Membrane Processing: Dairy and Beverage Applications", New Jersey, NJ: John Wiley \& Sons.

Tang, Y. P., T. Cai, D. Loh, G.S. O’Brien and T. S. Chung (2017), "Construction of Antifouling Lumen Surface on a Poly(vinylidene fluoride) Hollow Fiber Membrane via a zwitterionic Graft Copolymerization Strategy", Separation and Purification Technology, 176, 294-305.

Tu, C.-Y., Y.-L. Liu, K.-R. Lee and J.-Y. Lai (2005), "Surface Grafting Polymerization and Modification on Poly(tetrafluoroethylene) Films by Means of Ozone Treatment", Polymer, 46(18), 6976-6985.

Wang, L., K. Pan, L. Li, and B. Cao (2014), "Surface Hydrophilicity and Structure of Hydrophilic Modified PVDF Membrane by Nonsolvent Induced Phase Separation and Their Effect on Oil/Water Separation Performance", Industrial and Engineering Chemistry Research, 53(15), 6401-6408. 
Wang, Y., J. Kim, K. Choo, Y. Lee and C. Lee (2000), "Hydrophilic Modification of Polypropylene Microfiltration Membranes by Ozone-induced Graft Polymerization", Journal of Membrane Science, 169(2), 269-276.

Wenzel, R. N. (1949), "Surface Roughness and Contact Angle", Journal of Physical Chemistry, 53(9), 1466-1467.

Yan, L., Y. S. Li, C. B. Xiang and S. Xianda (2006), "Effect of Nano-sized $\mathbf{A l}_{2} \mathbf{O}_{3}$-particle Addition on PVDF Ultrafiltration Membrane Performance", Journal of Membrane Science, $276(1-2), 162-167$.

Yang, M.-C. and W.-C Lin (2003), "Protein Adsorption and Platelet Adhesion of Polysulfone Membrane Immobilized with Chitosan and Heparin Conjugate", Polymers for Advanced Technologies, 14(2), 103-113.

Yang, M.-C. and W.-C. Lin (2002), "The Grafting of Chitosan Oligomer to Polysulfone

Membrane via Ozone-Treatment and its Effect on Anti-Bacterial Activity", Journal of Polymer Research, 9(2), 135-140.

Young, T. (1805), “An Essay on the Cohesion of Fluids", Philosophical Transactions of the Royal Society of London, 95, 65-87, Retrieved from http://www.jstor.org/stable/107159

Yuan, Y., J. Zhang, F. Ai, J. Yuan, J. Zhou, J. Shen and S. Lin (2003), "Surface Modification of SPEU Films by Ozone Induced Graft Copolymerization to Improve Hemocompatibility", Colloids and Surfaces B:Biointerfaces, 29(4), 247-256.

Zhai, G., E. T. Kang and K. G. Neoh (2004), "Inimer Graft-Copolymerized Poly(vinylidene fluoride) for the Preparation of Arborescent Copolymers and Surface-Active Copolymer Membranes", Macromolecules, 37(19), 7240-7249.

Zhao, J., Q. Shi, S. Luan, L. Song, H. Yang, H. Shi, J. Jin, X. Li, J. Yin and P. Stagnaro (2011), "Improved Biocompatibility and Antifouling Property of Polypropylene Non-woven Fabric Membrane by Surface Grafting Zwitterionic Polymer", Journal of Membrane Science, 369(1), 5-12. 
Zhao, Y., K. Wu, Z. Wang, L. Zhao and S. Li (2000), “Fouling and Cleaning of MembraneA Literature Review", Journal of Environmental Sciences, 12(2), 241-251.

Zuo, X., S. Yu, X. Xu, J. Xu, R. Bao and X. Yan (2009), "New PVDF Organic-inorganic Membranes: The Effect of $\mathrm{SiO}_{2}$ Nanoparticles Content on the Transport Performance of Anion-exchange Membranes”, Journal of Membrane Science, 340(1-2), 206-213. 